Efficacy of new inhibitors of ethylene perception in improvement of the display quality of miniature potted roses (Rosa hybrida L.)

\author{
Der Naturwissenschaftlichen Fakultät \\ der Universität Hannover \\ zur Erlangung \\ des akademischen Grades eines
}

Doktors der Gartenbauwissenschaften

-Dr. rer. hort.-

genehmigte

Dissertation

von

Mantana BUANONG, M. Sc. Postharvest Technology

geboren am 8. November 1973 in Khonkaen, Thailand

Oktober 2005 
Referent: Prof. Dr. Margrethe Serek

Korreferent: Prof. Dr. Thomas Debener

Date of oral examination: $12^{\text {th }}$ January 2006 
Dedicated to

my beloved brother 


\section{Acknowledgements}

This thesis presents work supported by a grant from The Asian Development Bank (ADB), Thailand and I am very grateful that I stood a chance to conduct research in the postharvest field combined with the modern methods of molecular biology.

I would like to express my special thanks to my supervisor Prof. Dr. Margrethe Serek, a distinguished professor in the field of postharvest physiology of ornamental crops, for her untiring guidance and her constructive attitude throughout the course of study and during the preparation of this thesis.

I would also like to thank Prof. Ed Sisler - University of North Carolina, USA, for kindly providing the chemicals (1-OCP and 1-DCP) used in this research and his suggestion about preparing these substances.

I am very grateful to Dr. Heiko Mibus, who introduced me to this part of molecular biology. His insight into molecular biology and many fruitful discussions led to the idea of the molecular part of the study; his help and advice during my study was invaluable. Special thanks to other staff members of the Floriculture Section for their kind assistance and creating a positive atmosphere during the three-year period. Moreover, I thank my friends for their support that made this study and the entire stay in Germany enjoyable.

Finally, I would like to thank my parents, my brother and sister, together with my boyfriend, who contributed to the success of my research. Their encouragement enabled me to successfully complete this Doctoral study. 


\section{Table of contents}

Acknowledgements........................................................................

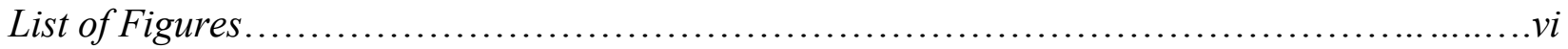

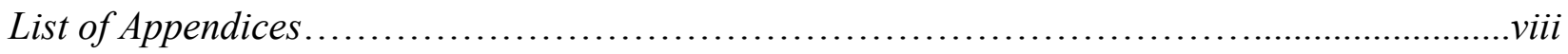

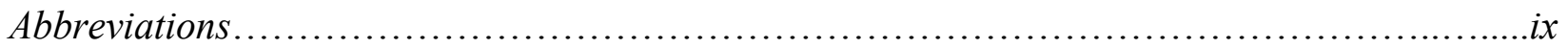

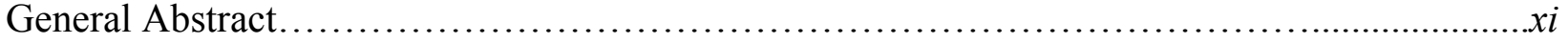

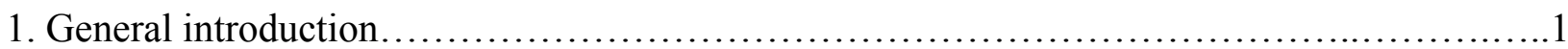

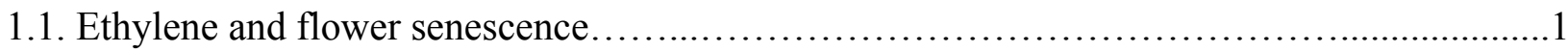

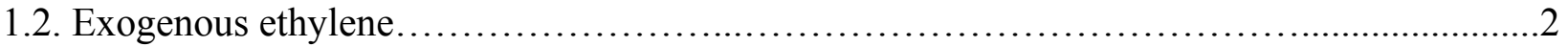

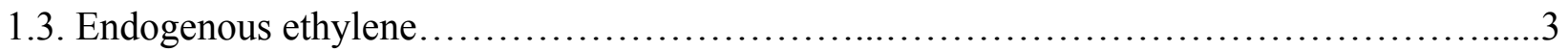

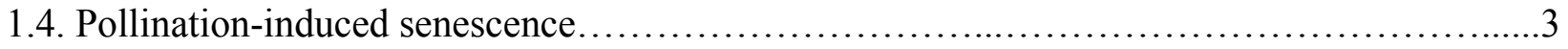

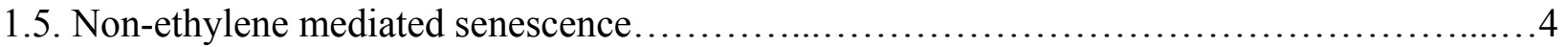

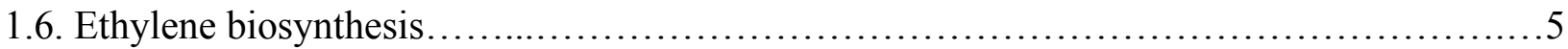

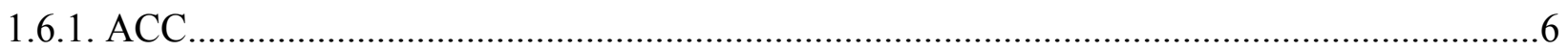

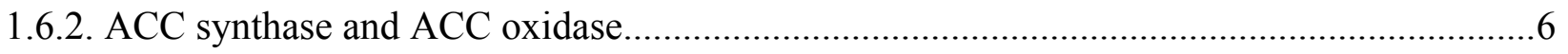

1.7. Strategies to breed ethylene-insensitive flower.........................................

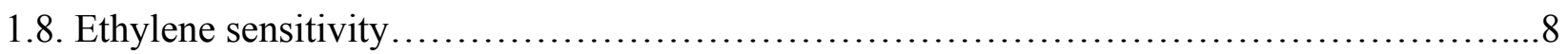

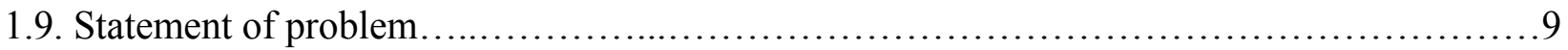

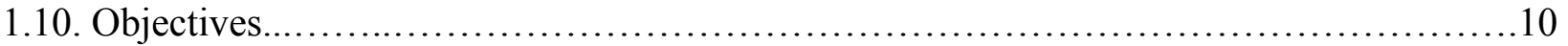

2. Efficacy of new inhibitors of ethylene perception in improvement of display quality of miniature potted roses (Rosa hybrida L.).................................................11

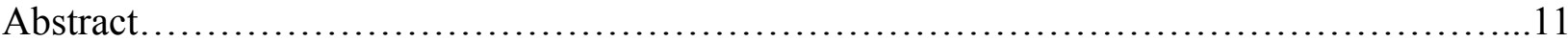

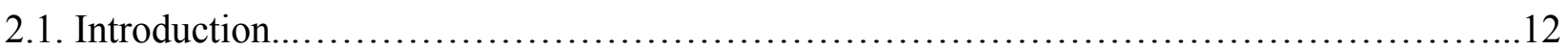

2.1.1. Compounds interacting with the ethylene receptor in plants............................12

2.1.1.1. Ethylene and ethylene analogues................................................. 12

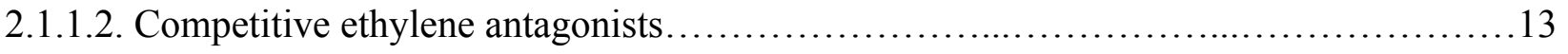

2.1.2. Mode of action of compounds blocking the receptor................................... 13

2.1.3. Ethylene antagonists inactivating the receptor for an extend period of time

2.2. Materials and Methods................................................................ 19

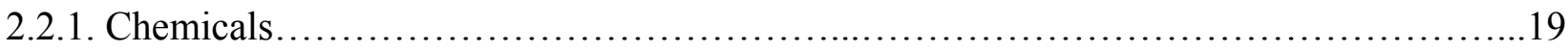




\section{Table of contents}

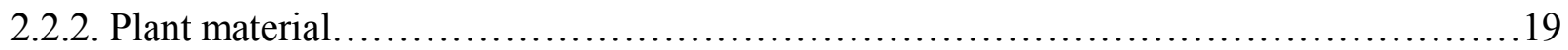

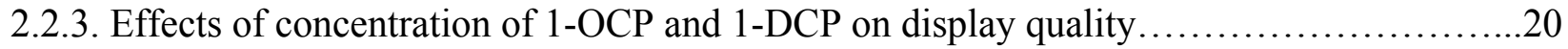

2.2.4. Effects of treatment time on 1-OCP and 1-DCP on display quality ......................20

2.2.5. Effects of temperature on efficacy of 1-OCP and 1-DCP on display quality ................21

2.2.6. Comparison of effectiveness of 1-MCP, 1-OCP and 1-DCP between 'Lavender' and

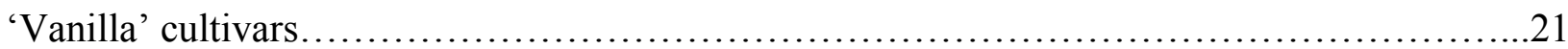

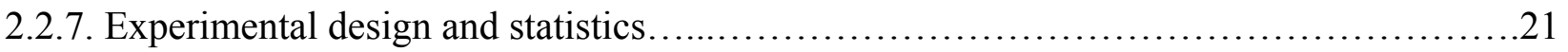

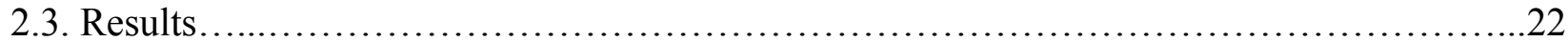

2.3.1. Effect of concentrations of 1-OCP and 1-DCP on display quality.......................22

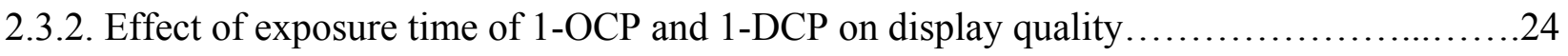

2.3.3. Effect of temperature of 1-OCP and 1-DCP on display quality ............................26

2.3.4. Efficacy of 1-MCP, 1-OCP and 1-DCP in cultivars 'Lavender' and 'Vanilla' ...............28

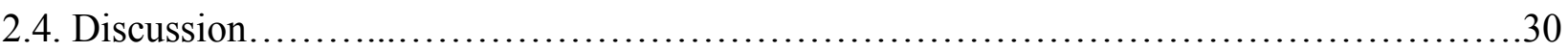

3. Expression analysis of genes for ethylene biosynthesis enzyme, ethylene perception and signal transduction pathway after pretreatment with ethylene inhibitors of miniature potted roses (Rosa

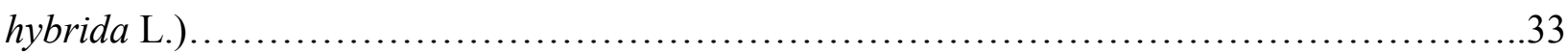

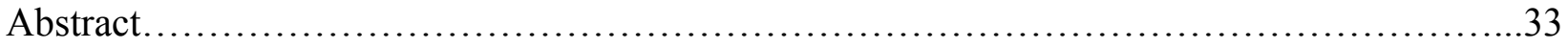

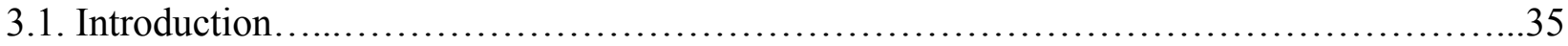

3.1.1. Expression regulation of genes for ethylene biosynthesis enzyme.......................35

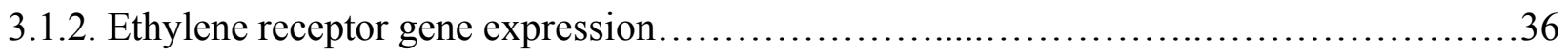

3.1.3. Ethylene insensitive mutant of ethylene receptor...................................40

3.1.4. Expression regulation of ethylene signal transduction pathway .........................42

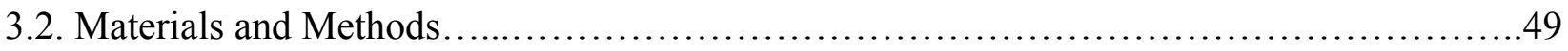

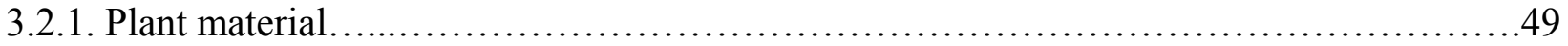

3.2.2. Database analyses and primer design............................................... 49

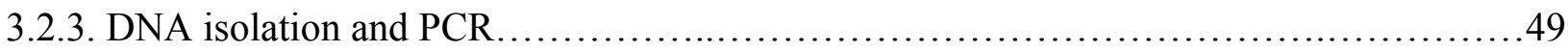

3.2.4. Cloning, DNA sequencing and sequence Analysis...................................50

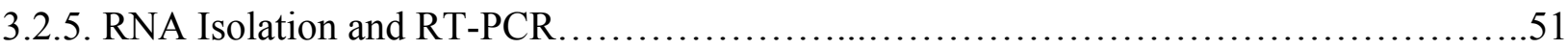

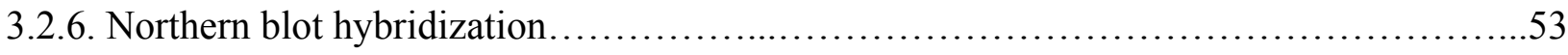

3.2.7. DIG labeling of the probes for northern blot hybridization...........................5 54 


\section{Table of contents}

3.2.8. Hybridization and washing conditions for northern blots..........................55

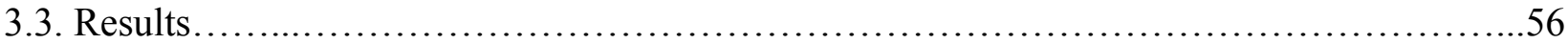

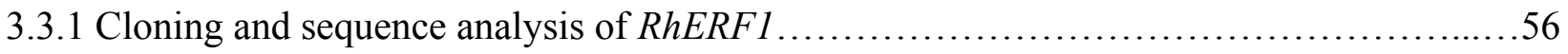

3.3.2 Expression patterns of genes for the ethylene biosynthesis enzyme, ethylene perception and signal transduction pathway after pretreatment with ethylene receptor inhibitors...............57

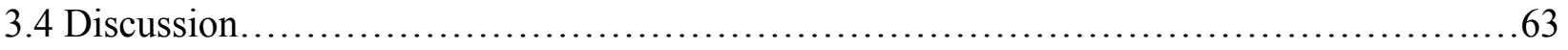

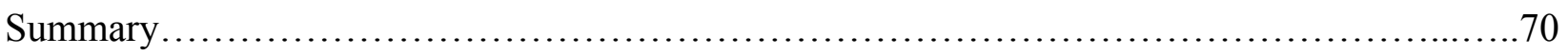

References................................................................. 74

Appendices........................................................................ 91 


\section{List of Figures}

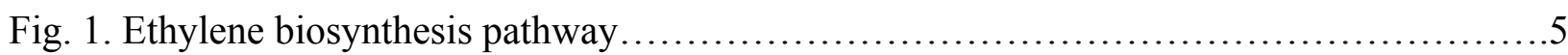

Fig. 2. Propose model of action of ethylene and 1-methylcyclopropene (1-MCP) on the ethylene receptor.

Fig. 3. Chemical structure of compounds interacting with the ethylene receptor.................18

Fig. 4. Mean of percent leaf drop (A, B) and total bud and flower drop (C, D) of miniature potted roses cultivar 'Lavender' pretreated with 1-OCP and 1-DCP at concentrations of 0, 200, 500, $1000,2000 \mathrm{nl} \mathrm{l}^{-1}, 1-\mathrm{MCP}\left(200 \mathrm{nl} \mathrm{l}^{-1}\right)$ for $6 \mathrm{~h}$ at $20^{\circ} \mathrm{C}$ and untreated controls. 23

Fig. 5. Mean of percent leaf drop (A, B) and total bud and flower drop (C, D) of miniature potted roses cultivar 'Lavender' pretreated with 1-OCP and 1-DCP at exposure time of 1-OCP and 1-DCP $\left(1000 \mathrm{nl} \mathrm{l}^{-1}\right)$ 0, 2, 4, 6, $12 \mathrm{~h}, 1$-MCP $\left(200 \mathrm{nl} \mathrm{l}^{-1}\right)$ for $6 \mathrm{~h}$ at $20{ }^{\circ} \mathrm{C}$ and untreated controls.

Fig. 6. Mean of percent leaf drop (A, B) and total bud and flower drop (C, D) of miniature potted roses cultivar 'Lavender' pretreated with 1-OCP and 1-DCP at temperatures of $5{ }^{\circ} \mathrm{C}, 10{ }^{\circ} \mathrm{C}, 15^{\circ} \mathrm{C}$, $20{ }^{\circ} \mathrm{C}, 1-\mathrm{MCP}\left(200 \mathrm{nl} \mathrm{l}^{-1}\right)$ for $6 \mathrm{~h}$ at $20^{\circ} \mathrm{C}$ and untreated controls.

Fig. 7. Mean of percent leaf drop and days of total bud and flower drop of miniature potted roses cultivar 'Vanilla' (A, C) and 'Lavender' (B, D) pre-treated with 1-OCP, 1-DCP (1000 nl 1'-1), respectively, and 1-MCP $\left(200 \mathrm{nl} \mathrm{l}^{-1}\right)$ for $4 \mathrm{~h}$ at $20^{\circ} \mathrm{C}$ and the control..........................29

Fig.8. Basis scheme of the two-component system....................................... 37

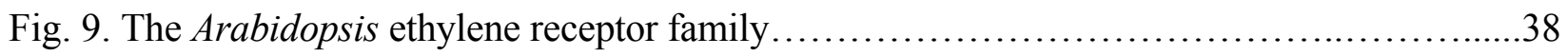

Fig.10. A current view of the ethylene signal transduction pathway formulated on the basis of clone

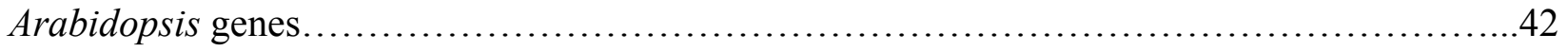

Fig. 11. A model for the role of kinase activity in ethylene signaling ........................ 44 Fig. 12. Alignment of the DNA-binding domains of RhERF1 in comparison with other ERF

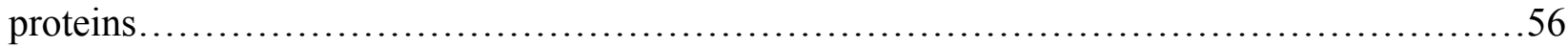

Fig. 13. Percent leaf drop of miniature potted roses cultivar 'Vanilla' (A) and 'Lavender' (B) after day 9 pretreated with $200 \mathrm{nl} \mathrm{l}^{-1}$ for $6 \mathrm{~h}$ and $1000 \mathrm{nl} \mathrm{l}^{-1}$ 1-OCP and 1-DCP for $4 \mathrm{~h}$ at $20^{\circ} \mathrm{C}$. .57 


\section{List of Figures}

Fig.14. Expression of genes for ethylene biosynthesis enzyme, ethylene perception and other ethylene related genes in miniature potted roses cultivar 'Vanilla' in untreated plant and pretreatment with 1-MCP, 1-OCP and 1-DCP after 9 days of continuous exposure of exogenous

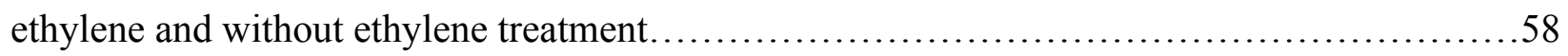
Fig.15. Expression of genes for ethylene biosynthesis enzyme, ethylene perception and other ethylene related genes in miniature potted roses cultivar 'Vanilla' in untreated plant and pretreatment with 1-MCP, 1-OCP and 1-DCP after 9 days of continuous exposure of exogenous

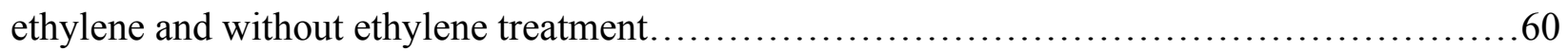
Fig.15. Expression of genes for ethylene biosynthesis enzyme, ethylene perception and other ethylene related genes in miniature potted roses cultivar 'Lavender' in untreated plant and pretreatment with 1-MCP, 1-OCP and 1-DCP after 9 days of continuous exposure of exogenous ethylene and without ethylene treatment 


\section{List of Appendices}

A 1 Degenerate primer pairs for RhERF1 using partial DNA fragment of Arabidopsis

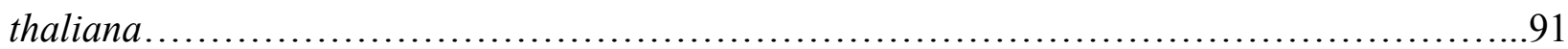

A 2 Sequence analysis of Rosa hybrida 92 bp partial DNA fragment.........................91

A 3 Sequence analysis for specific primers of Rosa hybrida ...............................92

A 4 Computer programs used for analysing gene sequences.............................. 98

A 5 The principle of ligation into a Topo TA Cloning Kit............................... 101 


\section{Abbreviations}

ACC

AdoMed

$\mathrm{ACO}$

ACS

AOA

AVG

BA

$\mathrm{CO}_{2}$

$\mathrm{CP}$

3,3-DMCP

DACP

1-DCP

DNA

DNAase

dNTP

E. coli

1-ECP

EDTA

$\mathrm{GC}$

1-HCP

LB medium

1-MCP

3-MCP

NCBI

$\mathrm{Nr}$

1-OCP

$\mathrm{RH}$

RNA

RNase

RT-PCR
1-Aminocyclopropane-1-carboxylic acid

Adenosylmethionine

ACC oxidase

ACC synthase

Aminooxyacetic acid

Aminoethoxyvinylglycine

Benzyladenine

Carbondioxide

Cyclopropene

3,3-dimethylcyclopropene

Diazocyclopentadine

1-Decylcyclopropene

Deoxyribose nucleic acid

Deoxyribonuclease

Deoxyribonucleotide tri-phosphate

Escherichia coli

1-Ethylcyclopropene

Ethylene diamine tetra acetate

Gas chromatograph

1-Hexylcyclopropene

Luria-Bertani medium

1-Methylcyclopropene

3-Methylcyclopropene

National center for biotechnology information

Never ripe (LeETR3)

1-Octylcyclopropene

Relative humidity

Ribose nucleic acid

Ribonuclease

Reverse transcriptase polymerase chain reaction 
SAM

STS

TAE buffer

Taq

Tris
S-adenosyl methionine

Silver thiosulfate

Tris-Acetate-EDTA buffer

Thermus aquaticus

tris-(hydroxymethyl) aminomethane

Genes/protein:

The symbol for genes is shown in italics and capitals (e.g. ETRl). The name of a mutation in a gene is italicized but not capitalized, e.g. etr1-1. The symbol for the protein encoded by the gene uses the same letters and numbers and is capitalized, but not italicized (e.g. ETR1)

$\begin{array}{ll}A C O & \text { ACC oxidase } \\ A C S & \text { ACC synthase } \\ C T R & \text { Constitutive triple response } \\ E I L & \text { EIN-like } \\ E I N & \text { Ethylene insensitive } \\ E R F & \text { Ethylene response factor } \\ E R S & \text { Ethylene response sensor } \\ E T R & \text { Ethylene resistant }\end{array}$




\section{Kurzfassung \\ Wirkung von neuen Inhibitoren der Ethlyenperzeption zur Verbesserung der Haltbarkeit von Topfrosen (Rosa hybrida L.)}

Ethylen ist ein wichtiges Nachernteproblem bei Topfrosen. So kommt es bei der Vermarktung durch das Verwelken der Blüten oder durch den Abwurf der Knospen, der Blüten und der Blätter zu Qualitätseinbußen. In dieser Arbeit wird die Wirkung und ein möglicher praktischer Einsatz von 1-MCP (1-Methylcyclopropen) Analogen, wie 1-OCP mit einer 8er-Carbon-Kette in der ersten Position und 1-DCP mit einer 10er-Carbon-Kette in der ersten Position für Topfrosen getestet. Die Sorte 'Lavender' Kordana mit einer hohen Ethylensitivität von Rosen Kordes, Sparrishoop, wurde, um die besten Bedingungen zu finden, im verkaufsfertigen Stadium mit unterschiedlichen Konzentrationen von 1-OCP, 1-DCP oder 1-MCP behandelt und anschließend, für das gesamte Experiment, kontinuierlich exogenem Ethylen ausgesetzt. Die Sorte 'Lavender' wurde dann mit der ethylen-tolerante Sorte 'Vanilla' verglichen. Der Versuch wurde vollkommen randomisiert mit 3 Wiederholungen und je 3 Töpfen pro Wiederholung durchgeführt. Ausgewertet wurde der Verlust der Blüten, Knospen und Blätter. Alle getesteten Konzentrationen der Chemikalien zeigten eine Wirkung im Vergleich zu den unbehandelten Kontrollpflanzen. 1-OCP und 1-DCP zeigte die beste Wirkung bei einer Konzentration von $1000 \mathrm{nl} \mathrm{l}^{-1}$. Damit war eine fünfmal höhere Konzentration, als die zum Vergleich genutzte optimale Konzentration von 1-MCP (200 $\left.\mathrm{nl} \mathrm{l}^{-1}\right)$, notwendig. Die Wirksamkeit von 1-OCP und DCP wurde in Abhängigkeit zur Behandlungszeit und der Temperatur untersucht. Eine Behandlungszeit von 4 Stunden reichte sowohl für 1-OCP als auch 1-DCP aus, um eine optimale Haltbarkeit der Topfrosen zu erreichen. Eine längere Behandlungszeit führte zu keiner Verbesserung. Offenbar hatte auch die Behandlung der Topfrosen bei unterschiedlichen Temperaturen keinen Einfluss auf die Wirkung von 1-OCP und 1-DCP. So zeigten sich keine Unterschiede in einem Temperaturbereich zwischen $10^{\circ} \mathrm{C}$ und $20^{\circ} \mathrm{C}$. Für die molekulargenetischen Untersuchungen wurden von der Sorte 'Vanilla' und 'Lavender' Blüten- und Blattproben nach der Behandlung mit 1-OCP, 1-DCP und 1-MCP nach 9 Tagen entnommen. Anschließend wurde die Expression von Genen der Ethylensynthese (5 unterschiedliche ACS Gene), der Ethylenperzeption (5 unterschiedliche Rezeptoren) und der Signaltransduktion (4 unterschiedliche Signaltransduktrionsgene) untersucht. Ein Signaltransduktionsgen $(R h E R F)$ wurde bei den Topfrosen erstmals isoliert. Das mögliche Polypeptid von RhERF1 besitzt eine ERF Domain mit einer hohen Homologie zu bereits bekannten ERF Domains. Northernhybridisierungen wurden mit den Ergebnissen der RT-PCR verglichen. Jedoch zeigte sich, dass aufgrund der hohen Homologie zwischen den unterschiedlichen Ethylenrezeptoren eine Unterscheidung des Hybridisierungssignals schwierig war. Die RT-PCR Analysen zeigten, dass die Expression von allen untersuchten Genen, mit Ausnahme der Gene RhACS1-2 und RhETR4 in den Blütenblätter der Kontrollpflanzen 'Vanilla' und 'Lavender' durch Ethylen induziert wird. Dahingegen wurde nach einer Behandlung mit den Ethylenrezeptorinhibitoren (1-OCP und 1-MCP) eine Unterdrückung der Expression bei allen untersuchten Genen, mit und ohne Ethylen nachgewiesen. Jedoch konnte eine starke Expression der Gene RhETR3, RhEIN3 und RhEIL nach einer Behandlung mit 1-DCP nachgewiesen werden. In der Abwesenheit von Ethylen zeigte sich eine starke Expression in den Blättern der 'Vanilla' Kontrollpflanzen bei allen Genen mit Ausnahme des Gens RhACS1. Nach der Behandlung mit den Ethylenrezeptorinhibitoren konnten keine Transkripte des untersuchten Gens in den Blättern von 'Vanilla' nachgewiesen werden. In den 'Vanilla' Blättern konnte eine Erhöhung der RhEIN3 Transkripte nach der Behandlung mit den Ethylenrtezeptorinhiobitoren bei exogenem Ethylen nachgewiesen. Hingegen wurde bei den identischen Bedingungen eine Unterdrückung der RhEIN3 Expression in den Blättern der Sorte 'Lavender' nachgewiesen werden. Möglicherweise sind die RhEIN3 Transkripte ein limitierender Faktor bei der Ethylensignaltransduktion. Diese könnten dann während der Regulation der Blütenseneszenz auf transkriptionaler Ebene reguliert werden. In der Abwesenheit von Ethylen wird die Expression der Gene RhACS1, RhETR 3 und RhERF1 unterdrückt. Eine ähnliche Wirkung zeigt auch 1-OCP, es inhibiert die Expression der Gene RhACS1, RhCTR2 and RhERF1. 1-DCP inhibiert ebenfalls die Expression der Gene RhEIN3 und RhEIL. Jedoch zeigt sich bei der Anwesenheit von Ethylen, nach einer Behandlung mit 1-MCP eine Expressionshemmung der Gene RhACS1, RhETR4, RhCTR1-2, RhEIL 
und RhERF1. Eine ähnliche Wirkung zeigt 1-OCP. Diese Behandlung führt zu der Expressionsinhibierung der Gene RhACS1, RhETR2, RhETR4, RhCTR1-2, RhEIN3 und RhERF1. Die Belandung mit 1-DCP unterdrückt die Expression der Gene RhACS1 und RhETR4. Die Ergebnisse zeigen, dass die Expression der Gene der Ethylensynthese, der Ethylenperzeption und der Signaltransduktion nach einer Behandlung mit Ethylenrezeptorinihibitoren und bei Anwesenheit und nicht Anwesenheit von Ethylen, sowohl über eine positive als auch negative Feedbackreaktion bei den Sorten 'Vanilla' and Lavender', reguliert wird. Dies könnte sowohl durch die Pflanzenart als auch durch das untersuchte Gewebe beeinflusst werden. Zusammenfassend zeigen die Ergebnisse (physiologisch und molekulargenetisch), dass eine Behandlung mit Ethylenrezeptorinihibitoren die Haltbarkeit bei Topfrosen, durch die Verhinderung des Verlustes der Knospen, der Blüten und der Blätter, verlängert. Wobei jedoch 1-MCP eine bessere Wirkung, durch eine mögliche Unterdrückung der Gene der Ethylensynthese, der Ethylenperzeption und der Signaltransduktion zeigt, als 1-OCP und 1-DCP.

Schlüsselwörter: ACC Synthase, Ethylenperzeption und Signaltransduktion, Ethylen, Ethyleninhibitoren, Haltbarkeit, Genexpression, Rosa hybrida, Seneszenz 


\section{Abstract \\ Efficacy of new inhibitors of ethylene perception in improvement of display quality of miniature potted roses (Rosa hybrida L.)}

Ethylene is an important postharvest problem in miniature potted roses that leads to loss of quality during marketing by accelerating flower senescence, and bud, flower and leaf drop. The effect of pretreatments with analogues of 1-MCP, 1-OCP substituted with an 8-carbon chain in the 1-position and 1-DCP with a 10carbon chain, and 1-MCP were studied to possibly come up with a potential commercial approach for improving display quality of miniature potted roses. 'Lavender' Kordana breeding line from Rosen Kordes, Sparrishoop, which is sensitive to ethylene, were grown and pretreated after harvest with different levels of 1-OCP, 1-DCP, 1-MCP or air and continuously exposed to exogenous ethylene throughout the experimental period to find the best conditions for 'Lavender' as compared with 'Vanilla', which is insensitive to ethylene. They were then arranged in a completely randomized design comprising 3 replications per treatment of 3 pots per replication and evaluated for bud and flower drop as well as leaf drop. All tested levels of all chemicals were effective when compared to untreated (control) plants. 1-OCP and 1-DCP were the most effective at concentrations $1000 \mathrm{nl}^{-1}$, which was five times higher than the concentration of 1-methylcyclopropene (1-MCP) $\left(200 \mathrm{nl} \mathrm{l}^{-1}\right)$ used as a standard. Exposure time of $4 \mathrm{~h}$ for both 1-OCP and 1-DCP was sufficient to improve display life of miniature roses and longer exposures did not have any additional beneficial effect. Apparently, exposing miniature potted roses to various temperatures did not have an influence on the performance of both 1-OCP and 1-DCP, which were effective at temperatures of $10^{\circ} \mathrm{C}$ to $20^{\circ} \mathrm{C}$. Samples of 'Vanilla' and 'Lavender' petals and leaves from the best condition of pretreatment of 1-OCP, 1-DCP and 1-MCP or air were taken for molecular studies in investigating the expression of genes responsible for ethylene biosynthesis enzyme (5 different ACS genes), ethylene perception (5 different receptors) and signal transduction pathway (4 different transcription regulating genes) after 9 days of continuous exposure to exogenous ethylene. One transcription regulating gene ( $R h E R F 1)$ was isolated from miniature rose. The putative polypeptide of $R h E R F 1$ had an ERF domain, which shares high homology with other reported ERF domains. Northern blot hybridization analysis was used to compare with results of RT-PCR. However, it was difficult to distinguish the hybridization signal of ethylene receptors between RhETR1 and RhETR2, which were high homolog. RT-PCR analysis revealed that ethylene induced the expression of all genes investigated in control 'Vanilla' and 'Lavender' petals except RhACS1-2 and RhETR4, respectively, while pretreatments of ethylene receptor inhibitors (1-OCP and 1-MCP) suppressed the expression of all genes in the presence or absence of ethylene. However, strong expression of RhETR3, RhEIN3 and RhEIL transcripts was detectable in 'Lavender' petals pretreated with 1-DCP. In the absence of ethylene, there was strong expression of all genes in control 'Vanilla' leaves but no expression of $R h A C S 1$, while the accumulation of all genes was eliminated after pretreatments of 'Vanilla' leaves with ethylene receptor inhibitors. However, the level of RhEIN3 mRNA was upregulated by pretreatment of ethylene receptor inhibitors in 'Vanilla' leaves in the presence of ethylene while the accumulation of RhEIN3 mRNA was suppressed in 'Lavender' leaves. RhEIN3 transcript is probably rate-limiting for ethylene perception and signal transduction pathway, which is regulated in leaves during flower senescence at the transcriptional level. In the absence of ethylene, 1-MCP suppressed the expression of RhACS1, RhETR3 and RhERF1 transcripts. Similarly, 1-OCP inhibited the expression of RhACS1, RhCTR2 and RhERF1 transcripts. Likewise, 1-DCP inhibited the expression of RhEIN3, RhEIL genes. However, in the presence of ethylene, pretreatment of 'Lavender' leaves with 1-MCP suppressed the expression of RhACS1, RhETR4, RhCTR 1-2, RhEIL and $R h E R F 1$ transcripts. Similarly, 1-OCP treatment inhibited the expression of RhACS1, RhETR2, RhETR4, RhCTR1-2, RhEIN3 and RhERF1 transcripts. Pretreating 'Lavender' leaves with 1-DCP suppressed the expression of RhACS1 and RhETR4 transcripts. These results indicated that the expression of genes for ethylene biosynthesis enzyme, ethylene perception and signal transduction pathway was regulated by both positive and negative feedback regulation mechanism in 'Vanilla' and Lavender' pretreated with ethylene receptor inhibitors in the presence or absence of ethylene. This might depend on plant species and tissues under investigation. Physiologically and molecularly, these results suggest that pretreatments with 
inhibitor of ethylene receptor improved the display life of miniature roses by delaying bud, flower and leaf drop, whereas 1-MCP is more effective than 1-OCP and 1-DCP, possibly by suppressing the expression of some genes for ethylene biosynthesis enzyme, ethylene perception and signal transduction pathway.

Key words: ACC synthase, display quality, ethylene, ethylene perception and signal transduction, gene expression, inhibitors of ethylene receptor, Rosa hybrida, senescence. 


\section{General Introduction}

\subsection{Ethylene and flower senescence}

Senescence can widely be defined as the combination of events that lead to the death of cells, tissues or organs (Reid and $\mathrm{Wu}, 1992$ ). This process occurs at many stages during the development of an organism and at many levels (Noodén et al., 1997). It is mediated by a series of highly coordinated physiological and biochemical changes, such as increased activity of hydrolytic enzymes, degradation of macromolecules, loss of cellular compartmentation and increase in respiratory activity. These changes are related to changes in gene expression and synthesis of protein (Borochov and Woodson, 1989; Van Altvorst and Bovy, 1995).

Flower senescence is a common cause of quality loss and reduced vase life of flowering plants and cut flowers (Serek and Reid, 2000a). Senescence in many flowers is accompanied by pollination promoting the production of ethylene which ultimately causes petal wilting (Nichol, 1977), abscission and sleepiness (florets failed to re-open) of petals (Marousky and Harbaugh, 1979) and a climacteric increase in ethylene production (Nichols, 1968; Singh and Moore, 1994). This is induced by several factors, e.g., water stress (Sankat and Mujaffar, 1994), carbohydrate depletion (Ketsa, 1989), microorganisms (Witte and Van Doorn, 1991), and ethylene effects (Wu et al., 1991a, b). The phytohormone ethylene plays a vital role in regulation of flower senescence in many species. Additionally, ethylene-induced senescence in some sensitive species may result from the production of endogenous ethylene or from exposure to exogenous ethylene (Van Altvorst and Bovy, 1995; Halevy and Mayak, 1979). The action of ethylene is based on two types of responses: the response to a change in the concentration of ethylene, and the response to a change in the sensitivity of tissue to ethylene (Sato-Nara et al., 1999). Certain plants are ethylene-sensitive and flowers of these plants deteriorate rapidly in the presence of ethylene. Ethylene can be produced by almost all parts of plants, although the production relies on the type of tissue and stage of development (Müller and Stummann, 2003). In carnation, a large amount of ethylene is synthesized several days after full opening of the flower during natural senescence (Manning, 1985; Peiser, 1986; Woodson et al., 1992), or several hours after compatible pollination (Nichols, 1977; Nichols et al., 1983; Larsen et al., 1995) or treatment with exogenous ethylene (Borochov and Woodson, 1989; Wang and Woodson, 1989). The increased 
ethylene production accelerates in-roll of petals resulting in wilting of the flower. Flowers develop the early stages of wilting symptoms when treated with ethylene and later disappear when ethylene treatment is stopped. This suggests that ethylene is required beyond the appearance of early visual symptoms to uphold the "senescence syndrome" (Mayak and Kofranek, 1976).

\subsection{Exogenous ethylene}

Senescence of climacteric flower petals is associated with an increased rate of ethylene production and respiration, concomitant with the onset of petal wilting. Exposure to exogenous ethylene promotes senescence of climacteric flower petals with activation of ACC synthase and/or ACC oxidase (Borochov and Woodson, 1989).

Woltering and Doorn (1988) studied petal senescence in mature flowers of 93 species from 22 families. Most of the flower families (Geraniaceae, Libiatae, Ranunculaceae, Rosaceae and Scrophulariaceae) showed initial abscission in response to ethylene except for a few families (Caryophyllaceae, Campanulaceae, Malvaceae and Orchidaceae), which showed wilting as their primary senescence symptom.

Moreover, Woltering and Doorn (1988) observed that abscission in Rosaceae is the initial symptom of flower senescence. Further evidence supporting this view has found that bud abscission of 'Victory Parade' roses occurs when plants are sensitive to ethylene (Serek, 1993). However, in miniature potted roses, petal wilting as a form of flower senescence is more obvious than petal abscission (Müller et al. 1998). The aging process of the flowers is apparently accelerated by exogenous ethylene. Increasing amounts of exogenous ethylene in postharvest environments also induces a variety of symptoms (petal abscission, leaf and bud drop) in rose cultivars, and there are marked differences in sensitivity and response to ethylene among cultivars (Müller et al., 1998). 


\subsection{Endogenous ethylene}

Ethylene clearly influences natural flower senescence as an integral part of the aging process in Ipomoea and Hibicus and serves to accelerate aging but may not be the initial causative agent. This accelerating effect of ethylene is apparently related to the autocatalytic nature of the ethylene biosynthetic system where ethylene stimulates its own synthesis in both flowers and ripening of climacteric fruits (Kende and Baumgartner, 1974; Kende and Hanson, 1976; Beyer and Sundin, 1978; Woodson et al., 1985; Halevy and Mayak, 1979). In carnation flowers, an increase in ethylene production rate, similar to the climacteric associated with fruit ripening, coincides with the first visible signs of senescence by petal in-rolling (Peiser, 1986; Mayak and Tirosh, 1993). During the aging of petals, the transition to autocatalytic ethylene production results from a change in tissue responsiveness to ethylene and an increase in their capacity to respond to exogenous ethylene by the induction of autocatalytic ethylene production, indicating a gradual release of the ethylene biosynthetic pathway from restriction (Wang and Woodson, 1989). Several studies have been shown that rose flower senescence is regulated by ethylene. Many cultivars of miniature roses also show a climacteric rise in ethylene production during flower senescence, even though large differences are found among cultivars. In some cultivars, flower senescence is accompanied by a clear climacteric rise in ethylene production, and by a moderate or low ethylene production in others. Longevity of miniature roses in the absence of exogenous ethylene is presumably a function of endogenous ethylene production. For example, the short life of individual flowers in 'Bronze' is associated with a clear climacteric peak in ethylene production, similar to that found in typical climacteric flowers. The excellent longevity of 'Charming Parade' in an ethylene-free environment, however, is related to a very low ethylene production of flowers (Müller and Stummann, 2003).

\subsection{Pollination-induced senescence}

Pollination in many flowers causes ethylene biosynthesis and developmental changes such as ovary growth and petal wilting and abscission. These processes are induced by a translocated signal that precedes the growing pollen tube signal, a compatible pollination, to ovary and petals. In addition, styles are sources of high ethylene production, which can be activated by pollination (Jones and Woodson, 1999a; Nichols, 1977). Two or three phases of pollination-induced ethylene 
production occur in petunia, tobacco, and carnation. The first peak of ethylene is detectable within a few minutes of pollination, then sustains climacteric of ethylene production and follows in response to a compatible pollination and hastens senescence of the style and petals. An unidentified senescence signal appears to be translocated to other flower parts, which become active sites of autocatalytic ethylene production within a few hours of pollination (Holden et al., 2003). Application of amino-oxyacetic acid (AOA), an inhibitor in ethylene biosynthesis, blocks pollination-induced ethylene production in orchid flowers, decreases ovary growth and delays senescence (Ketsa and Rugkong, 2000).

\subsection{Non-ethylene-mediated senescence}

Senescence of the petals of many cut flowers such as Compositae, Iridaceae, Liliaceae and also most of the important geophytes appears not to be related to ethylene (Reid, 1989; Woltering and Van Doorn, 1988).

Flower senescence in Hemerocallis, daylily, is ethylene-independent. The senescence of these flowers is not accelerated by exposure to exogenous ethylene, nor delayed by inhibitors of ethylene biosynthesis or by ethylene antagonists (Lukaszewski and Reid, 1989). The major events that occurred in the ethylene-unresponsive daylily are an early decline in phospholipid synthesis, an increase in cell permeability that leads to an increase efflux of sugars and ions, a respiration climacteric, early wilting and then autolysis of petal tissue. Moreover, flower senescence in daylilies is accompanied by both the decline in protein content and the breakdown of specific proteins in the petals. The inhibition of flower senescence by cyclohexamide (CHI) could maintain protein content and protein population of the petals. These effects of $\mathrm{CHI}$ may require de novo protein synthesis in these species during senescence and are key factors controlling petal senescence in a species where the regulation of this event appears to be independent of ethylene (Bieleski and Reid, 1992; Lay-Yee et al., 1992).

Gladiolus, like other geophytes in Liliaceace, is an ethylene-insensitive flower (Lay-Yee et al., 1992). Ethylene is not a factor in floret senescence since wilting of florets is not accelerated by exposure to ethylene, nor delayed by ethylene antagonists (Serek et al., 1994a). 
In Cyclamen persicum Mill flowers, senescence is not associated with an increase in ethylene production. Flowers do not respond to exogenous ethylene even when exposed to very high concentrations of the gas. Pollination, however, induces a dramatic increase in ethylene evolution. This presumably indicates that the promotion of senescence (corolla drop) in pollinated cyclamen flowers is mediated by ethylene (Halevy et al., 1984).

\subsection{Ethylene biosynthesis}

The pathway of ethylene biosynthesis in plants has been explained (Yang, 1985; Van Alvorst and Bovy, 1995).

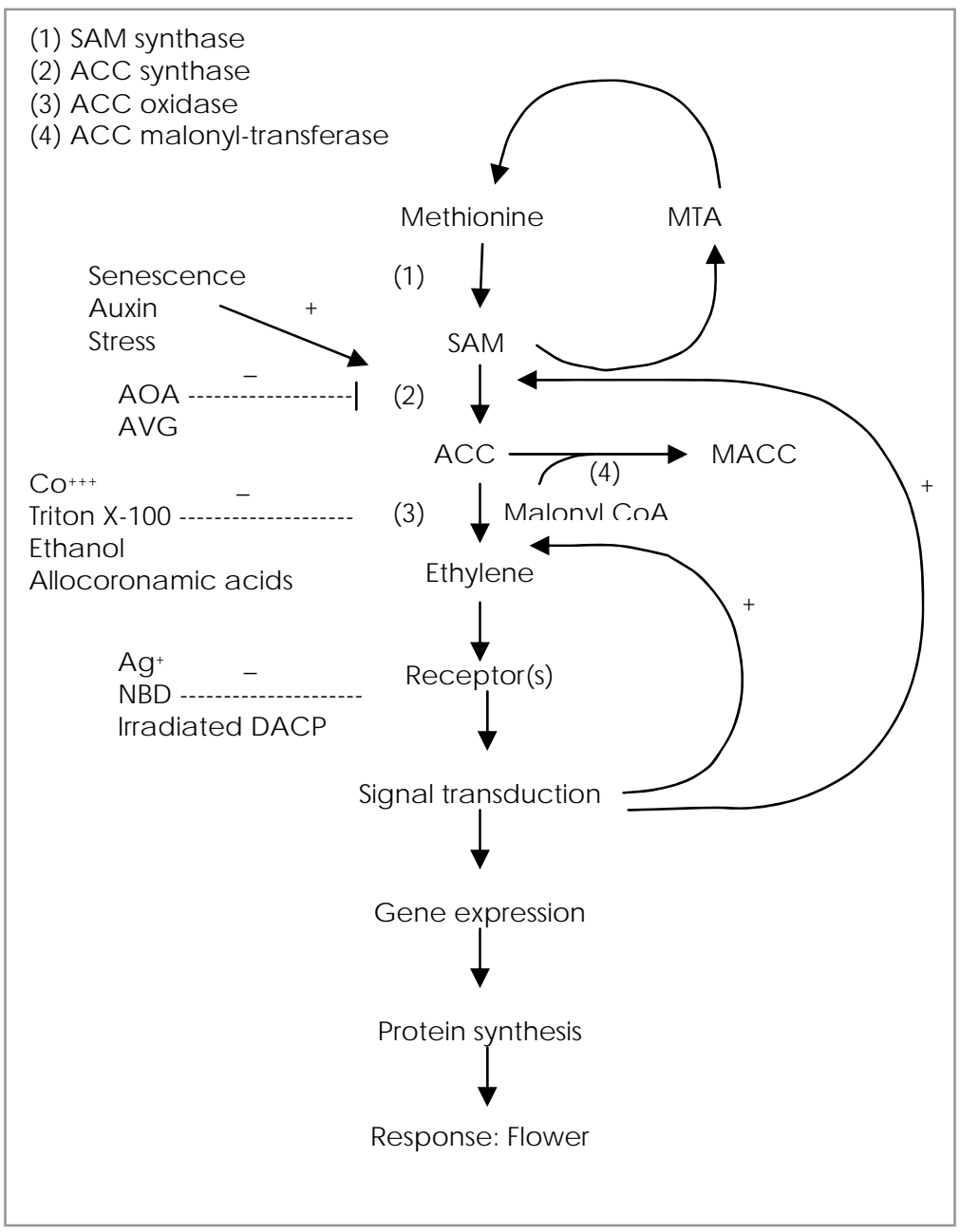

Fig. 1 Ethylene biosynthesis pathway by Van Alvorst and Bovy (1995). 
In higher plants, ethylene is synthesized from methionine via a pathway involving the conversion of S-adenosylmethionine (SAM) to 1-amino cyclopropane-1-caboxylic acid (ACC) and the oxidation of ACC to ethylene. The enzyme ACC synthase converts SAM to ACC while ACC oxidase catalyzes the conversion of $\mathrm{ACC}$ to ethylene, $\mathrm{HCN}$ and $\mathrm{CO}_{2}$. In addition, methionine is regenerated in the Yang cycle (Adam and Yang, 1979) (Fig. 1).

\subsubsection{ACC}

The intermediate precursor of ethylene in higher plants is 1-aminocyclopropene-1-carboxylic acid (ACC) (Adam and Yang, 1979). The endogenous ACC level in various flower parts increases during senescence (Veen and Kwakkenbos, 1982; Nichols et al., 1983; Hsieh and Sacalis, 1986). Application of ACC stimulates wilting in whole carnation flowers (Veen and Kwakkenbos, 1982). Exposure to ethylene of isolated carnation petals, separated into upper and basal parts, shows that the majority of ethylene production is evolved from the basal part of the petals. Endogenous ACC content in the basal portions of senescing carnation petal is 3 to 5 times higher than in the upper parts. The upper portions respond to ethylene by delaying wilting and much lower ethylene production. Application of ACC to the upper portion of senescing petals increases their ethylene production (Mor et al., 1985). During flower senescence, ACC is translocated from the basal part where it is synthesized to the upper part where it is converted into ethylene (Overbeek and Woltering, 1990). In addition, the endogenous ACC content of pollen correlates with the amount of ethylene that is produced by petunia styles immediately after pollination (Singh et al., 1992). The detection of ACC in petunia pollen indicates that ACC diffusing from pollen might be responsible for early ethylene production, initiating autocatalytic ethylene production (Stead, 1985).

\subsubsection{ACC synthase and ACC oxidase}

The biosynthesis of ethylene in flower tissues is under strict metabolic regulation and is subject to induction by a variety of signals including emasculation, pollination, wounding, auxin, abscissic acid and environment stress (Borochov and Woodson, 1989). The conversion of SAM to ACC is catalyzed by the peridoxal phosphate-requiring enzyme ACC synthase, which represents the ratelimiting step in ethylene biosynthesis in many plant tissues (Kende, 1989, 1993). All evidence 
indicates that ACC synthase is a cytoplasmic enzyme (Kende, 1993). Boller et al. (1979) found that ACC synthase is a soluble enzyme in tomato fruits. The final step in the ethylene biosynthetic pathway is catalyzed by ACC oxidase, formerly referred to as the ethylene-forming enzyme (EFE) (Kende, 1989, 1993). ACC oxidase is located in the cell walls of apple and tomato fruit cells. In apple, the enzyme is actually located at the external face of the plasma membrane (Ramassamy et al., 1998; Rombaldi et al., 1994). ACC oxidase requires ascorbate, $\mathrm{Fe}^{2+}$, and $\mathrm{CO}_{2}$ which act as essential cofactors (Smith and John, 1993a, b). Both ACS and ACO enzymes from a number of different species are encoded by multigene families whose members are differentially regulated in a tissue-specific manner by a variety of developmental cues, mechanical and environmental stresses, and by ethylene, which stimulates its own biosynthesis (Kende, 1993; Fluhr and Mattoo, 1996).

\subsection{Strategies to breed ethylene-insensitive flowers}

The development of ethylene-resistant cultivars that are mutant with impaired ethylene biosynthesis or sensitivity has been studied in carnations as a model system leading to a more focused breeding effort in the genetic improvement of postharvest longevity of these flowers. The extended vaselife genotypes are responsive to genetic differences by synthesis and response to ethylene. For example, genotype 799 is impaired in its ability to respond to ethylene by increasing ethylene production or premature petal senescence. The second genotype, 87-37G-2, appears to represent a mutation affecting the synthesis of ethylene but not ethylene responsiveness. The third genotype, $81-2$, is able to synthesize ethylene in response to ethylene treatment but failed to produce ethylene during normal aging. This pattern shows that these flowers fail to produce elevated ethylene during aging but respond to exogenous ethylene by increased ethylene synthesis and premature senescence (Brant and Woodson, 1992). Similar to Sandrosa carnations, these flowers do not exhibit an autocatalytic increase in ethylene production nor do they develop petal in-rolling, but the sensitivity to ethylene diminishes with age, whereas other flowers show increased sensitivity to ethylene with age (Mayak and Tirosh, 1993). In 'killer' carnations that show non-climacteric behavior, the lack of ethylene production is due to a limited-available ACC, likely resulting from low ACC synthase activity and failure to convert ACC into ethylene because of restricted ACC oxidase activity (Serrano et al., 1991). 
'Sandra' and 'Chinera' carnation flowers last about twice as long as those of 'White Sim' whose senescence closely correlates with the normal climacteric of respiration and ethylene production and is accompanied by a marked increase in ACC content and ACC oxidase activity. In contrast, the long vase life of Sandra flowers is due to inhibition, under normal conditions, of the pathway for ethylene biosynthesis (Wu et al., 1989, 1991a). Although behavior of non-climacteric carnation 'Sandra' fails to produce elevated ethylene during aging, it responds to exogenous ethylene by increasing ethylene synthesis and premature senescence. 'Chinera' flowers not only produce less ethylene during natural senescence, but are also much less sensitive to ethylene (Wu et al., 1991b).

\subsection{Ethylene sensitivity}

Various processes during plant development are determined both by ethylene production and by the tissue responsiveness to ethylene. Therefore, differences in sensitivity to hormones are the main factor controlling plant response (Trewavas, 1982). During senescence, changes in a climacteric rise in ethylene production and a gradual increase in ethylene sensitivity occur in the corollas of climacteric flowers such as carnation and petunia (Nichols, 1968; Halevy and Mayak, 1981; Whitehead and Halevy, 1989). In addition, pollination of these flowers leads to an acceleration of senescence involved in a marked stimulation of ethylene synthesis and a sudden increase in sensitivity of the corolla to ethylene (Whitehead and Halevy, 1989; Whitehead and Vasijevic, 1993; Porat et al., 1994; Halevy et al., 1996).

The increase in ethylene sensitivity following pollination is independent of endogenous ethylene production since it occurs in flowers treated with AOA, which prevents the increase in ethylene synthesis. An increase in ethylene sensitivity following pollination is thought to render the tissue to respond to low basal ethylene, thus inducing the later autocatalytic increase in ethylene production. This is also related to its ability to increase ethylene binding by altering certain membrane properties which could lead to an increase in the availability of ethylene binding sites (Porat et al., 1993, 1994, 1995b; Whitehead and Vasijevic, 1993). It is clear that ethylene cannot be the pollination signal inducing sensitivity to ethylene (Porat et al., 1993, 1994, 1995b).

The possibility that the sensitivity factor is short-chain saturated fatty acids $\left(\mathrm{C}_{7}-\mathrm{C}_{10}\right)$ has been postulated (Whitehead and Halevy, 1989). Application of these acids to the stigmas of petunia 
and carnation flower results in a sudden increase in ethylene sensitivity and a marked acceleration of senescence (Whitehead and Vasijevic, 1993). Treatment of Dutch iris (Iris) 'Sapphire Beauty' bulb with the short-chain saturated fatty acid octanoic acid $\left(\mathrm{C}_{8}\right)$ increases ethylene sensitivity by stimulating flowering (Botha et al., 1998).

However, in carnation, petunia and cymbidium (Cymbidium), short-chain saturated fatty acid does not play an important role in flower senescence and ethylene sensitivity (Wotering et al., 1993).

\subsection{Statement of the problem}

Miniature potted roses are popular greenhouse crops in many parts of the world. In the 1980s, there was an introduction of new varieties that have had a dramatic impact on the European and North American markets. Current annual world production is estimated at 60-80 million pots in Europe and 26 million pots in the United States. Major centers of production include Denmark, The Netherlands, the United States, Canada and Japan with production also in France, Germany and Italy (Pemberton et al., 2003; USDA, 2003: http://www.ars.usda.gov). The acceptability and trade value of miniature potted roses can be influenced by postharvest longevity, where in Denmark, extensive efforts have been taken to improve the quality and increase the production of these plants, for example with a breeding program (Serek and Andersen, 1993, Müller et al., 1998). Loss of quality during postharvest and marketing in miniature potted roses are important problems caused by ethylene action (Serek, 1993; Serek et al., 1994c), such as accelerated flower wilting, leaf yellowing, bud and leaf abscission and infection by grey mould (Botrytis cinerea). It is assumed that ethylene is not the primary cause of leaf yellowing in miniature potted roses, but that it accelerates flower senescence as well as bud, flower and leaf drop (Müller and Stummann, 2003). Variation in postharvest life of miniature roses is partly the result of differences in endogenous ethylene during flower senescence, stress-induced ethylene production and sensitivity to exogenous ethylene. Ethylene sensitivity has important implications during the transport and handling of potted roses in supermarkets and other areas where the air is commonly contaminated with ethylene (Müller et al., 1998, 2000a). In ethylene-contaminated air, rose cultivars with high sensitivity to exogenous ethylene exhibit a short flower life (Müller et al., 2000a). Ethylene action involves binding to a specific receptor (Schaller and Breecker, 1995; Sisler and Serek, 1997). Since ethylene inhibitors can block the plant tissues from endogenous 
and exogenous ethylene, they are considered very potent for horticultural use (Sisler and Serek, 1997; Feng et al., 2000). 1-MCP and some new putative inhibitors of ethylene action, which are structurally analogous to 1-MCP containing a longer side chain at 1-position (1-OCP and 1-DCP), have been found to be effective in protecting cut flowers against ethylene (Kebene et al., 2003a, b) and delaying the sensitivity of bananas to ethylene (Sisler et al., 2003). In addition, the expression patterns of the genes for the ethylene biosynthetic enzyme ACC synthase, and for ethylene receptors and signal transduction pathway during flower development and senescence processes seem essential to understanding ethylene response. Understanding the roles of the various ethylene-relevant genes in flower development may lead to an ability to selectively block processes in flower senescence that are economically detrimental, and to improve display life using both conventional breeding and biotechnological engineering.

\subsection{Objectives}

1. To investigate the effect of extended chain length of the activity of inhibitors of ethylene receptors $1-\mathrm{OCP}$ and 1-DCP as compared with 1-MCP, in preventing the effects of ethylene on display quality of miniature potted roses.

2. To determine the optimum concentrations, exposure time and temperature at which 1-OCP and 1-DCP effectively improve the longevity of miniature potted roses.

3. To determine the effectiveness of 1-OCP, 1-DCP and 1-MCP between miniature potted rose cultivar 'Lavender' with sensitivity to ethylene and 'Vanilla' with long-lasting vase life.

4. To investigate the effect of 1-OCP, 1-DCP and 1-MCP on the expression of the genes for the ethylene biosynthetic enzymes, ethylene perception and signal transduction pathway in miniature potted roses. 


\title{
2. Efficacy of new inhibitors of ethylene perception in improvement of display quality of miniature potted roses (Rosa hybrida L.)
}

\begin{abstract}
1-Octylcyclopropene (1-OCP) and 1-Decylcyclopropene (1-DCP), which act as ethylene receptor inhibitors and are analogues to 1-MCP, but are substituted with longer carbon chains in the 1-position, were investigated in miniature potted rose cultivar 'Lavender'. All tested levels of both chemicals were protected as compared to untreated plants. 1-OCP and 1-DCP were the most effective at concentrations of 1000 and $1500 \mathrm{nl} \mathrm{l}^{-1}$, which was five times higher than the concentration of 1-methylcyclopropene (1-MCP) $\left(200 \mathrm{nl} \mathrm{1^{-1 }}\right)$ used as a standard. The effectiveness of 1-OCP and 1-DCP was a function of time and temperature. At short $(2 \mathrm{~h})$ exposure times, the plants were highly sensitive to ethylene. Exposure time of $4 \mathrm{~h}$ for both 1-OCP and 1-DCP was sufficient to improve display life of miniature roses and longer exposures did not have any additional beneficial effect. Apparently, exposing miniature potted roses to various temperatures did not have an influence on the performance of either 1-OCP or 1-DCP. They were effective at temperatures between 5 to $20^{\circ} \mathrm{C}$. The effectiveness of this group of compounds on the display quality of miniature roses is discussed.
\end{abstract}

Key words: 1-DCP, Ethylene receptor inhibitors, 1-MCP, 1-OCP, Postharvest performance 


\subsection{Introduction}

Ethylene has been shown to play a central role in physiological and developmental processes such as seed germination, growth, flower initiation, organ abscission, fruit ripening, senescence of leaf and flowers and response to pathogen attack (Abeles et al., 1992). Ethylene binding would be mediated by a transition metal cofactor (Burg and Burg, 1967). The isotopic competition technique can explain the presence of a specific ethylene binding site in carnation petals exposed to ${ }^{14} \mathrm{C}-\mathrm{C}_{2} \mathrm{H}_{4}$. A substantial proportion of the bound radioactive ethylene could be displaced by the addition of unlabelled ethylene, identifying a specific binding site. Treatment with ethylene action inhibitors silver or 2,5-NBD to flowers reduces binding activity (Sisler et al., 1983). In addition, the binding of ethylene in petal tissues is significantly higher for young carnation petals than for older flowers. The peak in ethylene binding precedes the climacteric-like rise in ethylene production. Ethylene binding changes in senescent flowers because the number of binding sites and the affinity for ethylene in the older tissue decreases (Brown, 1986).

Copper is the metal required for the high affinity ethylene binding that receptors display (Rodriguez et al, 1999). Therefore, the binding of ethylene to its membrane associated with receptor sites is a crucial step in its action (Goren et al., 1984). Additionally, the number of receptors could have an essential role in determining the sensitivity to ethylene and the type of response that is elicited. When ethylene binds to the receptors, it induces a series of events that initiate a response to the hormone (Tian et al., 1997).

2.1.1 Compounds interacting with the ethylene receptor in plants

\subsubsection{Ethylene and ethylene analogues}

Compounds such as ethylene, some olefins, propylene, acetylene, carbon monoxide and isocyanides, which bind to the receptor, are capable of triggering ethylene-induced changes in the growth and development of plants. Ethylene and its analogues are thought to interact with a metal-containing receptor (Sisler and Wood, 1988; Sisler et al., 1990; Sisler and Serek, 2003). Of the group, ethylene is considerably more effective than the others, which are not used for some experimental research, but give some insight into how ethylene behaves (Sisler and Serek, 2001). 


\subsubsection{Competitive ethylene antagonists}

Compounds preventing an ethylene response interact with the receptor and compete with ethylene for binding. A single exposure of plant tissue to these compounds is enough to prevent binding of ethylene because they remain bound for a long period of time, with even high levels of ethylene not inducing any action (Sisler and Serek, 2003).

\subsubsection{Mode of action of compounds blocking the receptor}

Competitive ethylene antagonist compounds presumably bind to a metal in the ethylene receptor. They compete with ethylene for the receptor and prevent the ethylene receptor from binding in treated tissues. While they are bound, ethylene cannot bind (Sisler and Serek, 1997).

Both those compounds inducing a response and those blocking the receptor should bind to the supposed metal $(\mathrm{M})$ on the receptor and withdraw electrons from the metal, which causes a rearrangement or change in ligand $\left(\mathrm{L}_{1}-\mathrm{L}_{5}\right)$ on the metal. Then, ethylene (E) is likely to come off of the metal in a few minutes while other inhibitory compounds that block receptors appear to take at least several hours or, in some, many days to leave (Sisler and Serek, 1999) (Fig. 2). Ethylene leaves the complex and causes it to become active probably by ligand arrangement. Ethylene then would not be a part of the active complex, but the initiator of its formation. While the inhibitory compounds act in a similar manner to ethylene, they do not move away from the complex, thus an active complex is not formed (Sisler and Serek, 1997), which accounts for the mode of action of ethylene and 1-MCP that blocks ethylene responses (Sisler and Serek, 1997). 
Proposed model:

Inactive Inactive Active

1)

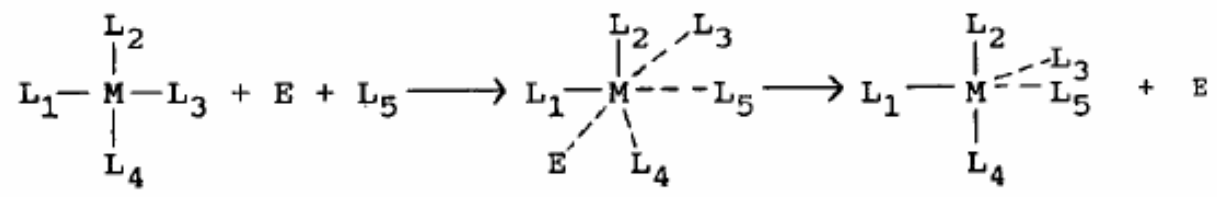

2)

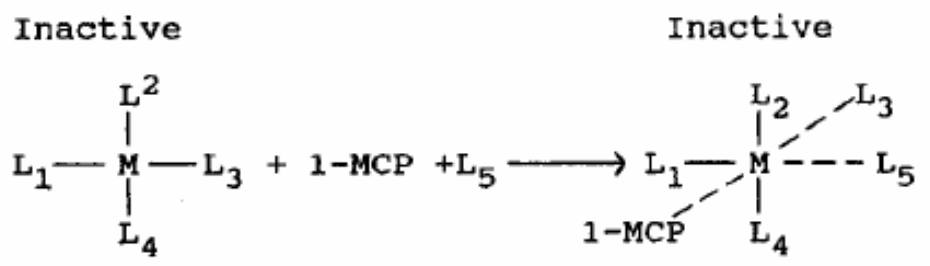

Fig. 2. Proposed model for action of ethylene and 1-methylcyclopropene (1-MCP) on the ethylene receptor (Sisler and Serek, 1997).

It is believed that the ligands could be in a protein group such as histidine, methionine, thiol groups, tyrosine groups and in a hydrophobic environment such as a membrane. Perhaps the double bonds in unsaturated fatty acids, on a single protein forming a cross link between two proteins, could be all ligands (Sisler and Serek, 1999).

\subsubsection{Ethylene antagonists inactivating the receptor for an extended period of time}

Silver ion, applied as Silver thiosulfate (STS), is a potent anti-ethylene compound in various plants. Silver acts through the irreversible interaction with ethylene binding sites (Sisler et al., 1986; Veen, 1986; Rodriguez et al, 1999). STS is in widespread commercial used to inhibit effects of ethylene and prolong vase life in many ornamentals including orchid (Cattleya) 'Loiuse Georgeianna' (Beyer, 1976), carnation (Veen, 1979), sweet pea (Lathyrus odoratus) (Mor et al., 1984), potted Christmas cactus (Schlumbergera truncate) (Serek and Reid, 1993) and potted rose (Rosa hybrida) (Serek, 1993). However, as Silver is a heavy metal, it cannot be used on food and feed, and many countries prohibit its use (Veen, 1986).

Cyclic olefins appear to block ethylene responses rather than to induce a response. All of these compounds are released from the receptor and diffuse from the binding site over a period of 
several hours. 2,5-norbonadiene (2,5-NBD) is found to compete with ethylene for binding sites in carnation petals, but it requires continuous exposure to be effective (Wang and Woodson, 1989; Sisler and Serek, 1999). Another compound in this group is trans-cyclooctene, which is much more effective, in terms of concentration, than 2,5-NBD. However, the practical use of this compound is limited by a very pungent and objectionable odor (Sisler et al., 1990).

Diazocyclopentadiene (DACP) is a putative photoaffinity label for ethylene binding sites. These compounds form highly reactive carbons under UV light, called diazo-compounds. Under UV light, nitrogen gas is split from the molecule leaving a carbine, which almost immediately reacts with many other compounds (Sisler and Serek, 2003). It binds irreversibly to the ethylene receptor or at least remains bound for many days to reduce tissue responses to ethylene in mung bean sprouts and tobacco leaves (Sisler and Blankenship, 1993), potted roses (Rosa hybrida) (Serek et al., 1994b) and tomato fruit (Tian et al., 1997). A major problem with DACP is that it is explosive in high concentrations, which limits its commercial usefulness (Sisler and Serek, 1997).

A series of cyclopropenes, cyclopropene (CP), 1-methylcyclopropene (1-MCP), 3-methylcyclopropene (3-MCP) and 3,3-dimethylcyclopropene (3,3-DMCP), have been prepared and tested by using banana fruit as an assay system. Based on the substitution of the cyclopropene ring in positions 1, 2 and 3, all compounds are effective in preventing banana from exogenous ethylene but none are more effective, concentration-wise, than 1-MCP (Sisler et al, 1996a, b, 1999, 2001). CP and $1-\mathrm{MCP}$ act at low concentrations. In banana, they are effective around $0.5 \mathrm{nl} \mathrm{l}^{-1}$. The required concentration of 3,3-DMCP is about 1000 times as high as CP and 1-MCP. It is effective in the $\mu 11^{-1}$ range and also protects banana for only 7 days (Sisler et al., 1996a, b). 3-MCP is also effective at higher concentrations than for 1-MCP. In banana, about 2.5 times as much 3-MCP is needed (Sisler et al., 1999).

In the substitution on the cyclopropene ring, both the concentration required for inactivation and duration of binding appear to be influenced by steric and inductive effects (Sisler et al., 1996b, 1999, 2001). The presence of the methyl groups in these compounds is associated with steric effect. Flat molecules (cyclopropene, 1-MCP and 3-MCP) are more active than compounds with the methyl groups isolated from the double bond. Inductive effect, however, is caused by methyl. 
A methyl group releases electrons into the cyclopropene ring and is capable of relieving the strain related to anti-ethylene effects of compounds in plants (Sisler etal., 2001).

The position of the methyl group is more important. In 1-MCP the methyl group is adjacent to the double bond, thus allowing an allylic-type of arrangement. This may interact with the ethylene receptor more rapidly than isolating a double bond in 3-MCP and result in a low concentration requirement for a given time exposure (Sisler, 1999).

Stability is an important factor in these compounds in considering commercial use. $\mathrm{CP}$ is unstable in the liquid phase even at $-78^{\circ} \mathrm{C}$, and in a dilute gas phase seems to polymerize at room temperature. 1-MCP, 3-MCP and 3,3-DMCP are relatively stable (Sisler et al., 1996a, b; Sisler et al., 2001).

1-MCP, one of the most useful compounds among substituted CPs, is a non-toxic compound, stable at room temperature, active at relatively low concentration that provides protection for a longer period of time up to 12 days after a single exposure, without any detectable odor. Moreover, in the floriculture industry 1-MCP can be used as a replacement of silver thiosulfate (STS), which is considered to be toxic (Sisler and Serek, 2001, 2003). Other CPs substituted with the methyl group in the 1-position have been developed and tested as ethylene antagonists (Sisler et al., 2001).

1-MCP prevents damage from exogenous ethylene in many potted plant species including heimalis begonia 'Najada' and 'Rosa' and tuberous begonia (Begonia $x$ tuberhybrida), rose 'Victory Parade' (Rosa hybrida) (Serek et al., 1994c), kalanchoe 'Tropicana' (Kalanchoe blossfeldiana) (Serek and Reid, 2000b), Christmas cactus (Schlumbergera truncate) and bellflower (Campanula carpatica) (Serek and Sisler, 2001) and in some countries has already been approved for use in edible crops (Blankership and Dole, 2003). However, the effect of 1-MCP on ethylene-induced petal abscission in ivy geranium 'Pink Blizzard' (Pelargonium peltalum) is transient (Cameron and Reid, 2001).

Recently, a series of cyclopropenes substituted with a methyl group in the 1-position, analogues of 1-MCP, protected for longer periods of time than those substituted in other positions (Sisler et al., 2003; Sisler and Serek, 2003). When the chain length is extended to more than four carbons, 
the minimum concentration requirement declines (Sisler et al., 2001), however, 2 or 3 carbon side chains substituted at the 1-position, 1-ethylcyclopropene (1-ECP) and 1propylcyclopropene (1-PCP), are still effective blockers of ethylene receptors and are able to inhibit ethylene action in a wide scope of systems. These include climacteric fruits like avocado and tomato, 'the triple response' in etiolated peas and abscission of citrus leaf explants (Feng et al., 2004). A concentration as low as $0.3 \mathrm{nl} \mathrm{l}^{-1}$ is needed for both 8-carbon chain, 1-octylcyclopropene (1-OCP), and 10-carbon, 1-decylcyclopropene (1-DCP), to protect against ethylene response in banana fruits. Furthermore, the time of protection for 1-substituted CPs at ambient temperature $\left(22-23^{\circ} \mathrm{C}\right)$ is significantly longer for 1-DCP (36 days) than that of 1-MCP (12 days) (Sisler et al., 2003). Further 1-substituted CP tests have been done on kalanchöe and sweet pea flowers, but their inhibiting effects are lower than in bananas (Kebenei et al., 2003a, b).

The effects of these compounds as ethylene antagonists are attributed to their structural molecular strain that permits a very tight binding to electron donor compounds such as low valency, in the receptor. They compete with ethylene for the binding sites and remain bound to the receptor for a long time, thus preventing ethylene from binding (Sisler et al., 1999). The activity of CPs depends on the concentration required for inactivation of the receptor, with the duration of binding possibly due to steric and inductive effects, regarding the position of a methyl group with respect to double bonds (Sisler et al., 1996a, b, 1999, 2001). Ethylene receptor inhibitors, such as $1-\mathrm{MCP}$, act by binding to a metal in the receptor. They compete with ethylene for the receptor, but do not induce ethylene responses (Sisler et al., 1990).

Ethylene mediated flower senescence is a significant problem in horticulture, most obvious in the floriculture industry. The regulation of flower senescence is of great interest to horticulturists in search of methods to improve the postharvest quality of ornamentals. The need for chemical protection from ethylene action has been recommended in many potted flowering plants in which low concentrations of ethylene causes rapid loss in display quality (Serek, 1993; Serek et al., $1994 b, c)$. Therefore, much research has been conducted in order to develop anti-ethylene agents that block the synthesis and action of ethylene, as mentioned before. It is proposed that the analogues inhibit ethylene action by competing for the binding sites on the ethylene receptor, similar to the mode of action suggested for 1-MCP (Feng et al., 2004). It is hypothesized that 
1-OCP and 1-DCP, CPs with 8 and 10-carbon chain length, respectively, could significantly improve the display quality of miniature roses, important commercial potted plants, in protecting them against ethylene. This study reported the difference in the display quality between the two cultivars 'Lavender' with short flower life and 'Vanilla' with long-lasting flower, after pretreatment with 1-OCP, 1-DCP and 1-MCP, and afterwards continuous exposure to ethylene. The influence of treatment conditions, such as concentration, exposure time and temperature, on the postharvest quality of miniature rose plants was then investigated.

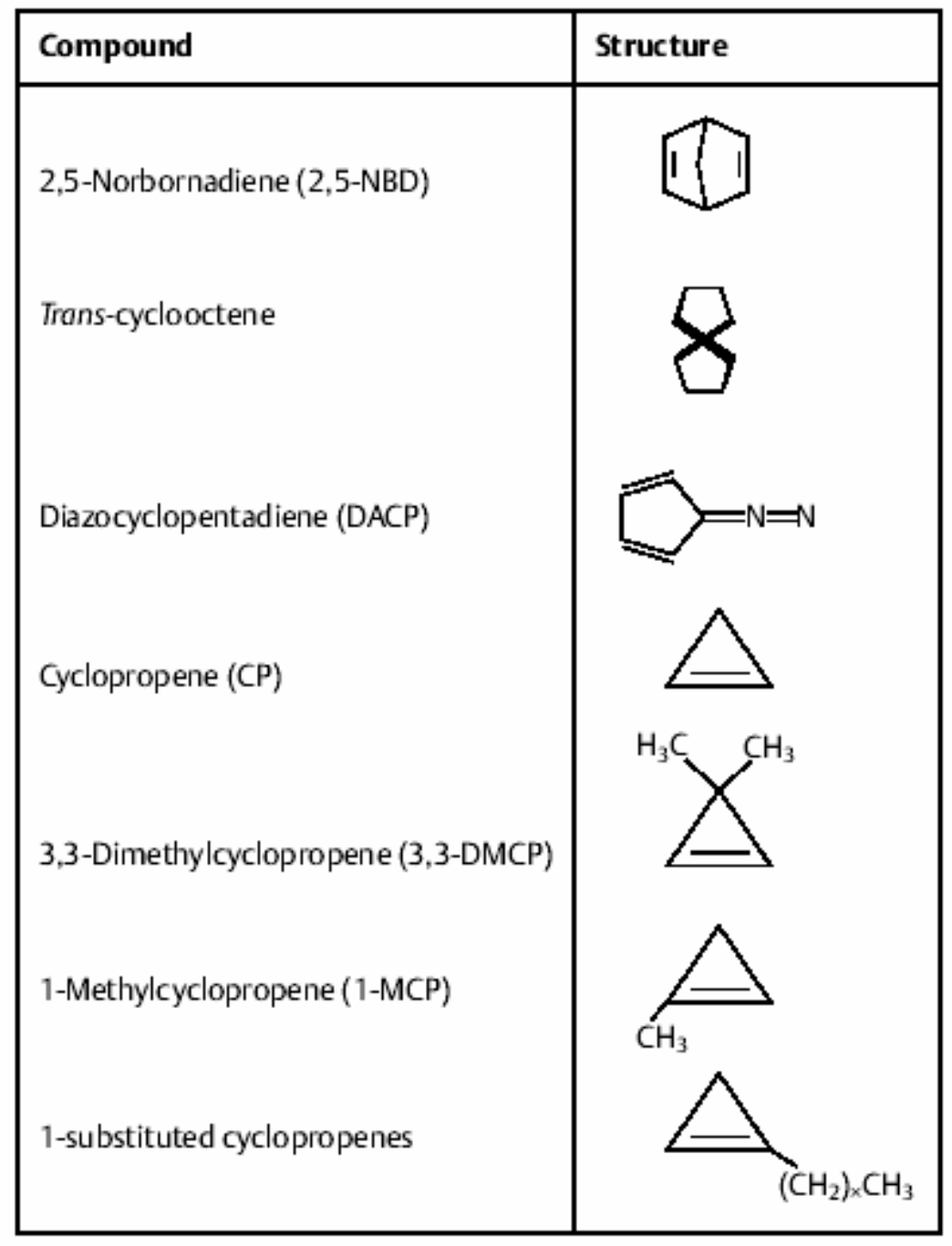

Fig. 3. Chemical structures of compounds interacting with the ethylene receptor (Sisler and Serek, 2003). 


\subsection{Materials and methods}

\subsubsection{Chemicals}

1-OCP and 1-DCP were synthesized at the Department of Molecular and Structural Biochemistry, North Carolina State University, Raleigh, USA, from 2-bromoalkenes and bromoform using $50 \% \mathrm{NaOH}$ to produce a carbine and form a 1,1,2-cyclopropane, which was then reacted with methyllithium at dry ice temperature, to form cyclopropenes (Al Dulayymi et al., 1996, 1997). These compounds were then sent on dry ice to the University of Hannover, Germany. The compounds were subsequently divided into smaller samples of $0.5 \mathrm{ml}$ and kept at $-80^{\circ} \mathrm{C}$ until needed for the experiments. Each sample was then diluted with ether to a volume of $50 \mathrm{ml}$ before being used for experiments. 1-MCP was obtained from AgroFresh Inc. (Rohm and Haas, AgroFresh Inc., Philadelphia, USA) in a commercially-available form.

\subsubsection{Plant material}

Rosa hybrida L. cultivar 'Lavender', which is sensitive to ethylene, was used to investigate the effects of extended chain length on the activity of inhibitors of ethylene receptors, 1-OCP and 1-DCP as compared with 1-MCP. In addition, miniature potted rose cultivar 'Vanilla', with excellent postharvest performance and low sensitivity to exogenous ethylene (Müller et al., 2001), was compared to 'Lavender' in the effects of exogenous ethylene after pretreatment with inhibitors of ethylene receptors (1-OCP and 1-DCP). 'Lavender', obtained from Kordana breeding line of Rosen Kordes, W. Kordes' Söhne Rosenschulen GmbH \& Co KG, Sparrishoop, Germany, was used to investigate the effect of 1-OCP concentration on display quality of miniature potted roses. The other miniature potted roses were produced in $10 \mathrm{~cm}$-diameter pots $(2$ cuttings per pot) in a greenhouse at the University of Hannover during January-December, under the following conditions: $19-20^{\circ} \mathrm{C} / 20^{\circ} \mathrm{C}$ (day/night temperature) and $60-85 \%$ relative humidity (RH), natural daylight was supplemented with $60 \mu \mathrm{mol} \mathrm{m} \mathrm{m}^{-2} \mathrm{~s}^{-1}$ from SON-T lamps (Osram, 400W, Philips, Eindhoven, The Netherlands) over a 16 h (7.00-23.00) photoperiod. Paclobutrazol was used as a growth retardant at a concentration of $0.5 \%$. Watering, fertilizer application and pest and disease control were carried out until plants were required for experiments. Miniature potted roses were used in the experiments when two to three flowers per pot had opened. 


\subsubsection{Effects of concentration of 1-OCP and 1-DCP on display quality}

'Lavender' plants were placed in 541 glass chambers. The plants were exposed to the desired concentrations of 1-OCP or 1-DCP $\left(200,500,1000\right.$ and $\left.1500 \mathrm{nl} \mathrm{l}^{-1}\right)$, respectively, and $200 \mathrm{nl} \mathrm{l}^{-1}$ of 1-MCP (Serek and Reid, 2000), sealed in glass chambers for $6 \mathrm{~h}$ at $20^{\circ} \mathrm{C}$. The calculated volumes of the 1-OCP and 1-DCP were pipetted on filter paper in the glass chambers to increase the surface area and facilitate evaporation. 1-MCP was released from a commercial powdered formulation (SmartFresh ${ }^{\mathrm{TM}}, 0.14 \%$ a.i.) via addition of a few drops of water $(\approx 0.5 \mathrm{ml})$. Control plants were sealed in identical containers containing air for $6 \mathrm{~h}$ at $20^{\circ} \mathrm{C}$. After the treatments, the chambers were vented for $30 \mathrm{~min}$ and the plants were transferred and placed randomly in a glass chamber, sealed and kept in an interior environment room, which was maintained at $20^{\circ} \mathrm{C}, 60$ $70 \% \mathrm{RH}$. The plants were exposed to $12 \mathrm{~h}$ light from cool white fluorescent tubular lamps providing $20 \mu \mathrm{mol} \mathrm{m} \mathrm{m}^{-2} \mathrm{~s}^{-1}$. The glass chambers were ventilated $\left(200 \mathrm{l} \mathrm{h}^{-1}\right)$ with air containing a range of ethylene concentration of $1.25(+/-0.25) \mu 1 l^{-1}$ provided by a simple diffusion system (Saltveit, 1978) throughout the experimental period. The concentration of ethylene was determined daily using a Perkin-Elmer portable digital gas chromatograph (GC Voyager FFKG312, Ontario, Canada) equipped with a photoionisation detector. The carrier gas was $\mathrm{N}_{2}$ at $40 \mathrm{ml} \mathrm{min}{ }^{-1}$, and the injection temperature was $60^{\circ} \mathrm{C}$ with a column temperature of $60^{\circ} \mathrm{C}$. The display quality was determined after every 3 days by recording the percentage of leaf drop $(80 \%$ leaf drop was considered unacceptable), and the number of days to onset of total bud drop (number of abscised or dead buds) and flower drop (individual flower longevity from the day of anthesis to petal drying or abscission).

\subsubsection{Effects of treatment time on 1-OCP and 1-DCP on display quality}

The optimum concentrations from section 2.2.3 were used. Potted 'Lavender' plants were selected and placed in 541 glass chambers. They were treated with $1000 \mathrm{nl} \mathrm{l}^{-1} 1$-OCP or 1-DCP in sealed glass chambers at $20^{\circ} \mathrm{C}$ but at different exposure times $(2,4,6$ and $12 \mathrm{~h})$. The 1-MCP

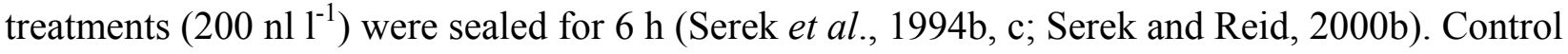
plants were sealed in identical containers containing air for $6 \mathrm{~h}$ at $20^{\circ} \mathrm{C}$. After treatments, the plants were exposed to the same procedure as previously described in section 2.2.3. 


\subsubsection{Effects of temperature on efficacy of 1-OCP and 1-DCP on display quality}

The temperature inside the growth chambers was set at 5, 10, 15 and $20^{\circ} \mathrm{C}$ and allowed to stabilize overnight. Potted 'Lavender' plants were selected and placed in 541 glass chambers. They were treated with $1000 \mathrm{nl} 1^{-1} 1-\mathrm{OCP}$ and 1-DCP in sealed glass chambers at $20^{\circ} \mathrm{C}$ but at different exposure times $(2,4,6$ and $12 \mathrm{~h})$. 1-MCP treatments $\left(200 \mathrm{nl} \mathrm{l}^{-1}\right)$ were sealed for $6 \mathrm{~h}$ (Serek et al., 1994b, c; Serek and Reid, 2000b). Control plants were sealed in identical containers containing air for $6 \mathrm{~h}$ at $20^{\circ} \mathrm{C}$. After treatments, the plants were handled as previously described in section 2.2.3.

2.2.6 Comparison of effectiveness of 1-MCP, 1-OCP and 1-DCP between 'Lavender' and 'Vanilla' cultivars

Potted 'Lavender' and 'Vanilla' plants were selected and placed in 541 glass chambers. They were treated with 1-OCP and 1-DCP at the best condition from the previous experiments in sealed glass chambers at $20^{\circ} \mathrm{C}$. 1-MCP treatments $\left(200 \mathrm{nl} \mathrm{l}^{-1}\right)$ were sealed for $6 \mathrm{~h}$ (Serek et al., 1994b, c; Serek and Reid, 2000b). Control plants were sealed in identical containers containing air for $6 \mathrm{~h}$ at $20^{\circ} \mathrm{C}$. After treatments, the plants were exposed to the same procedure as previously described in section 2.2.3. During the experimental period, 1-OCP and 1-DCP experiments were conducted separately and 1-MCP was used in both experiments as the standard.

\subsubsection{Experimental design and statistics}

The experiments were conducted in a completely randomized design using 3 pots per treatment and two replications. Each pot contained 2 miniature rose cuttings. The data obtained was subjected to analysis of variance (ANOVA) using the general linear models (Proc GLM)

procedure of the Statistical Analysis System (SAS, 2002) program package. Multiple comparisons among means was done using the Least Significant Difference (LSD) at $\mathrm{P}=0.05$. 


\subsection{Results}

\subsubsection{Effect of concentrations of 1-OCP and 1-DCP on display quality}

Display quality was characterized by leaf flower and bud drop. In 'Lavender' the most obvious symptom of ethylene sensitivity was accelerated leaf drop. Miniature rose plants treated with a concentration of $200 \mathrm{nl} \mathrm{l}^{-1}$ 1-OCP and 1-DCP reached $80 \%$ leaf drop after 9 days of continuous exposure to ethylene and were not different from untreated (control) plants (Fig. 4A, B). Plants pretreated with 500-1500 $\mathrm{nl} \mathrm{l}^{-1}$ of 1-OCP or 1-DCP exhibited reduced leaf drop and therefore improved display quality up to 15 days as compared to the control (Fig. 4A, B). Pretreatment with 1-MCP, 500-1500 $\mathrm{nl} \mathrm{l}^{-1}$ 1-OCP, and all used concentrations of 1-DCP significantly $(\mathrm{P}<0.001)$ increased the number of days to the total bud and flower drop compared to control plants. There were no differences between 1-MCP and long chains CPs (Fig. 4C, D). The best display quality was achieved by pretreating miniature roses with 1000, $1500 \mathrm{nl} \mathrm{l}^{-1}$ for both 1-OCP and 1-DCP (Fig. 4A, B, C, D). Increasing the concentration of 1-OCP and 1-DCP from 1000 to $1500 \mathrm{nl} \mathrm{l}^{-1}$ did not show further improvement in the display quality of the plants. Also, no toxicity was observed with a high concentration of $1500 \mathrm{nl} \mathrm{l}^{-1}$. Additionally, ether used to dissolve 1-OCP and 1-DCP had no effect on the display quality of 'Lavender' (data not shown). In terms of effectiveness of different concentrations, 1-MCP was more effective than 1-OCP and 1-DCP. 

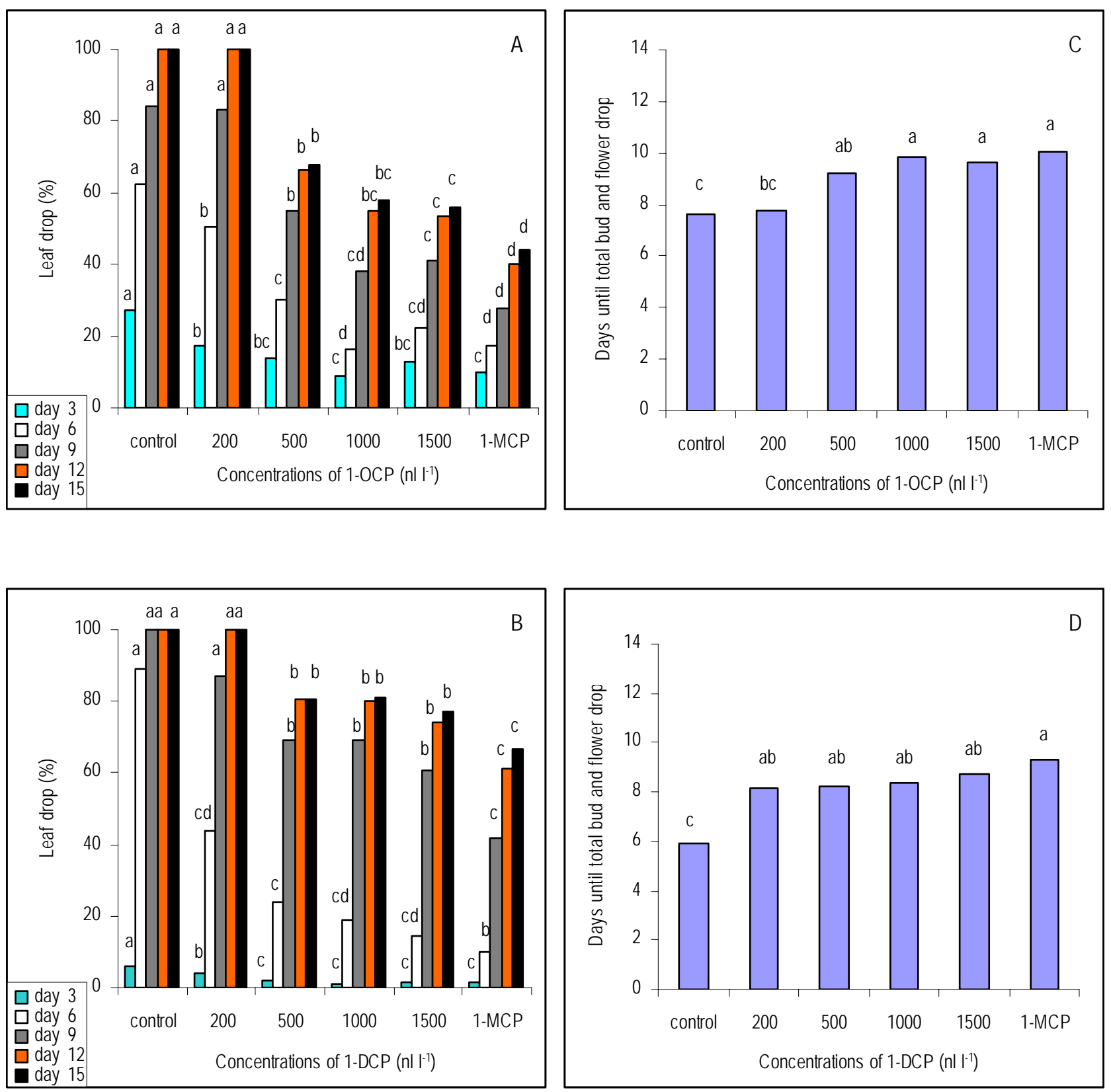

Fig. 4. Mean of percent leaf drop (A, B) and total bud and flower drop (C, D) of miniature potted rose cultivar 'Lavender' pretreated with 1-OCP and 1-DCP at concentrations of 0, 200, 500, $1000,1500 \mathrm{nl} \mathrm{l}^{-1}$ and untreated controls, respectively. These were compared to treatment with 1-MCP $\left(200 \mathrm{nl} \mathrm{l}^{-1}\right)$ for $6 \mathrm{~h}$ at $20^{\circ} \mathrm{C}$. After the treatments, the plants were exposed to $1.25(+/-0.25)$ $\mu \mathrm{l}^{-1}$ continuous ethylene throughout the experiments. Bars marked with the same letter (for figures A, B, C, D bars representing the same day) are not statistically different at $P<0.05$. Means were separated by LSD. 
2.3.2 Effect of exposure time of 1-OCP and 1-DCP on display quality

Exposing miniature potted roses to $1000 \mathrm{nl}^{-1}$ 1-OCP or 1-DCP for 4 to $12 \mathrm{~h}$ significantly $(\mathrm{P}<0.001)$ delayed leaf drop (Fig. 5A, B) and increased the number of days to the onset of total bud and flower drop (Fig. 5C, D). However, an exposure time of $2 \mathrm{~h}$ had no effect on leaf drop or total bud and flower drop. Plants pretreated for a short time $(2 \mathrm{~h})$ showed a fast response to ethylene by reaching $80 \%$ leaf drop after day 9 (Fig. 5A, B) and took about 7 days to reach the total bud and flower drop for both 1-OCP and 1-DCP (Fig. 5C, D). The untreated (control) plants reached $80 \%$ leaf drop within 6 days as well as the total bud and flower drop, respectively (Fig. $5 \mathrm{~A}, \mathrm{~B}, \mathrm{C}, \mathrm{D})$. Within the time range (4-12 h), 1-OCP treatments were less effective than 1MCP, with respect to leaf drop. It also took 1-OCP treated plants 8 days to attain the total bud and flower drop while 1-MCP-treated plants took 12 days. The 1-DCP treatments were not different from 1-MCP with respect to percent leaf drop. Exposing plants to $1000 \mathrm{nl} \mathrm{l}^{-1} 1$-DCP for 2 to $12 \mathrm{~h}$ significantly increased the number of days to total bud and flower drop (Fig. 5D). Additionally, after $12 \mathrm{~h}$ exposure to 1-DCP, it took 10 days to attain total bud and flower drop. However, 1-MCP was the most effective in preventing bud and flower drop. 

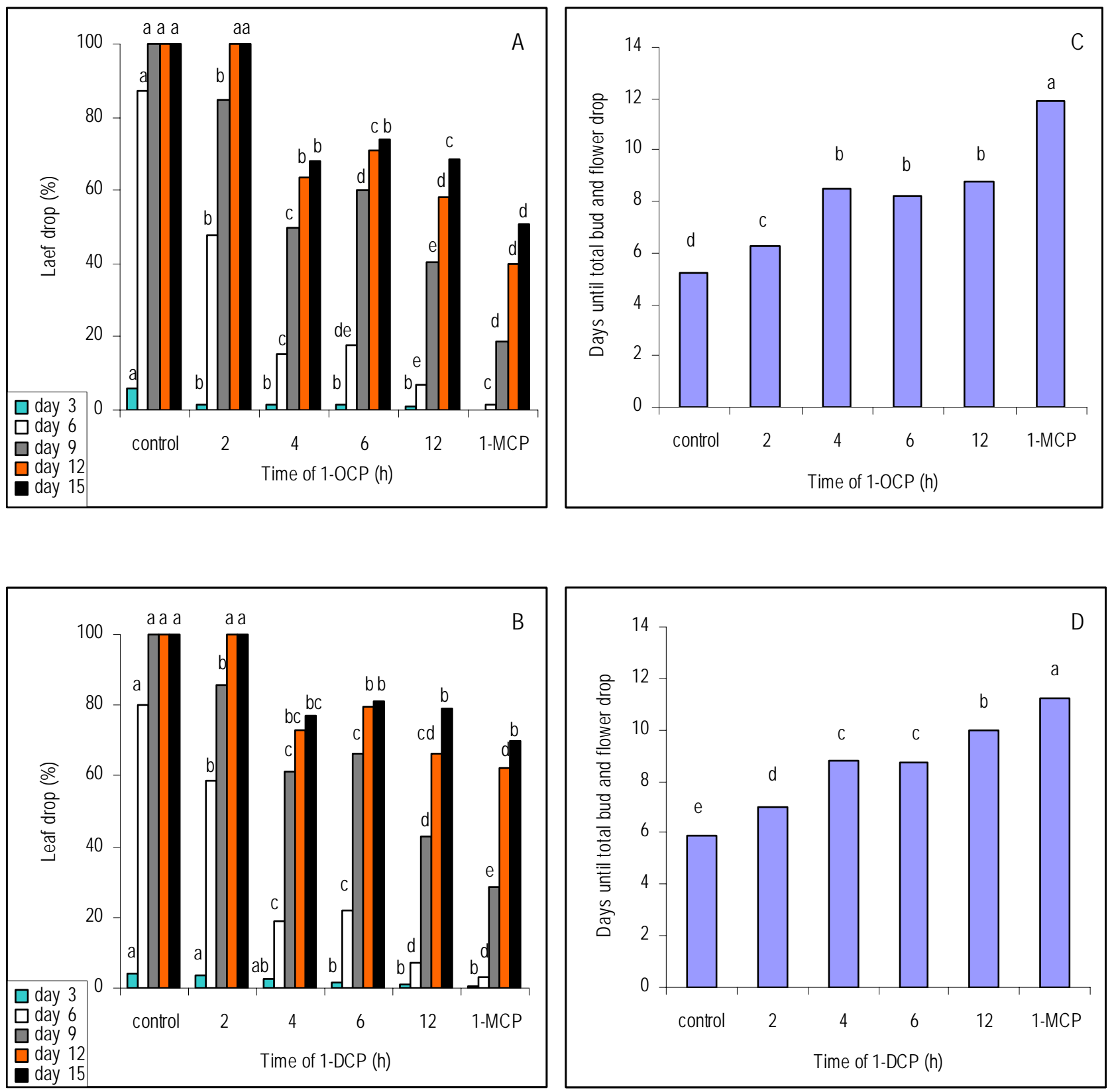

Fig. 5. Mean of percent leaf drop (A, B) and total bud and flower drop (C, D) of miniature potted

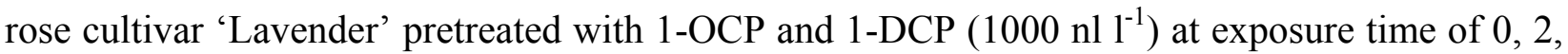
4, 6, $12 \mathrm{~h}$ and untreated controls, respectively. These were compared to treatment with 1-MCP $\left(200 \mathrm{nl} \mathrm{l}^{-1}\right)$ for $6 \mathrm{~h}$ at $20^{\circ} \mathrm{C}$. After the treatments, the plants were exposed to $1.25(+/-0.25) \mu 11^{-1}$ continuous ethylene throughout the experiments. Bars marked with the same letter (for figures A, $\mathrm{B}, \mathrm{C}, \mathrm{D}$ bars representing the same day) are not statistically different at $P<0.05$. Means were separated by LSD. 


\subsubsection{Effect of temperature of 1-OCP and 1-DCP on display quality}

Treatment of miniature roses with 1-OCP and 1-DCP $\left(1000 \mathrm{nl} \mathrm{l}^{-1}\right)$ for $4 \mathrm{~h}$ at all temperature regimes $\left(5,10,15\right.$ and $\left.20^{\circ} \mathrm{C}\right)$ significantly improved their display quality as showed by reduced leaf drop, total bud and flower drop compared with the control (Fig. 6A, B, C, D). All temperature levels significantly $(\mathrm{P}<0.001)$ decreased leaf drop and increased number of days to the onset of total bud and flower drop as compared to the untreated (control) plants (Fig. 6A, B, C, D). No significant difference was observed in display life among all the temperature levels (5 to $20^{\circ} \mathrm{C}$ ) in flowers treated with 1-OCP and 1-DCP. Plants treated with 1-MCP gave better results than that of 1-OCP and 1-DCP. 

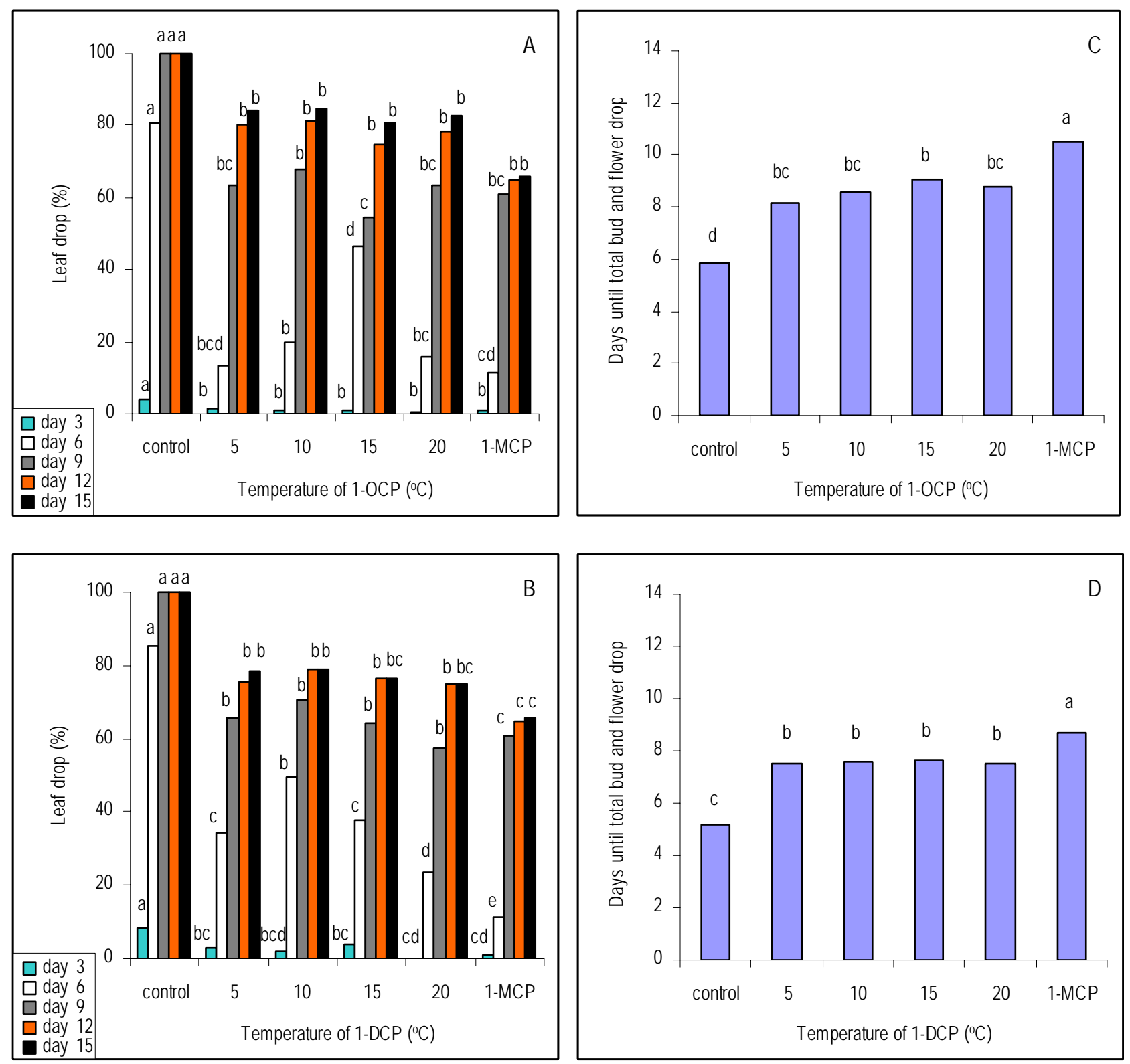

Fig. 6. Mean of percent leaf drop (A, B) and total bud and flower drop (C, D) of miniature potted rose cultivar 'Lavender' pretreated with 1-OCP and 1-DCP at temperatures of $5^{\circ} \mathrm{C}, 10^{\circ} \mathrm{C}, 15^{\circ} \mathrm{C}$, $20^{\circ} \mathrm{C}$, and untreated controls, respectively. These were compared to treatment with 1-MCP (200 $\left.\mathrm{nl}^{-1}\right)$ for $6 \mathrm{~h}$ at $20^{\circ} \mathrm{C}$ and untreated controls. After the treatments, the plants were exposed to $1.25(+/-0.25)$ $\mu 11^{-1}$ continuous ethylene throughout the experiments. Bars marked with the same letter (for figures A, B, C, D bars representing the same day) are not statistically different at $P<0.05$. Means were separated by LSD. 


\subsubsection{Efficacy of 1-MCP, 1-OCP and 1-DCP in cultivars 'Lavender' and 'Vanilla'}

Efficacy of ethylene action inhibitors 1-MCP, 1-OCP and 1-DCP between 'Vanilla' (long lasting flower) and 'Lavender' (short flower life) was investigated. In both cultivars, ethylene accelerated flower senescence. However, there were distinct differences between 'Vanilla' and 'Lavender' when they were continuously exposed to $1.25 \mu 1^{-1}$ ethylene (Fig. 7A, B, C, D). Untreated 'Vanilla' plants attained 40\% leaf drop after 6 days of continuous exposure to ethylene, while the display quality of 'Lavender' was clearly reduced to $80 \%$ leaf drop in the same period (Fig. 7A, B). Additionally, it took 6 days to attain total bud and flower drop in 'Lavender' (Fig. 7D). Pretreatment with ethylene receptor inhibitors 1-OCP, 1-DCP and 1-MCP, improved the display quality in both cultivars. In 'Vanilla', the trend of percent leaf drop in flowers treated with 1-OCP and 1-DCP was similar to that of 'Lavender'. Also, 1-OCP-treated plants reached 100\% leaf drop after day 15 and were less effective than 1-DCP (Fig. 7A, B). There was no significant difference between the display quality of 1-DCP and 1-MCP. However, it took 9 and 10 days for 'Vanilla' plants to attain total bud and flower drop for 1-OCP and untreated (control) plants, respectively. It took 11 and 12 days for 'Vanilla' plants treated with 1-DCP and 1-MCP to attain the total bud and flower drop (Fig. 7C), respectively. In 'Lavender', 1-OCP compared favorably with 1-DCP with respect to percent leaf drop, while pretreatment with 1-MCP was the most effective in improving the display quality of miniature roses. The untreated 'Lavender' plants took 6 days to attain total bud and flower drop while it took 8,9 and 10 days for 1-OCP, 1-DCP and 1-MCP, respectively (Fig. 7D). 

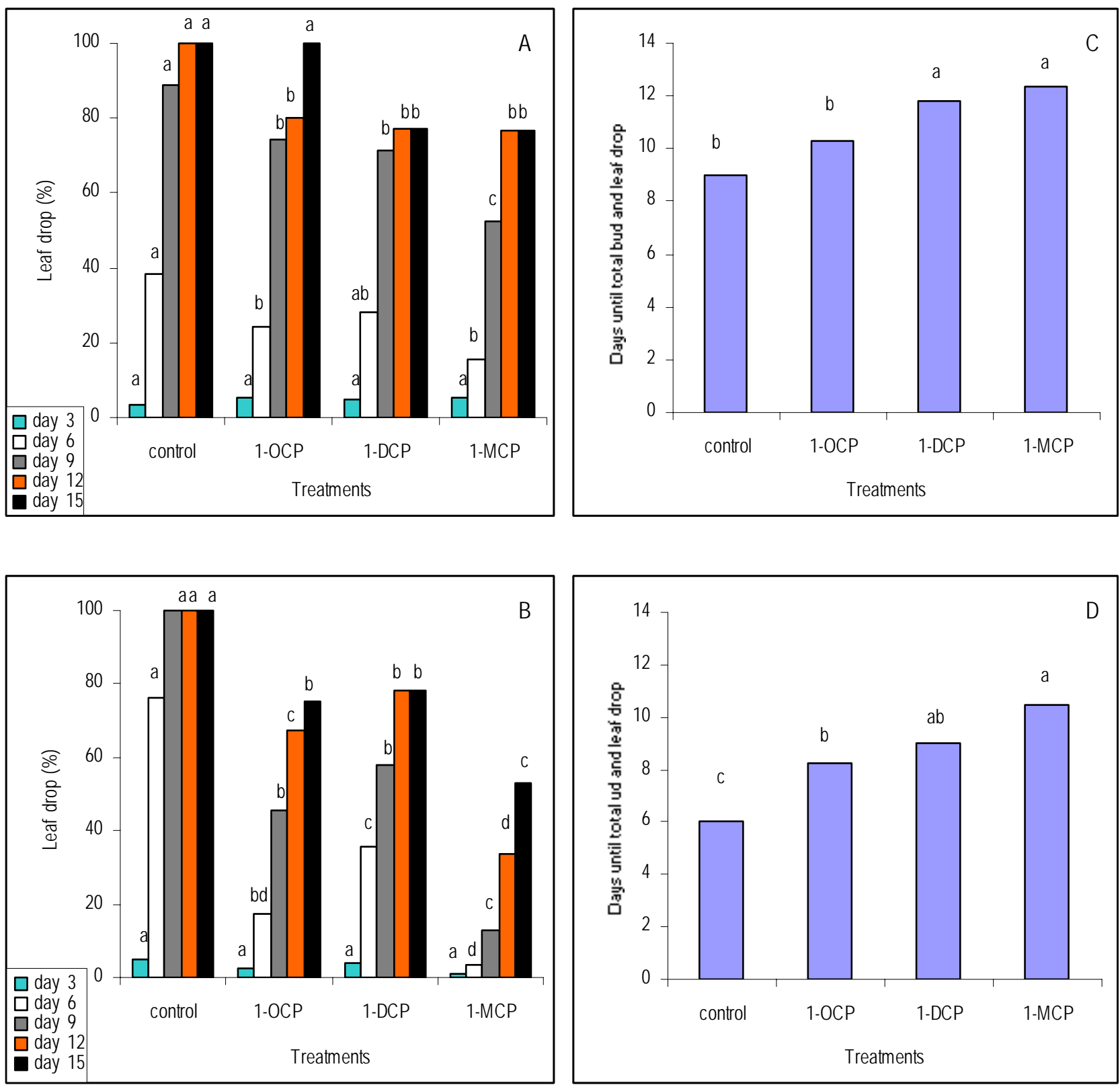

Fig. 7. Mean of percent leaf drop and days of total bud and flower drop of miniature potted rose cultivars 'Vanilla' (A, C) and 'Lavender' (B, D) pretreated with 1-OCP, 1-DCP (1000 nl 1'-1), respectively, 1-MCP $\left(200 \mathrm{nl} \mathrm{l}^{-1}\right)$ for $6 \mathrm{~h}$ at $20^{\circ} \mathrm{C}$ and the control. After the treatments, the plants were exposed to $1.25(+/-0.25) \mu 11^{-1}$ continuous ethylene throughout the experiments. Bars marked with the same letter (for figures A, B, C, D bars representing the same day) are not statistically different at $P<0.05$. Means were separated by LSD. 


\subsection{Discussion}

The duration of quality improvement was dependent on the concentrations. 1-OCP and 1-DCP, two structural analogues of 1-MCP with substitution in 1-position, were considered to be putative inhibitors of ethylene action. Their potency was evaluated by their ability to counteract ethyleneinduced responses (leaf, bud and flower abscission). These two analogues exerted their effect in a similar manner to 1-MCP by blocking the binding site of ethylene in the receptor (Sisler and Serek, 1997; Feng et al., 2004). In this study, all of these compounds were effective in blocking the ethylene receptor and improving the display quality of miniature potted roses when compared to untreated control plants. Based on the substitution with 8 and 10 carbon chains at 1-position of the cyclopropene, both compounds were effective in improving display quality from exogenous ethylene, but in terms of concentration, they were less effective than 1-MCP. Moreover, the concentration required for 1-OCP and 1-DCP was about 5 times higher than that of 1-MCP. This is in contrast to the previous studies of Sisler et al., (2003) and Kebenei et al., (2003a, b), where 1-OCP was effective at lower concentrations than 1-MCP in delay ripening in bananas and improving display life and quality of kalanchöe and sweet pea, respectively. Sisler and Serek (1997) suggested that for the maximum response in growing vegetative tissue, a higher concentration of an inhibitor is needed. Besides, flowers on intact plants, as used by Müller et al. (2000a, 2002b), may react differently to exogenous ethylene treatments than detached kalanchöe flowers (Kebenei et al., 2003a, b). Probably the presence of many leaves in whole plants could have absorbed higher amounts ethylene than excised flowers (Müller and Stummann, 2003). In miniature roses, pretreatment with 1-MCP obviously reduced the rise in autocatalytic ethylene production in flowers (Müller and Stummann, 2003), whereas in vegetative tissue, such as tobacco leaves, ethylene production was autoinhibitited by a negative feedback control (Philosoph-Hadas et al., 1985). Furthermore, another factor that should be taken into consideration is the time it takes ethylene inhibitors to bind to the receptors and regain activity. This suggests that the same receptor is becoming active again or that new receptors are being produced (Sisler et al., 1990). The fact that some time after the treatment with 1-OCP or 1-DCP the tissue became sensitive to ethylene again, assumes that free binding sites on the ethylene receptor are present in the tissue at the point of recovery from the inhibition. However, the analogue 1-OCP was found to be a more potent inhibitor than 1-DCP, when pretreating ethylene- 
sensitive cultivars like 'Lavender'. In contrast, pre-treating 'Vanilla', which has long-lasting flowers, with 1-DCP was more effective than 1-OCP.

Both 1-OCP and 1-DCP are gases at room temperature (Closs, 1966). They need to be dispersed as liquids that need time to evaporate and diffuse to the binding sites in order to bind to them. Display quality was dependent on exposure time, such that longer exposure times improved the display quality better than shorter exposure times. Similar observations were reported on other cyclopropenes (Dupille and Sisler, 1995; Sisler et al., 1996a, 1999). Molecular weight has no influence on evaporation, in that higher molecular weight compounds bind as rapidly as the lower ones, suggesting evaporation time into the gaseous phase is not a big factor (Sisler et al., 2003). Continuous exposure for longer periods results in saturation of the receptor and further treatment does not give any additional effect. For example, exposure of both chemicals for $12 \mathrm{~h}$ gave the same effect as $4 \mathrm{~h}$ exposure. Therefore, a 4-h exposure is sufficient to give better improvement against ethylene. Shorter exposure time $(2 \mathrm{~h})$ with the same concentration was not satisfactory. This may require a higher concentration of the respective cyclopropenes (Sisler et al., 1999, 2003) for the same beneficial effect to be realized.

Temperature has a direct influence on the exposure time and concentration of the treatment. At lower temperatures, a higher concentration and longer time of treatment is required (Sisler et al., 1996a, 1999; Sisler and Serek, 1997). In this study, the temperature range $5-20^{\circ} \mathrm{C}$ had no effect on the activity of both chemicals, implying that pre-treatment of potted roses with these compounds can be done within temperatures that range from $5-20^{\circ} \mathrm{C}$ without any affects on their effectiveness. Contrary to kalanchöe (Kebenei et al., 2003a, b), the activity of 1-OCP was influenced by temperature, and it was more potent at 15 and $20^{\circ} \mathrm{C}$ than at lower $\left(5\right.$ and $\left.10^{\circ} \mathrm{C}\right)$ temperatures. In carnations and Penstemon, a higher concentration of 1-MCP was required at low temperatures in order to give protection against ethylene (Serek et al., 1995a; Sisler et al., 1996a).

Differences in ethylene production and/or sensitivity are a vital factor regulating flower life. For this reason ethylene partly resulted in differential display quality (Müller et al., 1998, 2001). Ethylene caused leaf, bud and flower drop, but there were differences among cultivars. 'Lavender', which is sensitive to ethylene, significantly exhibited $80 \%$ leaf drop as well as a total bud and flower drop within 6 days as compared to 'Vanilla', which took 9 days. It could be 
assumed that 'Lavender' was similar to cultivar 'Bronze', in which exposure to ethylene induces an autocatalytic rise in ethylene with constant increase in endogenous ethylene levels (Müller et al., 2001). Although 'Vanilla' had excellent longevity and seemed to be almost completely insensitive to exogenous ethylene (Müller et al., 2001), continuous exposure to ethylene caused flower, bud and leaf drop. In the current study, 'Vanilla' had about $80 \%$ leaf and total bud drop within 9 days, which was retarded by ethylene inhibitors. In the miniature rose 'Victory Parade', 1MCP protected against exogenous ethylene, increased display life and reduced abscission of buds, flowers and leaves (Serek et al., 1994c). Therefore, for ethylene-sensitive cultivars like 'Lavender', ethylene inhibitor treatment will be an important practical tool in increasing the postharvest life after ethylene exposure. It would also be more effective in improving the display quality of the ethylene-sensitive cultivar 'Lavender' than ethylene-insensitive 'Vanilla'.

In conclusion, these results demonstrated the potency of 1-MCP and long chain CPs, 1-OCP and 1-DCP, as ethylene antagonists in improving display quality of miniature potted roses. Additionally, 1-MCP was the most potent ethylene inhibitor in terms of concentration and duration of exposure in improving display quality as compared to 1-OCP and 1-DCP. Therefore, 1-MCP is more suitable for use in potted plants while 1-OCP is more effective in prolonging the display life of individual flowers like kalanchöe. 


\section{Expression analysis of genes for ethylene biosynthesis enzyme, ethylene perception and signal transduction pathway after pretreatment with ethylene receptor inhibitors of miniature potted roses (Rosa hybrida L.)}

\section{Abstract}

In order to investigate transcript abundance of genes for ethylene biosynthesis enzyme (RhACS1-5), ethylene perception (RhETR1-4) and signal transduction pathway (RhCTR1-2, RhEIN3, RhEIL), expression of these transcripts in petal and leaf tissues was examined in two rose cultivars 'Vanilla' and 'Lavender' during continuous exposure to exogenous ethylene and ethylene-free air after pretreatment with inhibitors of ethylene receptors 1-MCP, 1-OCP and 1-DCP. Additionally, one of the ethylene-responsive element-binding factor $(E R F S)$ genes was isolated from miniature potted roses (RhERF1) which was 92 bp long, encoding a predicted polypeptide for an Ap2 DNA binding domain and sharing high homology with other reported ERF domains. Northern blot hybridization analysis was used to compare with results of RT-PCR. However, it was difficult to distinguish the hybridization signal of ethylene receptors between RhETR1 and RhETR2, which were highly homologue. RT-PCR analysis revealed that ethylene induced the expression of all genes investigated in control 'Vanilla' and 'Lavender' petals except RhACS1-2 and RhETR4, respectively, while pretreatments of 1-MCP and 1-OCP led to the supression of all investigated mRNAs in the presence or absence of ethylene. However, strong expression of RhETR3, RhEIN3 and RhEIL transcripts was detectable in 'Lavender' petals pretreated with 1-DCP. In the absence of ethylene, strong expression of all genes was detectable in control 'Vanilla' leaves but there was no expression of RhACS1, while the accumulation of all genes was eliminated after pretreatments of 'Vanilla' leaves with ethylene receptor inhibitors. The level of RhEIN3 mRNA was upregulated by pretreatment of 1-MCP, 1-OCP and 1-DCP in 'Vanilla' leaves in the presence of ethylene, while the accumulation of RhEIN3 transcript was suppressed in 'Lavender' leaves after pretreatment of 1-MCP and 1-OCP. RhEIN3 transcript is probably rate-limiting for ethylene perception and signal transduction pathway, which is regulated in leaves during flower senescence at the transcriptional level. In the absence of ethylene, 1-MCP suppressed the expression of RhACS1, RhETR3 and RhERF1 transcripts. Similarly, 1-OCP inhibited the expression of $R h A C S 1, R h C T R 2$ and RhERF1 transcripts. 1-DCP inhibited the expression of 
RhEIN3, RhEIL genes. However, in the presence of ethylene, pretreatment of 'Lavender' leaves with 1-MCP suppressed the expression of RhACS1, RhETR4, RhCTR1-2, RhEIL and RhERF1 transcripts. Similarly, 1-OCP treatment inhibited the expression of RhACS1, RhETR2, RhETR4, RhCTR1-2, RhEIN3 and RhERF1 transcripts. Pretreating 'Lavender' leaves with 1-DCP suppressed the expression of RhACS1 and RhETR4 transcripts. These results indicated that the expression of genes for the ethylene biosynthesis enzyme, ethylene perception and signal transduction pathway was regulated by both positive and negative feedback regulation mechanisms in 'Vanilla' and Lavender' pretreated with ethylene receptor inhibitors in the presence or absence of ethylene. This might depend on plant species and tissues under investigation. Physiologically and molecularly, these results suggest that pretreatments with inhibitors of ethylene receptors improved the display life of miniature roses by delaying bud, flower and leaf drop. However, 1-MCP is more effective than 1-OCP and 1-DCP by suppressing the expression of ethylene signal transduction genes or the feedback regulations of genes for ethylene biosynthesis and ethylene perception.

Key words: ACC synthase, display quality, ethylene, ethylene perception and signal transduction, gene expression, inhibitors of ethylene receptor, Rosa hybrida, senescence 


\subsection{Introduction}

3.1.1 Expression regulation of genes for ethylene biosynthesis enzyme

Ethylene biosynthesis and perception are modulated during development of plant tissues (Abeles et al., 1992) and responsible for inducing many biochemical processes which lead to programmed cell death, including the expression of senescence-related genes (Woodsons et al., 1992; Kim et al., 1997). Ethylene biosynthesis in higher plants has been well characterized and 1-aminocyclopropane-1-carboxylic acid (ACC) synthase (ACS), an enzyme of ethylene biosynthesis, has been recognized as the rate-limiting step (Yang and Hoffman, 1984; Kende, 1993).

In all plants, $A C C$ synthase is encoded by a medium-size gene family, which is differentially regulated in a tissue-specific manner by a variety of developmental cues, mechanical and environmental stresses and by ethylene itself (Kende, 1993; Zarembinski and Theologis, 1994). In tomato fruits, ACC synthase is a soluble enzyme (Boller et al., 1979). This indicates that ACC synthase is a cytoplasmic enzyme (Kende, 1993).

Sequence analysis of the Arabidopsis genome reveals that $A C S$ genes are putatively encoded by twelve genes (Yamagami et al., 2003). All genes, except ACS3, are transcriptionally active and differentially expressed in Arabidopsis during growth and development. Additionally, IAA induces all genes, except $A C S 7$ and $A C S 9$; cyclohexamide (CHI) enhances the expression of all functional $A C S$ genes. These $A C S$ genes, which have a biochemically-diverse function in unique cellular environments for the biosynthesis of ethylene, permit the signaling molecule to exert their unique effects in a tissue- or cell-specific manner (Yamagami et al., 2003).

In Rosa hybrida, ACS genes consist of a multigene family (Mibus and Serek, 2004; Wang et al., 2004). Analysis of the expression of $A C S$ genes shows that RhACS1 is specifically expressed in rose petals, the ovary and sepals. This expression increases dramatically as the flower matures to senescence and also correlates positively with ethylene levels (Wang et al., 2004). 


\subsubsection{Ethylene receptor gene expression}

Ethylene actions are involved with binding to a receptor, followed by activation of one or more signal transduction pathways that lead to the cellular response. Ultimately, ethylene exerts its effects primarily by changing the pattern of gene expression (Taiz and Zeiger, 2002). Furthermore, the development of molecular genetic approaches in the model plant Arabidopsis has established the linear signal transduction pathway for the response to ethylene (Hongwei and Ecker, 2004). Genetic screens based on the triple-response phenotype, inhibition of hypocotyls and root cell elongation, radial swelling of hypocotyls and exaggerated curvature of the apical hook, have been extensively conducted on etiolated Arabidopsis seedlings to isolate mutants that are affected in their response to ethylene (Bleecker et al., 1988; Guzman and Ecker, 1990). Two classes of mutants have been identified:

1. Mutants that fail to respond to exogenous ethylene (ethylene-resistant or ethyleneinsensitive mutants).

2. Mutants that display the response even in the absence of ethylene (constitutive mutants).

Ethylene-insensitive mutants are identified as tall seedlings extending above the lawn of short, triple-responding seedlings when grown in the presence of ethylene. Conversely, constitutive ethylene response mutants are identified as seedlings displaying the triple response in the absence of exogenous ethylene (Guzman and Ecker, 1990).

The ETR1 gene is the first member of the receptor gene family to be cloned from Arabidopsis (Chang et al., 1993). Expression of ETR1 protein, which is obtained from plants and transgenic yeast, is not only membrane-associated but also exists as a covalently-linked dimer. Two cycteines at the N-terminus (Cys4 and Cys6) are the sites of disulphide cross-linkage between ETR1 monomers. This N-terminal sensor domain also consists of all the elements essential and sufficient to bind ethylene with high affinity when expressed in yeast (Schaller et al., 1995; Schaller and Bleecker, 1995). The C-terminal half of the ETRI protein contains all of the conserved sequence elements found in the histidine kinase domains of bacterial two-component regulators. These are typically composed of a sensor protein with an input domain receiving signals and a catalytic transmitter domain which autophosphorylates on an internal histidine 
residue. The second component is a response regulator protein consisting of a receiver domain, which receives phosphate from the transmitter and an output domain that mediates responses depending on the phosphorylation state of the receiver. The ETR1 protein has a receiver domain fused to the C-terminus of the histidine kinase domain (Parkinson, 1993; Maeda et al., 1994). In addition, the two-component system is a signaling mechanism primarily used by bacteria to respond to a broad array of environmental signals (Stock et al., 2000). However, the region that is located between the hydrophobic sensor domain and the histidine kinase transmitter is of unknown function. Besides, there are two blocks of sequence within this region, which shows homology to sequences that flank the chromophore-binding domain in the light-sensing phytochromes from higher plants and cyanobacteria (Kehoe and Grossman, 1996). It has been reported that the region between these blocks of homology in ETRI contains a GAF domain associated with cyclic GMP binding and light regulation in a number of proteins, but the function of the GAF domain in ETRl is unknown (Aravind and Ponting, 1997). Studies of ETRl indicate that localization of transmembrane domains on the receptor also serve to the endoplasmic reticulum (ER), an unusual location for a hormone receptor, but compatible with the ready diffusion of ethylene in aqueous and lipid environments (Chen et al., 2002).

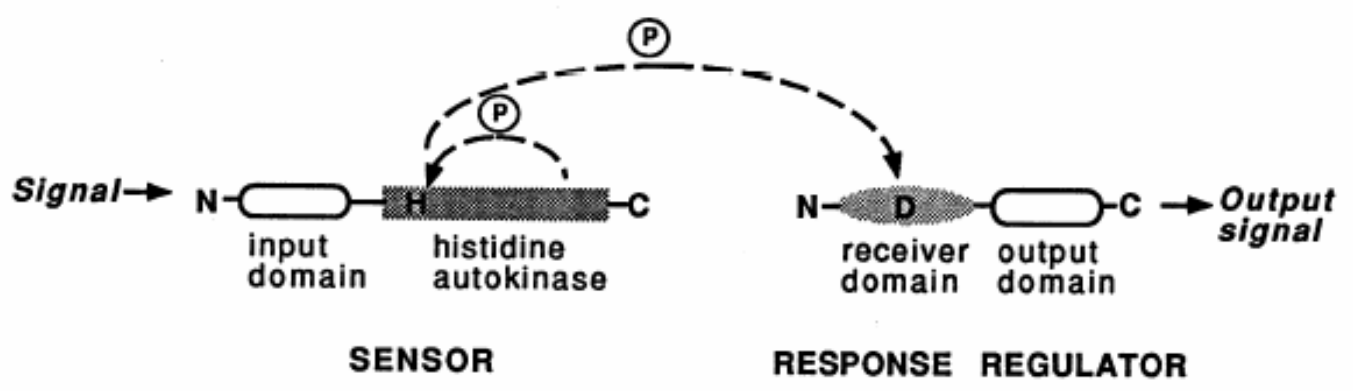

Fig. 8. Basic scheme of the two-component system (Chang and Meyerowitz, 1995).

Ethylene-binding domain of ETR1 lies within the first 165 amino acids of the protein containing the sequences that are necessary and sufficient to bind ethylene. Further characterization of ethylene binding to ETRI occurs in a hydrophobic pocket, located at the $\mathrm{N}$ terminus of the receptor, and requires a transition metal, copper, as a cofactor (Schaller and Bleecker, 1995; Rodriguez et al., 1999). The identification of a copper ion is associated with the ethylene-binding domain of ETR 1 with theoretical considerations dating back to Stanley Burg's original hypothesis 
that ethylene binding would be mediated by a transition metal cofactor (Burg and Burg, 1967). Interestingly, silver $(\operatorname{Ag}(\mathrm{I}))$, which has long been known to inhibit ethylene-responses, may also occupy the binding site and interact with ethylene but fail to induce the changes that would normally occur following copper-mediated ethylene binding (Rodriguez et al., 1999). Cloning of Arabidopsis RAN1 resembles copper transporting P-type ATPase and rescues a copper transport defect in yeast (Hirayama et al., 1998). Within the plant, RAN1 potentially serves to produce functional ethylene receptor via intracellular delivery of copper. The loss-of-function of ran1 mutants displays a rosette-lethal phenotype, which is thought to be caused either by general effects due to the reduced copper availability for other copper-utilizing enzymes, or by disruption of ethylene receptor function (Hirayama et al., 1998; Woeste and Kieber, 2000).

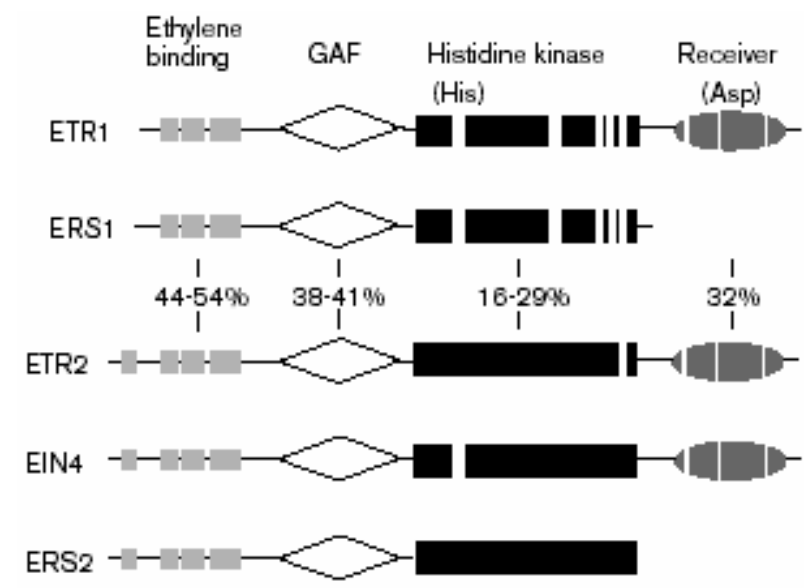

Fig. 9. The Arabidopsis ethylene receptor family (Chang and Shockey, 1999).

Five ETR1-like genes have been identified in Arabidopsis so far. These five genes can be divided into two main subfamilies based on sequence similarity and structure features of the protein. Members of type-I subfamily ETRI and ERS1 (Hua et al., 1995, 1998), are most closely related in sequence and have three hydrophobic subdomains at the N-terminus. The type-II subfamily receptors, ETR2 (Sakai et al., 1998), ERS2 and EIN4 (Hua et al., 1998), share close sequence similarity and all have four hydrophobic subdomains at the N-terminus.

Like ETR1, ERS1 binds ethylene when expressed in yeast (Schaller et al., 1995), and its transmitter domain containing all the conserved subdomains $(\mathrm{H}, \mathrm{N}, \mathrm{G} 1, \mathrm{~F}$ and $\mathrm{G} 2)$ is thought to be required for histidine kinase activity. ERS1 differs from ETRl in that it lacks the fused 
receiver domain. Conversely, members of the ETR2-like subfamily appear to be degenerate in the histidine kinase domain. Each member of this subfamily lacks one or more elements that are thought to be essential for histidine kinase activity; therefore it is unlikely that they are functional kinases (Schaller et al., 1995).

In miniature potted roses, fragments of four ethylene receptor genes have been isolated and cloned, termed RhETR1-4 (Müller et al., 2000a, b). They are an ethylene receptor gene family with 2 subfamilies, as in Arabidopsis. RhETR1 and RhETR4 exhibit high amino acid similarity to AtERS1, while RhETR2 is more similar to AtETR1. Three of the receptors belong to subfamily 1 , whereas RhETR3 belongs to subfamily 2 . The northern blot analysis is conducted in miniature roses for RhETR1-3 during flower senescence after treatment with ethylene and ABA to investigate the differences in flower longevity and ethylene sensitivity in miniature roses. The relative transcript abundance in the flowers varies significantly during development and after hormone treatment, but the expression of all three genes is detectable at all flower stages. Exposure to low ethylene concentrations results in an upregulation of RhETRI and RhETR3 in flowers of 'Bronze', a short-life flower, and are distinctly higher than long-lasting 'Vanilla'. It is assumed that differences of cultivars in flower sensitivity to ethylene may partly be due to differences in receptor expression levels during flower development (Müller et al., 2000a, b).

While RhETR2 expression varies slightly during flower development and in response to ethylene and ABA treatment, the expression of RhETRl and RhETR3 exhibits differently during flower development and appears to be rate-limiting for ethylene perception and the determinants of flower longevity. It is found that the expression of RhETRl in 'Bronze' is distinctly higher than long-lasting 'Vanilla'. Although the expression of RhETRl precedes the ethylene production by the flowers, abundance of the RhETR3 transcript increases during flower senescence in 'Bronze', indicating that the ethylene response system in rose flowers consists of multiple receptor genes with an overlapping pattern of expression. In 'Vanilla', a cultivar with excellent flower longevity despite moderate ethylene production (Müller et al., 2000b), expression of RhETRI and RhETR3 is reduced. These results indicate that differences in flower life among rose cultivars - in an ethylene free environment and in response to exogenous ethylene - may be due to differences in receptor expression levels. These results do not conform to the standard model of ethylene signal transduction (Bleecker, 1999), which predicts that a reduction in the level of receptors would 
result in increased ethylene sensitivity, while an increase in receptor numbers would result in decreased sensitivity.

\subsubsection{Ethylene-insensitive mutant of ethylene receptor}

Mutations in the ethylene receptors cause ethylene insensitivity or constitutive ethylene responses, dependent on the nature of the mutation. Ethylene insensitivity is a result of single amino acid changes within the region of the receptor involved in ethylene binding (Chang et al., 1993; Hua et al, 1995, 1998; Sakai et al, 1998). The ethylene-insensitive mutations are dominant. Little or no effect of single loss-of-function mutations upon ethylene signaling transduction is investigated by experiments using combinations of receptor knock-out (Hua and Meyerowitz, 1998), indicating that there is functional overlap among the receptor family members and the receptors serve as negative regulators of the ethylene response pathway, because elimination of receptors activates ethylene responses. According to this model for negative regulation, wild-type ethylene receptors actively repress ethylene responses in the air but express in the presence of ethylene. Wild type receptors switch to a signaling inactive state that allow for induction of ethylene responses (Bleecker, 1999). In contrast to the single and double loss-of-function, triple and quadruple receptor mutants show constitutive-ethylene response phenotypes because the basal levels of ethylene, which are constitutively produced in these plants, are sufficient to inactivate the remaining receptor 'repressive' activity (Cancel and Larsen, 2002). Therefore, an ethylene-insensitive mutation in one member of the five-member ethylene insensitivity suggests that signaling by one family member is enough to repress ethylene responses. Conversely, lossof-function mutations in three receptors are simultaneously sufficient to induce ethylene responses (Hua and Meyerowitz, 1998). Ethylene bind to the receptor alters the activity of the His kinase domain, which in turn influences downstream components CTR1 and EIN2 (Guzman and Ecker, 1990; Kieber et al., 1993; Ecker, 1995).

Mutant, etrl-1, which no longer binds copper, is incapable of binding ethylene (Rodriguez et al., 1999), and the receptor is unable to turn CTR1 “on" even when ethylene is present, resulting in the ethylene-insensitive phenotype. The expression of the Arabidopsis etrl-1 gene in transgenic carnations delays flower senescence, which leads to a significant increase in vase life. About half of the transgenic plants obtain flower senescence, which delays a 3-fold increase in vase life by at 
least 6 days relative to control flowers, with a maximum delay of 16 days. These flowers do not show the phenotype typical of ethylene-dependent carnation flower senescence (Bovy et al., 1999). The expression of the ACO1 gene in etrl-1 transgenic carnation flowers is down regulated, suggesting that the autocatalytic induction of ethylene biosynthesis is absent due to dominant ethylene insensitivity. The delay in senescence observed in etr $1-1$ transgenic flowers is longer than in flowers pretreated with inhibitors of either ethylene biosynthesis (AOA) or ethylene receptor (STS) (Van altvorst et al., 1995, 1997; Bovy et al., 1999). Agrobacteriummediated transformation of tomato, tobacco and petunia plants with Arabidopsis etrl-1 gene under control of the constitutive CaMV $35 \mathrm{~S}$ promoter is successfully conferred ethylene insensitivity. An ethylene-insensitive phenotype delays flower senescence after pollination and after exogenous ethylene treatment (Wilkinson et al., 1997). Ciardi and Klee (2001) elucidated mode of the dominant etr1-1 mutation, which causes a substitution of tyrosine (Y65) for cysteine at amino acid position 65, eliminating both ethylene and copper binding (Fig. 10). Since ethylene does not bind, phosphorylation cannot be inactivated and the ethylene response is constitutively suppressed. Additionally, ethylene inhibitor action, STS and 1-MCP, associated with theoretical considerations (Sisler and Serek, 1997), can be explained at the molecular level that the receptor (ETR1) exhibits strong affinity for another metal, silver, and mediates ethylene binding. Silver probably acts by displacing copper in the active site of the receptor complex that still binds to ethylene (Ciardi and Klee, 2001). Therefore it must prevent a conformational change that would normally occur following copper-mediated ethylene binding. The compound 1-MCP, can also be bound by ethylene, but binding does not increase ethylene sensitivity and serves to block ethylene perception instead (Fig. 10). Although ethylene receptors are capable of binding several different molecules, the interaction required to induce an ethylene response is extremely specific (Ciardi and Klee, 2001). 


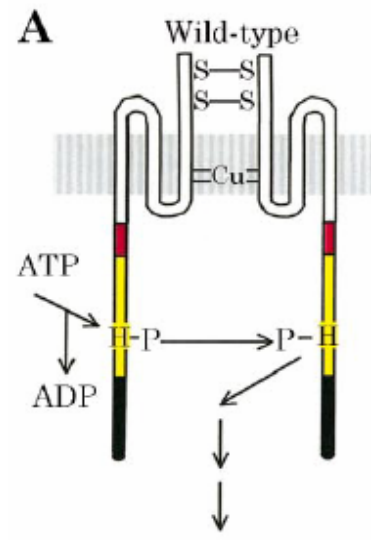

no ethylene response

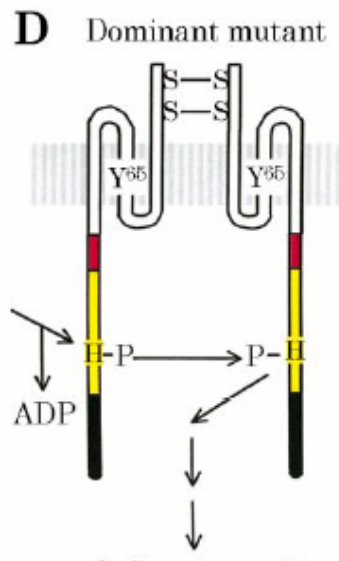

ethylene insensitive

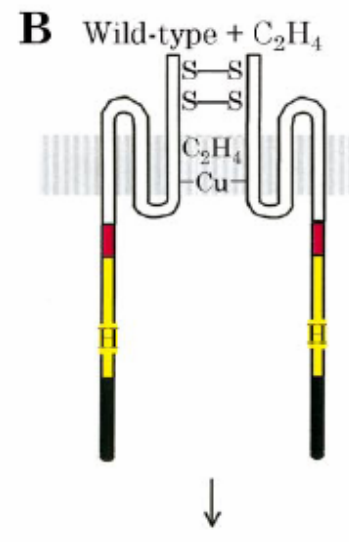

ethylene response

E Wild-type + Ag

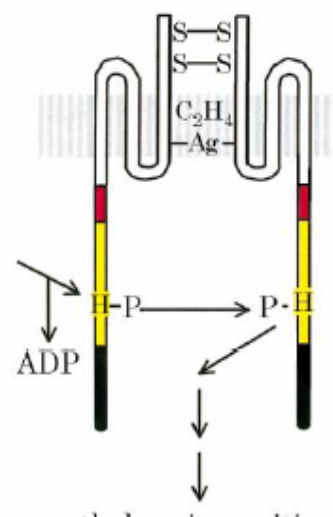

ethylene insensitive
C Loss-of-function mutant $\square$ Ethylene-binding region

GAF domain

Histidine kinase

Response regulator

Membrane

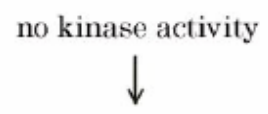

ethylene response

F Wild-type + MCP

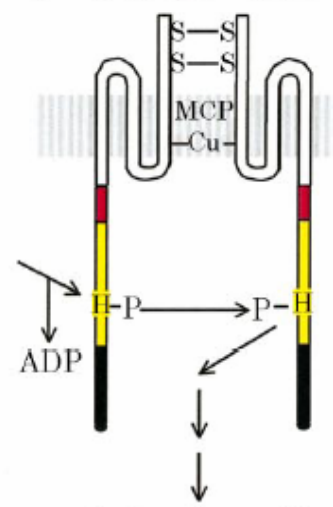

ethylene insensitive

Fig. 10. A model for the role of kinase activity in ethylene signalling. A, The Arabidopsis ETR1 receptor. B, Ethylene binding to wild-type receptor. C, Loss-of-function mutations in multiple ethylene receptors. D, The dominant etr1-1 mutation. E, Silver ion competes with copper for receptor binding sites. F, The ethylene action inhibitor 1-methylcyclopropene (1-MCP) competes with ethylene to bind to the receptor. (Ciardi and Klee, 2001).

\subsubsection{Expression regulation of ethylene signal transduction pathway}

Genetic analysis indicates that CTR1, which encodes a protein consisting of 821 amino acids, acts downstream of the receptor in the ethylene signal pathway and localizes at the ER (Kieber et al., 1993; Roman et al., 1995; Sakai et al., 1998; Guo et al., 2003). Because CTR1 has no obvious trans-membrane domain or membrane motifs, its ER localization probably results from direct interaction with the ER-associated receptor (Guo et al., 2003). CTRl is a negative regulator of the 
ethylene-response pathway because $\operatorname{ctr} 1$ null mutants exhibit constitutive ethylene responses even in the absence of ethylene (Kieber et al., 1993). The deduced CTR1 protein sequence is most similar to the Raf family of protein kinase, which initiates mitogen-activated protein (MAP)kinase signaling cascades in mammals (Fig. 11) (Kyriakis et al., 1992; Pelech and Sanghera, 1992). The similarity of CTRl known $M A P K K K S$ implies that ethylene signaling may operate through a MAP-kinase cascade. Although many genes with homology to MAPKKs and MAPKs have been identified in the Arabidopsis genome sequence, currently none have been involved with ethylene signaling. Thus, no intermediate components have been identified genetically or biochemically to act between the receptors and the CTRl kinase. The two-hybrid yeast assay shows that the amino-terminal domain of CTR 1 can interact with the His kinase domains of ETR 1 and ERS1 (Clark et al., 1998). The function of CTR1 is dependent on both its carboxy-terminal Ser/Thr kinase activity and the association of its amino-terminal domain with ER-bound ethylene receptors. Interestingly, CTR 1 is also able to interact weakly with carboxy-terminal domain ETR2 (type-II). Thus, it is hypothesized that all five ethylene receptors are able to interact with CTRI via their carboxy-terminal kinase domains. However, type-I receptors (ETRI and ERS1) have a high affinity for CTR1, whereas type-II (at least ETR2) possess a low binding affinity for CTR1 (Cancel and Larsen, 2002). Loss of function in the ethylene receptors or CTR1 results in the induction of ethylene responses. In air, the ethylene receptors maintain CTRI in an "on" state that serves to repress the ethylene responses. Binding of ethylene to the receptors turns CTR1 "off" and leads to derepression of the pathway. Specifically, inactivation of CTR 1 would result in the activation of EIN2, and consequently activation of the transcriptional cascade that involves the EIN3/EIL and the ERFs (Ecker, 1995). 


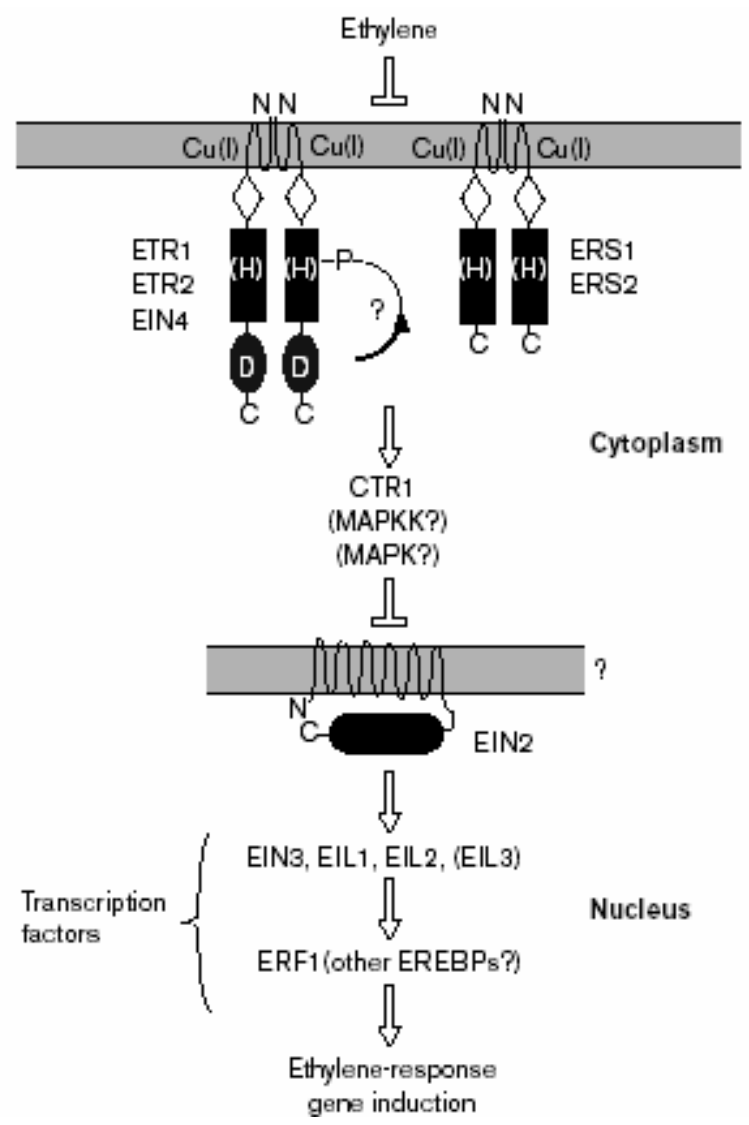

Fig. 11. A current view of the ethylene signal transduction pathway formulated on the basis of cloned Arabidopsis genes (Chang and Shockey, 1999).

In Arabidopsis, signal propagated from CTR1 to the nucleus requires EIN2 to encode an integral membrane protein of 1294 amino acids. Null mutations in EIN2 result in the complete loss of ethylene responsiveness throughout plant development, suggesting that EIN2 is an essential positive regulator in the ethylene signal pathway (Fig. 11). EIN2 comprises 12 predicted transmembrane domains in the third of the polypeptide, a region that resembles members of the NRAMP family, including metal-ion transporters. The carboxy-terminal portion of EIN2 is a novel sequence predicted to be soluble and cytosolic. EIN2 is also membrane-associated, but lacks detectable metal transport activity. The amino-terminal domain may serve as a sensor of divalent cations or as a membrane anchor. Overexpression of hydrophobic carboxy-terminal domain in an EIN2 null background results in constitutive activation of some, but not all, of the ethylene response pathway. These results suggest that ethylene regulation of this activity requires the EIN2 amino-terminal domain. It is hypothesized that the amino-terminal region of EIN2 
represents an input domain, interacting with upstream signaling factors, while the carboxyterminal region represents an output domain, interacting with downstream signaling factors (Alonso et al., 1999).

Based on genetic evidence, EIN3 is a novel nuclear-localized DNA binding protein that encodes a protein of 628 amino acids and acts downstream of EIN2. EIN3, which contains acidic, pralinerich and glutamine-rich domains found in transcriptional activation domains, is nuclear-localized. Loss of function of EIN3 results in an ethylene insensitive phenotype, indicating that EIN3 is a positive regulator of ethylene signal transduction (Fig. 11). In Arabidopsis, EIN3 is a multigene family, in which EIN3 and EIN3-like (EIL1) are the most closely related proteins. Loss of function mutation in the EIL1 gene shows incomplete ethylene insensitivity like ein3 mutants, but eill mutants are more sensitive to ethylene than ein3 mutants. In addition, overexpression of EIN3 and EIL1 genes confers a constitutive ethylene response phenotype on dark-grown seedlings as well as those grown in the light. Moreover, EIN3 and EIL proteins comprise a novel family of sequence-specific DNA-binding proteins and define a primary ethylene response element (PERE) present in the promoters of several ethylene-regulated genes (Chao et al., 1997). EIN3 is both necessary and sufficient for the activation of ethylene responsive target genes, particularly for ERF1 (Solano et al., 1998).

$E R F 1$, which is induced by the EIN3/EIL1, is itself a transcription factor, indicating that ethylene signal transduction involves a transcription cascade (Fig. 11) (Solano et al., 1998), and is formerly known as EREBP (ethylene-responsive element-binding protein). This gene belongs to a family of ethylene-responsive element-binding factor $(E R F)$ proteins (Ohme-Takagi and Sinshi, 1995; Fujimoto et al., 2000). ERF1, known to be a trans-acting factor responsible for ethyleneregulated expression of genes, induces ripening and senescence and interacts specifically with sequences consisting of AGCCGCC motifs (GCC box) that are found in the promoters of several pathogenesis genes, such those encoding $\beta$-1, 3-glucanase, basic chitinase, and defensin (PDF1.2) (Ohme-Takagi and Sinshi, 1995; Hao et al., 1998; Solano et al., 1998). Some ERFs contain GCC boxes, a cis-acting promoter element, which is both necessary and sufficient to confer ethylene responsiveness in their promoters indicating that they are targets for other members of the $E R F$ family, and suggesting the existence of a tertiary level of transcriptional regulation in ethylene signal transduction (Solano et al., 1998). Moreover, ERFs share a well-conserved 58-59 amino 
acid domain, ERF domain, which has a novel structure containing three $\beta$-sheets and an $\alpha$-helix binding to DNA as a monomer, with high affinity (Allen et al., 1998; Hao et al., 1998). This domain is related to the AP2 domain in the Arabidopsis gene APATALA2 (Jokofu et al., 1994), although ERF proteins contain a single DNA-binding domain whereas the APATALA2-type proteins typically contain two (Riechmann and Meyerowitz, 1998). Overexpression of ERF1 induces a partial triple-response phenotype in dark-grown seedlings, with the seedlings lacking the exaggerated apical hook normally associated with the triple response (Solano et al., 1998). This result indicates that the roles of $E R F 1$ are not confined to the pathogenesis response and other factors. ERF1 is required for initiating a full ethylene response. Analysis of the $E R F$ family in Arabidopsis reveals that some members, such as ERF1, function as transcriptional activators while other members function as repressors (Fujimoto et al., 2000).

$E R F S$ can be divided into three classes based on their amino acid sequences. All classes consist of the ERF domain, but the acidic domain in class I has been found in the N-terminal region. In addition, members of this group possess a region rich in basic amino acids (P/L-K-K/R-R-R) that could serve as a putative nuclear localization signal (Raikhel, 1992). In class II, ERF domain is located close to the N-terminus of the protein. It comprises 58 amino acids, with one residue shorter than that of class I ERFs. Class III has the longest coding region among members of ERF protein. Acidity domains are located in both the $\mathrm{N}$ - and C-terminal region flanking the ERF domain. Additionally, a putative mitogen-activated protein $(M A P)$ kinase phosphorylation site is conserved in the C-terminal region. Class I and III are activators, whereas class II has active repressors that can suppress the activity of other transcriptional activators without competing for DNA binding sites (Fujimoto et al., 2000; Ohta et al., 2001). Class IV is the new ERF class that displays a novel and highly conservative N-terminal motif (MCGGAII/L). Though the function of $M C G G A I I / L$ motif has not been established, deletion studies indicate that it is required neither for nucleus localization nor for binding to the GCC box (Tournier et al., 2003). In Arabidopsis, AtERF1 and AtERF2 belong to class I, AtERF3 and AtERF4 possess class II and AtERF5 is the only identified member of class III (Fujimoto et al., 2000). ERF proteins play important roles in plant responses to signals that are induced by extracellular stress. They are involved in the induction of gene expression by stress factors, such as pathogens and cold, and by components of stress signal transduction pathways, such as ethylene, abscisic acid and jasmonic acid (OhmeTakagi and Shinshi, 1995; Büttner and Singh, 1997; Stockinger et al., 1997; Zhou et al., 1997; 
Finkelstein et al., 1998; Solano et al., 1998; Menke et al., 1999). Most of the members of this family have been characterized and shown to participate in stress and/or hormonal responses (Solano et al., 1998; Fujimoto et al., 2000). The ERF domain-containing Pti4/5/6 gene products bind to the pathogenesis-related Pto protein kinase in tomato (Zhou et al., 1997) and over expression of Pti4 in Arabidopsis induces the expression of GCC box-containing genes (Wu et al., 2002), thereby enhancing resistance to pathogen attack (Gu et al., 2002).

In Rosa hybrida, the expression of RhCTRI (66\% amino acid identity to Arabidopsis CTR) and RhCTR2 (87\% amino acid identity to AtEDRI and 90\% identity to LeCTR2) during flower senescence and in response to ethylene has been examined. $R h C T R I$ levels have been upregulated in senescing flowers, while $R h C T R 2$ is constant during flower senescence. The expression of both genes increases in response to ethylene, indicating the role of these genes in ethylene sensitivity and postharvest performance (Müller et al., 2002a). However, it can be assumed that flowers become more sensitive to ethylene during senescence. CTR expression will decrease in the developmental stage of flowers and in response to exogenous ethylene as the prediction of the negative regulator model.

RhEIN3, a cDNA encoding part of an EIN3 transcription factor homologue, has been isolated in Rosa hybrida. The deduced protein has $83 \%$ and $88 \%$ identity to the corresponding regions of Arabidopsis EIN3 and EIL1, respectively. The expression of RhEIN3 transcript during flower development has been investigated in the miniature rose cultivars 'Bronze', of short flower life and high ethylene production, and 'Vanilla', long-lasting and moderate ethylene production, at three stages of flower development: the bud, the opening flower and the incipient senescence stage. For the opening flower stage, changes in expression of RhEIN3 after ethylene and ABA treatment have been investigated. The gene RhEIN3 is constitutively and stably expressed during flower development in both cultivars and in response to ethylene and ABA. The constitutive pattern of RhEIN3 expression could not be correlated with the previous observed cultivar differences in flower life or ethylene sensitivity in flower or leaves of miniature roses (Müller et al., 2002b). These observations are in accordance with previous studies in Arabidopsis (Chao et al., 1997) and tobacco (Kosugi and Ohasi, 2000), in that ethylene does not affect the level of EIN3 mRNA, and suggests that control of ethylene sensitivity occurs upstream of EIN3 and its homologues. 
Therefore, the biochemical investigation of inhibitors of ethylene responses, and studies of the ethylene signal transduction pathway using a molecular genetic approach can determine the manner in which ethylene influences these processes. From the previous study of physiological investigation, it is assumed that the difference in the display quality of miniature potted roses after pretreatment with air, 1-OCP, 1-DCP, 1-MCP and afterwards continuous exposure to ethylene, might have an influence on the expression of genes for ethylene biosynthesis enzymes, ethylene perception and the signal transduction pathway. Two selected cultivars, 'Vanilla' (longlasting flower) and 'Lavender' (short flower life) were selected in order to understand the mechanisms that regulate ethylene induced flower senescence and genetic control of the ethylene response pathway. This could lead to a possibility of selective block processes in flower development that are economically detrimental, and to improve display quality using new chemicals for ethylene receptor inhibition. However, there is no report about the ERF domaincontaining genes in miniature roses so far. In order to identify and characterize differentiallyexpressed genes that might provide more insight into explaining the genetic basis of the ethylene response pathway, the cloning and initial characterization of a novel $E R F$ gene, $R h E R F 1$, from Rosa hybrida was reported. 


\subsection{Materials and Methods}

\subsubsection{Plant material}

The plants were grown as previously described in chapter 2.2.6. They were harvested after continuous exposure to exogenous ethylene and ethylene-free air for 9 days and then put in $15 \mathrm{ml}$ polyethylene tubes (Sarstedt, Germany) and immediately frozen in liquid nitrogen. They were then ground in liquid nitrogen and stored at $-80^{\circ} \mathrm{C}$ in a deep freezer until extraction of DNA or RNA.

\subsubsection{Database analyses and primer design}

A sequence comparison between known ERF sequences of different plant species was done according to Mibus (2003). The ERF primer pairs were designed using program Primer 3 (Steve and Skaletsky, 2000) (http://frodo.wi.mit.edu/cgi-bin/primer3/primer3 www.cgi) and was commercially synthesized by MWG Biotech AG, as shown in Table 1 .

Table1. Primer pair for amplification of the Ap2 (DNA binding Domain) coding sequence of ERF1

\begin{tabular}{|c|c|c|c|c|c|}
\hline \multirow[t]{2}{*}{ Name } & \multirow[t]{2}{*}{ Sense Primer } & \multirow[t]{2}{*}{ Name } & \multirow[t]{2}{*}{ Antisense Primer } & Annealing & Size (bp) \\
\hline & & & & Temp $\left({ }^{\circ} \mathrm{C}\right)$ & \\
\hline ERF1s & 5'TACAGAGGCGTTAGGAAGCG3' & ERF1as & 5'CGAAAGTGCCAAGCCAGA3' & 55 & 92 \\
\hline
\end{tabular}

\subsubsection{DNA isolation and PCR}

Genomic DNA was isolated from $80 \mathrm{mg}$ of ground petals of miniature roses 'Vanilla' and 'Lavender' using DNeasy ${ }^{\mathrm{R}}$ Plant Mini Kit (Qiagen GmbH, Hilden, Germany), according to the manufacturer's instructions. The concentration of 'Vanilla' and 'Lavender' genomic DNA was determined by comparing it with standard concentrations $\left(5,10,25,50,100\right.$ and $\left.200 \mu \mathrm{g} \mathrm{ml}^{-1}\right)$ of $\lambda$ DNA (Fermentas GmbH, St, Leon-Rot, Germany) in 1\% agarose flatted gel electrophoresis visualised by staining with $40 \mu \mathrm{g}$ ethidium bromide. A temperature gradient PCR was performed to optimize the annealing temperatures for the ERF primer (Table 1) and various gene-specific primers (table 2) to minimize the number of incorrect base pairings (mismatches). This 
phenomenon is enhanced by low annealing temperature which is responsible for mismatching (Rychlick et al., 1990). For PCR analysis, 15 ng genomic DNA was used as a template in a $20 \mu 1$ volume reaction that contained $0.03 \mu \mathrm{M}$ of ERF1 primer pair: ERFs and ERFas (Table 1) or $1.2 \mu \mathrm{M}$ gene-specific primer pairs (table 2), $150 \mu \mathrm{M}$ of each dNTP and 0.2 units of DyNAzyme ${ }^{\mathrm{TM}}$ II DNA polymerase (Finnzymes Oy, Espoo, Finland) in the 10x (100 mM Tris-HCL, pH 8.3, 500 $\mathrm{mM} \mathrm{KCl}, 20 \mathrm{mM} \mathrm{MgCl}_{2}$ and $0.01 \%$ gelatin) Williams buffer. The reaction mixture was incubated in a Thermocycler (Biometra, Göttingen, Germany) and the PCR conditions were: 2 min at $94^{\circ} \mathrm{C}$ (initial denaturation), followed by 40 cycles lasting $1 \mathrm{~min}$ at $94^{\circ} \mathrm{C}$ (denaturation), $1 \mathrm{~min}$ at $49^{\circ} \mathrm{C}$ to $56^{\circ} \mathrm{C}$ (40 cycles) (annealing), and $2 \mathrm{~min}$ at $72^{\circ} \mathrm{C}$ (extension) and a cooling step at $4^{\circ} \mathrm{C}$.

\subsubsection{Cloning, DNA sequencing and sequence analysis}

Orange G (30\% Glycerin, $20 \mathrm{mM}$ EDTA-pH 8, 1.25\% Orange $\mathrm{G}$ and $10 \mathrm{ml}$ deionised water) loading buffer was added to the PCR products and centrifuged for 5 seconds. This mixture was then loaded into 1\% agarose gels and separated in a flatted gel electrophoresis using 1xTAE (40 mM Tris-Acetate, 1mM EDTA, pH 8.0) Buffer. The gels had a capacity of either $50 \mathrm{ml}$ or $150 \mathrm{ml}$ and were run at $120 \mathrm{~V}$ or $80 \mathrm{~V}$, respectively. They were also visualised by staining with 0.3 $\mu \mathrm{g} / \mathrm{ml}$ ethidium bromide and observed using a BioDocAnalyze UV trans-illuminator (Biometra, Göttingen, Germany). The sizes of amplicons were estimated by comparing them to a 100 base pair-ladder DNA marker. The desirable fragments were cloned by ligation into a TA plasmid cloning vector using $\mathrm{pCR}^{\mathrm{R}} 4-\mathrm{TOPO}^{\mathrm{R}}$ TA Kit (Invitrogen, Carlsbad, CA; Appendix. 5) and transformed into Escherichia coli.

The plasmid vector $\left(\mathrm{pCR}^{\mathrm{R}} 4-\mathrm{TOPO}^{\mathrm{R}}\right)$ was supplied linearised, also called "activated vector". The Vaccinia virus Topoisomerase I binds to duplex DNA at specific sites and cleaves phosphodiester backbone after 5'-(T/C)CCTT in one strand (Shuman, 1991) and the energy released is conserved through formation of a covalent bond between 3' phosphate of the cleaved strand and a tyrosyl residue (Tyr-274) of topoisomerase I. The phosphate-tyrosyl bond between DNA and enzyme can subsequently be attacked only by a 5' hydroxyl of the original cleaved strand, reversing the reaction and releasing topoisomerase (Shuman, 1994). The plasmid vector has two adjacent cutting surfaces and since both DNA fragments are blocked by Topoisomerase, this prevents self ligation. Moreover, the vector allows direct selection of positive recombinants via disruption of 
the lethal Escherichia coli, $c c d$ B gene (Bernard et al., 1994) since the cells that contain a nonrecombinant vector are killed upon plating, which eliminates the need for blue/white screening.

After cloning (50 ng of the PCR product) and transformation into Escherichia coli according to the manufacturer's instructions (TOPO TA Cloning kit; Invitrogen), $125 \mu$ l S.O.C. medium (2\% Tryptone, $0.5 \%$ Yeast extract, $10 \mathrm{mM} \mathrm{NaCl}, 2.5 \mathrm{mM} \mathrm{KCl}, 10 \mathrm{mM} \mathrm{MgCl} 2,10 \mathrm{mM} \mathrm{MgSO}_{4}, 20 \mathrm{mM}$ glucose) was added to the plasmid-E. coli mixture and shaken horizontally using a shaker at 240 rpm for 1.5 hours at $37^{\circ} \mathrm{C}$ in order for bacteria to multiply. The transformants were then cultured in $\mathrm{LB}(1 \%$ Tryptone, $0.5 \%$ Yeast extract, $1 \% \mathrm{NaCl}, 950 \mathrm{ml}$ deionised water, $\mathrm{pH} 7.0)$ medium containing $150 \mu \mathrm{g} \mu 1^{-1}$ Ampicillin at $37^{\circ} \mathrm{C}$. Plasmid DNA from transformed E. coli was recovered using the NucleoSpin ${ }^{\mathrm{R}}$ Plasmid Kit (Macherey-Nagel GmbH, Düren, Germany). Positive transformants were directly analysed using $0.2 \mu \mathrm{g} \mathrm{T} 3$ and $0.2 \mu \mathrm{g} \mathrm{T} 7$ primer pairs in a PCR reaction. The nucleotide sequences for T3 5'-ATTAACCCTCACTAAAGGGA-3' and T7 5'TAATACGACTCAACTATAGGG-3'. Sequencing by dideoxynucleotide method was performed commercially by MWG Biotech AG (Ebersberg-Munich, Germany). The isolated sequences were analysed using CLUSTAL W program, European Bioinformatics Institute (EMBL; Higgens, 1994), and the homology search was done using the BLUSTN programme, National Center for Biotechnology Information (NCBI; Altschul et al., 1997).

\subsubsection{RNA Isolation and RT-PCR}

Total RNA was isolated from $30 \mathrm{mg}$ of ground petals and leaves of miniature rose cultivars 'Vanilla' and 'Lavender' after treatment with continuous ethylene for 9 days or ethylene-free air as described in section 2.2.6, using Invisorb ${ }^{\mathrm{R}}$ Spin Plant RNA Mini Kit (Invitek $\mathrm{GmbH}$, Berlin, Germany) following the protocols by the manufacture. Total RNA was determined by use of a spectrophotometer (Biorad, California). To check for the presence of contaminating genomic DNA, total RNA was compared with standard concentrations (5, 10, 25, 100 and $200 \mu \mathrm{g} \mathrm{ml}^{-1}$ ) of $\lambda$ DNA (Fermentas $\mathrm{GmbH}$, St. Leon-Rot, Germany) in a flatted gel electrophoresis visualized by staining with $0.3 \mu \mathrm{g} / \mathrm{ml}$ ethidium bromide then stored at $-20^{\circ} \mathrm{C}$ for short-term or $-80^{\circ} \mathrm{C}$ deep freezer for long-term storage, until further use. Under these conditions, no degradation of RNA is detectable for at least 1 year. RNA was handled using latex hand gloves and was kept under ice when taking aliquots. Additionally, the laboratory working 
surfaces and equipments were cleaned with RNase degrading chemicals (RNase Exitus; AppliChem).

cDNA was synthesized and used as a template for PCR. Before RT-PCR, the residual genomic DNA in the total RNA preparation was removed through a RNase-free DNase treatment as follows: $0.5 \mu \mathrm{g}$ RNA was treated with $1 \mu 1$ 10x buffer, 0.5 units Deoxyribonuclease I (Rnase-free) (Fermentas GmbH, Heidelberg, Germany), 0.5 units RiboLock ${ }^{\mathrm{TM}}$ Ribonuclease Inhibitor (Fermentas $\mathrm{GmbH}$, Heidelberg, Germany), then the mixture was incubated in a Thermocycler (Biometra, Göttingen, Germany) for $30 \mathrm{~min}$ at $37^{\circ} \mathrm{C}$. After incubation, $40 \mu \mathrm{M}$ EDTA was added to the mixture to deactivate DNase. This was done at $65^{\circ} \mathrm{C}$ for $10 \mathrm{~min} .0 .5 \mu \mathrm{g}$ of total RNA was used as a template for cDNA synthesis using M-MLV RT, RNase H Minus: a point Mutant (Promega Corporation, Manheim, Germany). First strand cDNA synthesis was carried out using first strand oligo $(\mathrm{dT})_{23}$ for $10 \mathrm{~min}$ at $40^{\circ} \mathrm{C}$, then $2 \mathrm{~h}$ at $50^{\circ} \mathrm{C}$ and a final deactivation for $10 \mathrm{~min}$

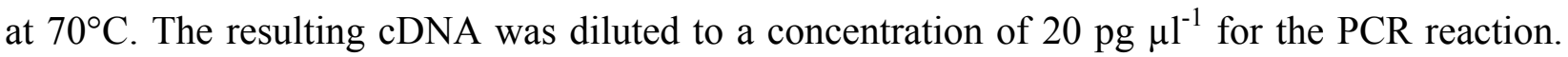
The PCR reaction mixture contained $2 \mu \mathrm{l}$ of cDNA, $2 \mu \mathrm{l}$ of 10x Williams Buffer (see section 3.2.3) recommended by the supplier (Biometra, Göttingen, Germany), $150 \mu \mathrm{M}$ dNTPs, $1.2 \mu \mathrm{M}$ gene-specific primer pairs and 0.5 units Taq DNA polymerase (Invitek GmbH, Berlin, Germany) in a total volume of $20 \mu \mathrm{l}$. Primers $(0.25 \mu \mathrm{M}$ of each) used for the amplification of $\beta$-Actin (used as a reference) were: ACC synthase; RhACS1, RhACS2, RhACS3, RhACS4, RhACS5, ETR genes; RhETR1, RhETR2, RhETR3, RhETR4, CTR genes; RhCTR1, RhCTR2, EIN3 and EIN-like genes; $R h E I N 3, R h E I L$ and $E R F$ gene; RhERF1 were designed from sequences available in the databases (Rosa hybrida) (http://www.ncbi.nlm.nih.gov) (Table 2). For the PCR reaction, between 35-45 cycles, were observed with the clear differences of amplification detected at 40 cycles. The reaction mixture was incubated in a Thermocycler (Biometra, Göttingen, Germany). PCR conditions were: $5 \mathrm{~min}$ at $94^{\circ} \mathrm{C}$ (initial denaturation), followed by 40 cycles consisting of $30 \mathrm{~s}$ at $94^{\circ} \mathrm{C}$ (denaturation), $30 \mathrm{~s}$ at $49^{\circ} \mathrm{C}$ to $55^{\circ} \mathrm{C}$ (annealing) (see Table.2), and $30 \mathrm{~s}$ at $72^{\circ} \mathrm{C}$ (extension) and a cooling step at $4^{\circ} \mathrm{C}$. The products of PCR were separated as described for the normal PCR above. PCR and the experiments themselves were repeated three times for each sample. A representative result is presented in chapter 3.3.2. 
Table 2. Gene specific primer pairs for $\beta$-Actin (Accession No. X55751), ACC synthase; RhACS1 (Accession No. AY061946), RhACS2 (Accession No. AY525066), RhACS3 (Accession No. AY525067), RhACS4 (Accession No. AY525068), RhACS5 (Accession No. AY525069), ETR genes; RhETR1 (Accession No. AF394914), RhETR2 (Accession No. AF127220), RhETR3 (Accession No. AF154119), RhETR4 (Accession No. AF159172), CTR genes; RhCTR1 (Accession No. AY032953), RhCTR2 (Accession No. AY029067), EIN3 and EIN-like genes; RhEIN3 (Accession No. AF443783), RhEIL (Accession No. AY052825) and ERF gene; RhERF1 designed using the program Primer3 (http://frodo.wi.mit.edu/cgi-bin/primer3/primer3 www.cgi).

\begin{tabular}{|c|c|c|c|c|c|}
\hline Name & Sense Primer & Name & Antisense Primer & $\begin{array}{l}\text { Annealing } \\
\text { Temp }\left({ }^{\circ} \mathrm{C}\right)\end{array}$ & $\begin{array}{l}\text { Size } \\
\text { (bp) }\end{array}$ \\
\hline Actin_for & 5'AGATCTTTATGGAAACATTGTGCTC3' & Actin_Rev & 5'ATCCAGACACTGTATTTCСТСТСТ3' & 49 & 150 \\
\hline RhACS1s & 5'AAAACCCAGAAGCCTCCATT3' & RhACS1as & 5'ATTTCTGGTTCCCGTTCCTT3' & 55 & 205 \\
\hline RhACS2s & 5'AAAACCCAGAAGCCTCCATT3' & RhACS2as & 5'ATTTCTGGTTCCCGTTCCTT3' & 55 & 249 \\
\hline $\operatorname{RhACS} 3 s$ & 5'CCATGGCCTTTTGTCCTTTA3' & RhACS3as & 5'ACTGCAGCCAATGAGCTTTT3' & 55 & 126 \\
\hline RhACS4s & 5'GCTTCCAACTTGGGATCAAA3' & RhACS4as & 5'ТТССААССССАТАСТАСССАЗ' & 55 & 237 \\
\hline RhACS5s & 5'CAGCCGGATTCAAGAGAAAC3' & RhACS5as & 5'CTCTTATGTTTTGCCTCGCC3' & 55 & 203 \\
\hline RhETR1s & 5'TGGTATGAACCTTCAACTTTCTCAT3' & RhETR1as & 5’TGCTATTCTTGAAGAGTCTATGCGA3' & 55 & 393 \\
\hline RhETR2s & 5'CTCAAACTTCCAAATCAATGACTG3' & RhETR2as & 5'GGATCTGCTAATGGAGCAGAATAT3' & 55 & 213 \\
\hline RhETR3s & 5'CACTGCTATAACGCTCATCACTCT3' & RhETR3as & 5’ATCCTTGAAGAGTCCCAACTAATG3' & 55 & 661 \\
\hline RhETR4s & 5'TTTGAATCTGCAACTTTCTCACAC3' & RhETR4as & 5'TGTCATGAACCACGAAATGC3' & 55 & 500 \\
\hline RhCTR1s & 5'GCTTCTGATGTTGCTGTGAA3' & RhCTR1as & 5'TCAATGGCCTCAAAGATTCC3' & 52 & 706 \\
\hline $\operatorname{RhCTR2s}$ & 5'TTCCTTCCAAGGGGAAGTCT3' & RhCTR2as & 5'CCСАСТCCAAGCCAATTTTA3' & 55 & 357 \\
\hline RhEIN3s & 5'CCCTGCAGCCATAGACAAGT3' & RhEIN3as & 5'ACCCTGATTTCATCCACCAA3' & 56 & 236 \\
\hline RhEILs & 5'TCCCTGGTTTGATGGAAGAC3' & RhEILas & 5'GAGGCCACСАTTCСТСАTTA3' & 56 & 192 \\
\hline RhERF1s & 5'TTCTTCCACGGGTCTCTGATCTC3' & RhERF1as & 5'GCTTCCTAACGCCTCTGTAA3' & 55 & 64 \\
\hline
\end{tabular}

The $\beta$-Actin primer used as a reference gene is in boldface.

\subsubsection{Northern blot hybridization}

Polysomal RNA was extracted as described in section 3.2.5. Northern blotting was performed according to Terefe (2005). Equal amounts ( $8 \mu \mathrm{g}$ per sample) of total RNA were denatured in freshly prepared loading buffer (2.2 M formaldehyde, $50 \%$ foramide, $0.5 \mathrm{x}$ MOPS and $0.05 \%$ bromophenol blue $(0.25 \%(\mathrm{w} / \mathrm{v})$ bromophenol blue, $30 \%(\mathrm{v} / \mathrm{v})$ Glycerin) in a final volume of 30 $\mu 1$ for $15 \mathrm{~min}$ at $65^{\circ} \mathrm{C}$. The denatured RNA was then fractioned by electrophoresis in $1 \%$ agarose gel containing $0.7 \mathrm{M}$ formaldehyde in 1x MOPS-buffer (200 $\mathrm{mM}$ 3-(N-Morpholino)- 
propanesulfonic acid (MOPS), $80 \mathrm{mM}$ Sodium acetate 3-hydrate, $12.5 \mathrm{mM}$ EDTA, $\mathrm{pH}$ 7.0) for $4-5 \mathrm{~h}$ (at the constant voltage of $5 \mathrm{~V} / \mathrm{cm}$ gel length). The gels were stained with $1,5 \mu \mathrm{g} / \mathrm{ml}$ ethidium bromide to check the intactness of the RNA under UV light, then washed first in water for $15 \mathrm{~min}$ and twice in 10x SSC (1.5 M NaCl, $0.15 \mathrm{M} \mathrm{Na}$-citrate, $\mathrm{pH}$ 7.0) for $15 \mathrm{~min}$ each. RNA was then transferred to positively-charged nylon membranes (Hybond- $\mathrm{N}^{+}$, Amersham Biosciences UK Ltd, Buckinghamshire, England) in 10x SSC using a vaccuum-system (Pharmacia; 60 mbar, 90 min). After crosslinking by irradiation with UV light, the membranes were rinsed with water and stored until hybridization.

\subsubsection{DIG labeling of the probes for northern blot hybridization}

The ethylene receptor and signal transduction pathway, RhETRI-2, RhEIN3 and RhEIL were labeled with DIG (digoxigenin) (Roche Diagnostics GmbH, Mannheim, Germany) for nonradioactive hybridization. DIG labeling was performed by PCR using 10 pg plasmid, containing each gene of interest: $2.5 \mu \mathrm{M}$ of each standard $\mathrm{T}_{3}$ 5'-ATTAACCCTCACTAAAGGGA-3' and $\mathrm{T}_{7}$ 5'-TAATACGACTCAACTATAGGG-3' primers, 10x reaction William Buffer (GeneCraft $\mathrm{GmbH}$, Lüdinghausen, Germany) as recommended by the supplier (Biometra, Göttingen, Germany), 10x DIG DNA labeling mix and 1 unit DyNAzyme ${ }^{\mathrm{TM}}$ II DNA polymerase (Finnzymes Oy, Espoo, Finland) filled to a final volume of $20 \mu \mathrm{l}$ with $\mathrm{ddH}_{2} \mathrm{O}$. The reaction mixture was incubated in a Thermocycler (Biometra, Göttingen, Germany). PCR conditions were: $2 \mathrm{~min}$ at $94^{\circ} \mathrm{C}$ (initial denaturation), followed by 40 cycles lasting $30 \mathrm{~s}$ at $94^{\circ} \mathrm{C}$ (denaturation), $1 \mathrm{~min}$ at $50^{\circ} \mathrm{C}$ (annealing), $2 \mathrm{~min}$ at $72^{\circ} \mathrm{C}$ (extension) and $5 \mathrm{~min}$ at $72^{\circ} \mathrm{C}$ (final extension). As a control, additional PCR reactions were set for every probe, labeled by using normal dNTPs without DIG. $5 \mu$ l DIG-labeled PCR product and the control were checked by flatted electrophoresis in 1\% agarose gel visualised by staining with $40 \mu \mathrm{g}$ ethidium bromide. The size of fragments was estimated using 100 base pair-ladder DNA marker. Due to the presence of DIG, the DIG-labeled probes migrate slower and appear to be larger than PCR fragments obtained using the normal dNTPs. The DIG-labeled probes were denaturated at $95^{\circ} \mathrm{C}$ for $10 \mathrm{~min}$ and immediately chilled on ice for denaturation. The denaturated probe was then used for northern blot hybridization. 


\subsubsection{Hybridization and washing conditions for northern blots}

The membranes were prehybridized in prehybridization solution containing Dig Easy Hyb (Roche Diagnostics $\mathrm{GmbH}$, Mannheim, Germany) at $50^{\circ} \mathrm{C}$ for $30 \mathrm{~min}$. Hybridization was carried out overnight at the same condition with $100 \mathrm{ng}$ of the denatured DIG-labeled probe in $7.5 \mathrm{ml}$ Dig Easy Hyb. After hybridization, membranes were washed twice for 5 min each in $2 x$ $\mathrm{SSC} / 0.1 \% \mathrm{SDS}$ at $50^{\circ} \mathrm{C}$. The membranes were then agitated in $1 \mathrm{x}$ blocking solution (Roche Diagnostics $\mathrm{GmbH}$, Mannheim, Germany) for $30 \mathrm{~min}$ to eliminate nonspecific background and for another $30 \mathrm{~min}$ in an Anti-Dig-AP solution (Roche Diagnostics GmbH, Mannheim, Germany) (2.5 $\mu \mathrm{l}(0.75 \mathrm{unit} / \mu \mathrm{l})$ Anti-Dif-AP in $50 \mathrm{ml} 1 \mathrm{x}$ blocking solution). Detection of the DIG-labeled probes was performed according to the instructions of the supplier, using CDP-star (Roche Diagnostics GmbH, Mannheim, Germany) as substrate. X-ray films (Hyperfilm, Amersham Biosciences UK Ltd, Buckinghamshire, England) were exposed to the membranes for about $1 \mathrm{~h}$. The transcript sizes were estimated by comparison with the RNA Molecular Weight Marker I (Roche Diagnostics GmbH, Mannheim, Germany) covering the range 0.3-6.9 kb. Blots were used for multiple hybridizations after stripping in 0.1x SDS boiling. 


\subsection{Results}

3.3.1 Cloning and sequence analysis of RhERF1

Using PCR with primer pairs deduced from the conserved region (Ap2 Domain) of Arabidopsis ERF homologues, a fragment encoding a partial ERF homologue was amplified from genomic DNA from 'Vanilla' and 'Lavender'. A database search revealed that the deduced amino acid sequence of RhERFI contained a highly conserved DNA binding domain. This consisted of 30 amino acids (92 bp for partial-length of DNA sequence) and a shared high identity with other reported ERF domain-containing proteins (Fig. 12).

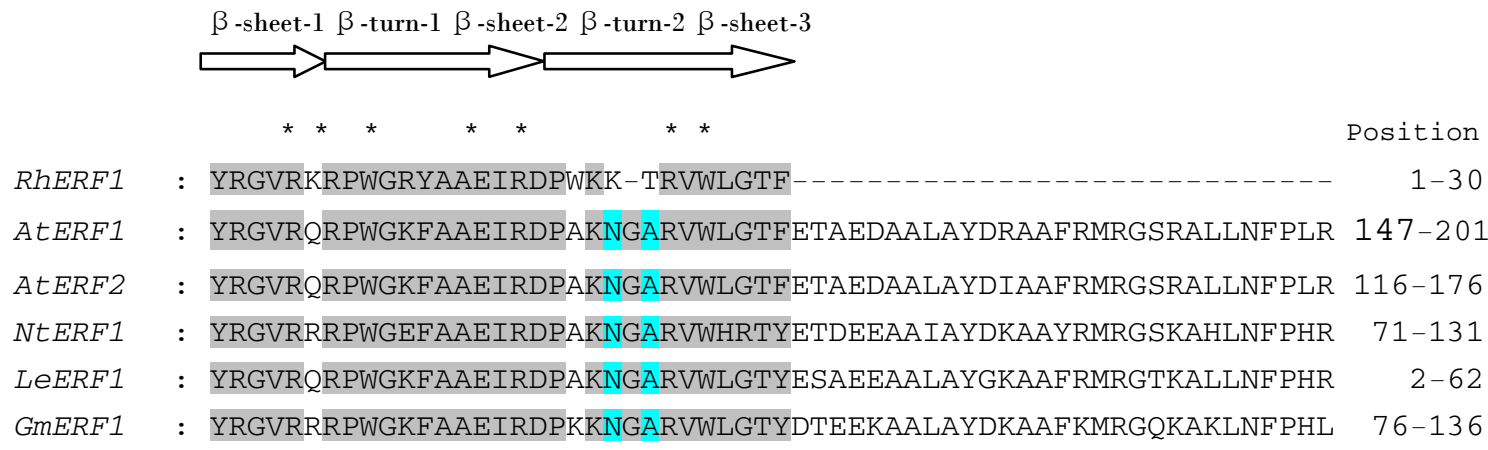

YRGVR RPWGKFAAEIRDP K G RVWLGTY

Fig. 12. Alignment of the DNA-binding domains of RhERF1 in comparison with other ERF proteins: AtERF1 (GeneBank Accession No. AAL25588), AtERF2 (GeneBank Accession No. NM_124093), NtERF1 (GeneBank Accession No. AF057373), LeERF1 (GeneBank Accession No. AY192367), GmERF1 (GeneBank Accession No. AAM45475). The identical amino acids among all the aligned ERF proteins are marked in grey. The amino acids with asterisks in the $E R F$ consensus indicate residues that interact with nucleotides with one word in the GCC box. The numbers at right indicate the position of the amino acids in the ERF domain for each protein. 
3.3.2 Expression patterns of genes for the ethylene biosynthesis enzyme, ethylene perception and signal transduction pathway after pretreatment with ethylene receptor inhibitors

Ethylene caused leaf, bud and flower drop, but there were differences among cultivars. In both cultivars, ethylene accelerated flower senescence. Continuous exposure to exogenous ethylene at $1.25 \mathrm{nl} \mathrm{l}^{-1}$ hastened leaf drop (as expressed in percentage) for 'Vanilla' and 'Lavender' (Fig 13A, B). 'Vanilla' control plants attained 90\% leaf drop after 9 days of continuous exposure to ethylene, as opposed to 'Lavender', which attained 100\% leaf drop after the same period. Pretreatment with ethylene receptor inhibitors, 1-OCP, 1-DCP and 1-MCP, significantly improved the display quality in both cultivars (Fig 13A, B). 1-MCP was the most effective of all ethylene receptor inhibitors tested in improving the display quality in both cultivars. However, 1OCP and 1-DCP were not different from each other with respect to leaf drop in both cultivars (see chapter 2) (Fig. 13A, B).
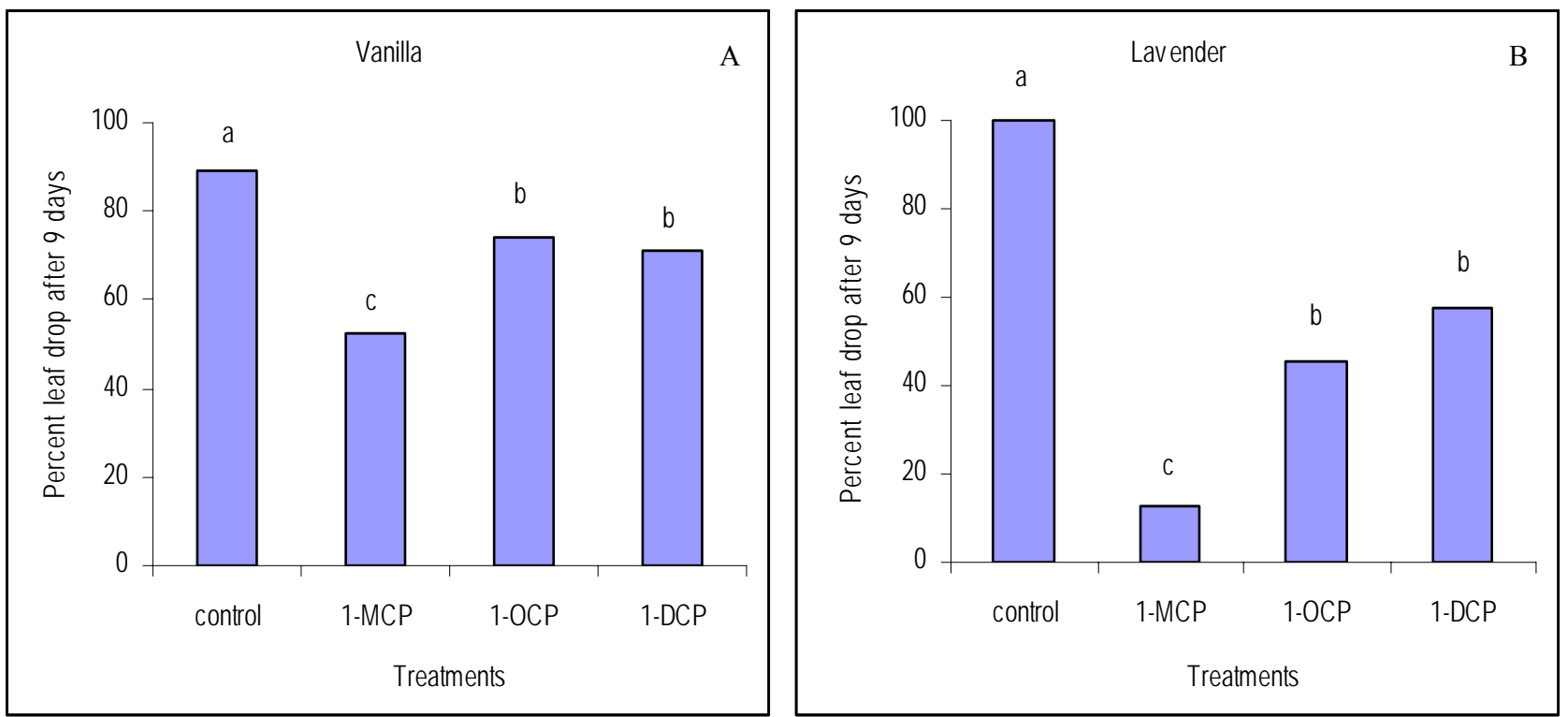

Fig. 13. Percent leaf drop of miniature potted rose cultivars 'Vanilla' (A) and 'Lavender' (B), after day 9 pretreated with 200nl $\mathrm{l}^{-1} 1$-MCP for $6 \mathrm{~h}$, and $1000 \mathrm{nl} \mathrm{l}^{-1} 1$-OCP and 1-DCP for $4 \mathrm{~h}$ at $20^{\circ} \mathrm{C}$, respectively. After treatments, the plants were exposed to $1.25(+/-0.25) \mu 11^{-1}$ continuous ethylene throughout the experiments. Bars marked with the same letter are not statistically different at $P<0.05$. Means were separated by LSD (selected data from Fig. 7; p. 28). 
To investigate transcript expression, abundance of genes for the ethylene biosynthesis enzyme, ethylene perception and other ethylene-related genes (RhACS1, RhACS2, RhACS3, RhACS4, RhACS5, RhETR1, RhETR2, RhETR3, RhETR4, RhCTR1, RhCTR2, RhEIN3, RhEIL and $R h E R F 1)$ in petal and leaf tissues was examined in the two rose cultivars 'Vanilla' and 'Lavender'. This was done after pretreatment with air, $200 \mathrm{nl} \mathrm{l}^{-1} 1$-MCP for $6 \mathrm{~h}, 1000 \mathrm{nl} \mathrm{l}^{-1}$ 1-OCP and 1-DCP for $4 \mathrm{~h}$ at $20^{\circ} \mathrm{C}$, followed by either continuous exposure to exogenous ethylene or ethylene-free air for 9 days (Fig. 15-16, A, B). Two ACS genes, RhACS1 and RhACS2, were expressed in rose tissues while $R h A C S 3-5$ was undetectable in the investigated tissues (leaves and petals) (method previously described). Northern blotting with RhETR2 probes from miniature rose was performed to compare the results of RT-PCR. The position was consistent with the expected size of RhETR2, but transcription signals of ethylene perception could not be clearly seen on the autoradiogram (Fig. 14). RT-PCR was utilized to compare the expression level of ethylene receptors in miniature rose tissues.

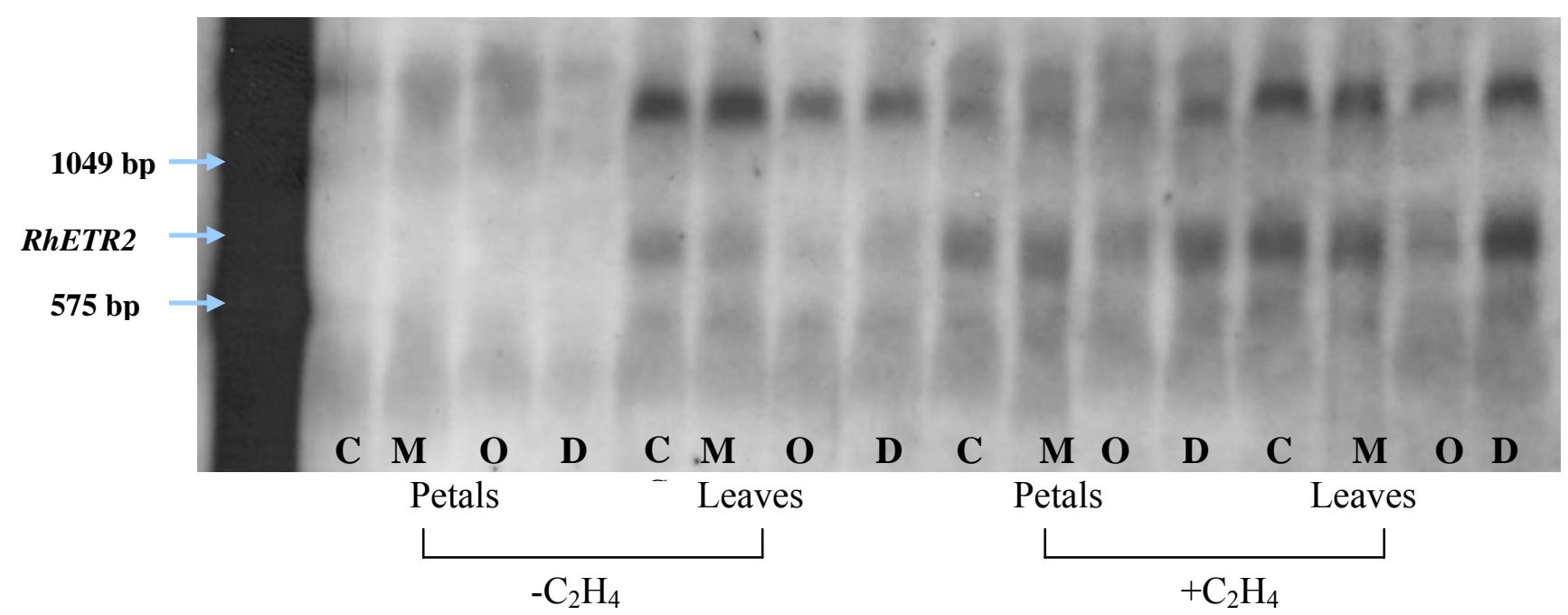

Fig. 14. Northern blot hybridization analysis of ethylene receptor, RhETR2, on $8 \mu \mathrm{g}$ total RNA obtained from petals and leaves of miniature rose cultivar 'Vanilla' in untreated (control) plant (C) and pretreatment with $200 \mathrm{nl} \mathrm{l}^{-1}$ 1-MCP (M) for $6 \mathrm{~h}$ and $1000 \mathrm{nl} \mathrm{l}^{-1}$ 1-OCP (O) and 1-DCP (D) for $4 \mathrm{~h}$ at $20^{\circ} \mathrm{C}$ after 9 days of continuous exposure of exogenous ethylene $\left(+\mathrm{C}_{2} \mathrm{H}_{4}\right)$ and without ethylene treatment $\left(-\mathrm{C}_{2} \mathrm{H}_{4}\right)$. 
Pretreating 'Vanilla' petals with 1-MCP, 1-OCP and 1-DCP led to the suppression of the mRNA level of genes for ethylene biosynthesis, ethylene perception and ethylene signal transduction in both the presence and absence of ethylene (Fig. 15A). In the untreated petals (control), ethylene induced the expression of genes for ethylene perceptions (RhETR1, RhETR2, RhETR3 and RhETR4) and other ethylene-related genes (RhCTR1, RhCTR2, RhEIN3, RhEIL, RhERF1). However, RhACS1 and RhACS2 were not affected by ethylene treatment, and in the absence of ethylene they had no effect on the expression of any of the genes investigated. (Fig. 15A).

The absence of ethylene in 'Vanilla' control leaves led to a strong expression of $R h C T R 2$, moderate expression of RhETR1, RhETR2, RhETR4, RhEIN3, RhEIL, weak expression of RhACS1, RhETR3, RhERF1 and no expression of RhACS1 (Fig. 15B). Moreover, pretreating 'Vanilla' leaves with 1-MCP, 1-OCP and 1-DCP, in the absence of ethylene, eliminated the abundance of mRNAs for all investigated genes (Fig. 15B). In 'Vanilla' control leaves, the ethylene treatment resulted in strong expression of RhETR1, RhETR2, RhETR4, RhCTR2 and $R h E I L$, moderate expression of $R h A C S 2, R h C T R 1$ and RhEIN3, weak expression of RhETR 3 and RhERF1 and no expression of RhACS1 (Fig. 15B). Furthermore, RhEIN3 was strongly and constitutively expressed after pretreating 'Vanilla' leaves with 1-MCP, 1-OCP and 1-DCP (Fig. 15B), while RhEIL was also expressed in 'Vanilla' leaves in response to 1-OCP and 1-DCP. Pretreating 'Vanilla' leaves with 1-DCP in the presence of ethylene led to a weak accumulation of RhETRI-2, RhCTRI-2 transcripts (Fig. 15B). 
Vanilla:

Petals

$-\mathrm{C}_{2} \mathrm{H}_{4}$

$+\mathrm{C}_{2} \mathrm{H}_{4}$

A

RhERF A

RhEIL

RhEIN3

RhCTR2

RhCTR1

RhETR4

RhETR3

RhETR2

RhETR1

RhACS2

RhACS1

$\beta$-Actin

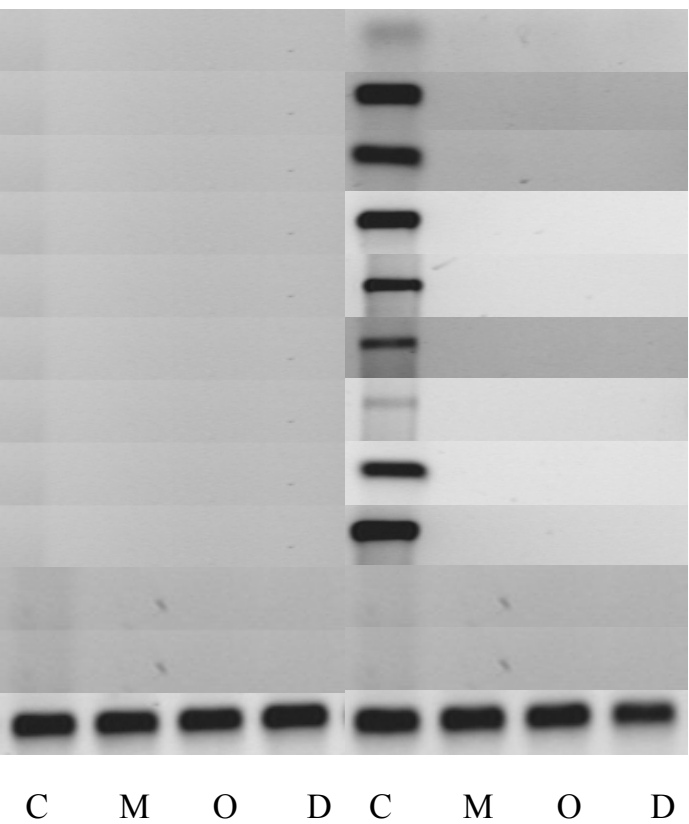

Leaves

$-\mathrm{C}_{2} \mathrm{H}_{4}$

$+\mathrm{C}_{2} \mathrm{H}_{4}$

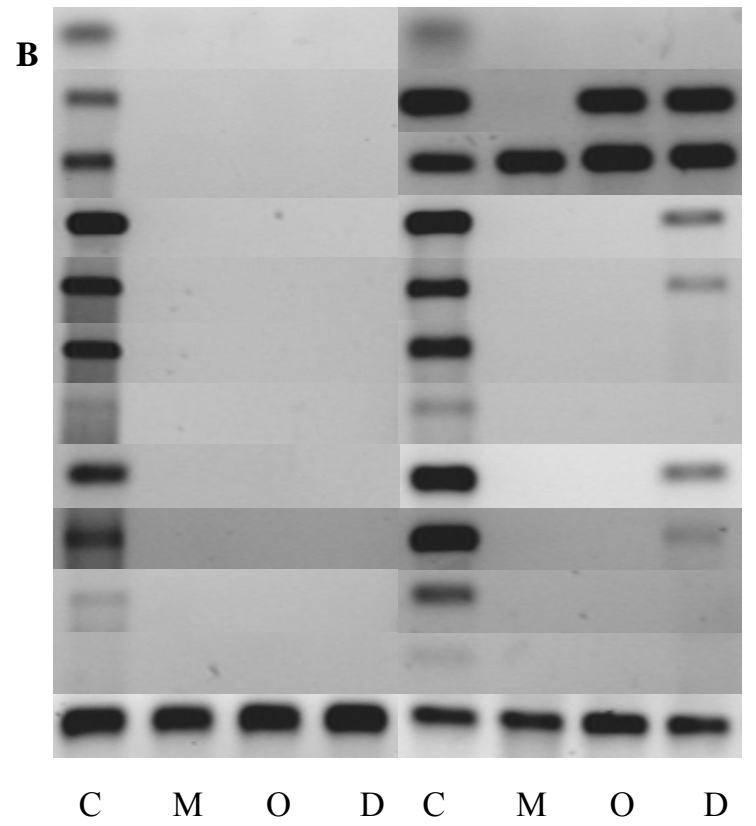

Fig. 15. Expression of genes for ethylene biosynthesis, ethylene perception and ethylene signal transduction in miniature potted rose cultivar 'Vanilla' (A, B) in untreated (control) plant and pretreatment with 1-MCP, 1-OCP and 1-DCP after 9 days of continuous exposure of exogenous ethylene $\left(+\mathrm{C}_{2} \mathrm{H}_{4}\right)$ and without ethylene treatment $\left(-\mathrm{C}_{2} \mathrm{H}_{4}\right)$. Lane 1, control (C); lane 2, 1-MCP

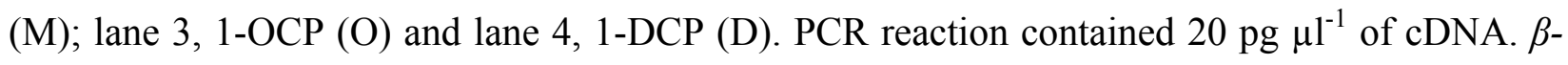
Actin was used as an internal control to normalize the amount of cDNA.

In the absence of ethylene, none of the genes were detectable at 40 cycles of PCR reaction in the petals of 'Lavender', irrespective of the treatment applied (Fig. 16A). Exposing 'Lavender' control petals to ethylene resulted in strong expression of RhETR2, RhCTR1, RhCTR2, RhEIN3 and RhEIL, moderate expression of RhETR1 and RhETR3, weak expression of RhACS1, RhACS2 and RhERF1 and no expression of RhETR4 (Fig. 16A). However, pretreating 'Lavender' petals with 1-MCP and 1-OCP inhibited the expression of all genes while strong accumulation of RhETR3, RhEIN3 and RhEIL transcripts was detectable in 'Lavender' petals pretreated with 1-DCP (Fig. 16A). 
In the absence of ethylene, pretreating 'Lavender' leaves with 1-MCP upregulated the expression of RhACS2, RhCTRI and RhEIL as compared to the control leaves (Fig. 16B), while downregulating the expression of RhETR1, RhETR2 and RhETR3 as opposed to the control. Also, 1-MCP suppressed the expression of $R h A C S 1, R h E T R 3$ and $R h E R F 1$, whereas it had no effect on the expression of RhETR4 and RhCTR2 (Fig. 16B). Similarly, pretreatment of 'Lavender' leaves with 1-OCP upregulated the expression of $R h A C S 2, R h E T R 4, R h C T R 1, R h E I N 3$, but downregulated the expression of RhETR2, RhETR3 as compared to the control leaves (Fig. 16B). 1-OCP inhibited the expression of RhACS1, RhCTR2 and RhERF1 and had no effect on the expression of RhETRl and RhEIL as compared to the control. Likewise, pretreatment of 1-DCP upregulated the expression of all RhACS and RhETR genes, but downregulated the expression of $R h C T R 2$ as opposed to control leaves. Moreover, 1-DCP inhibited the expression of RhEIN3, RhEIL and had no effect on the expression of RhCTRl and RhERFl as compared to the control (Fig. 16B).

In the presence of ethylene, pretreating 'Lavender' leaves with 1-MCP suppressed the expression of $R h A C S 1, R h E T R 4, R h C T R-2, R h E I L$ and $R h E R F 1$, while it downregulated the expression of RhETR1-2 and RhEIL, and had no effect on the expression of RhACS2, RhETR3 when compared to control 'Lavender' leaves. Similarly, pretreatment of 1-OCP inhibited the expression of RhACS1, RhETR2, RhETR4, RhCTR1-2, RhEIN3 and RhERF1 but upregulated the expression RhEIL. 1-OCP downregulated the expression of RhETRl whereas it did not affect the expression of RhACS2, RhETR3 when compared to the control (Fig 16B). Pretreating 'Lavender' leaves with 1-DCP suppressed the expression of RhACS1 and RhETR4. However, 1-DCP upregulated RhETR3 and RhCTR2 while it downregulated the expression of RhETR2, RhEIN3, RhEIL and $R h E R F 1$, but had no effect on the expression of RhACS2, RhETRI and RhETR3 when compared to the control (Fig. 16B). 
Lavender:

Petals

$-\mathrm{C}_{2} \mathrm{H}_{4}$

A

RhERF A

RhEIL

RhEIN3

RhCTR2

RhCTRI

RhETR4

RhETR3

RhETR2

RhETRI

RhACS2

RhACSI

$\beta$-Actin

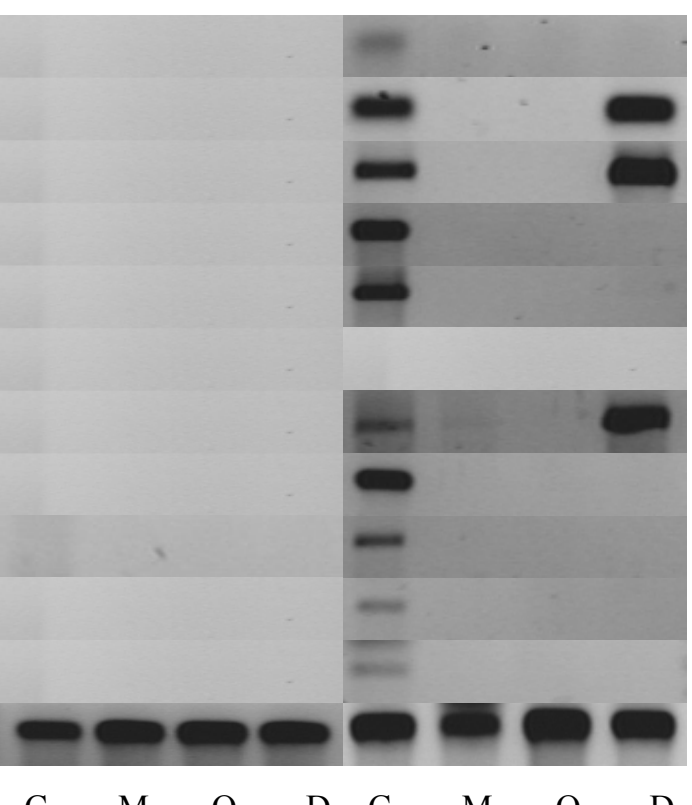

$\begin{array}{lllllllll}\text { C } & M & \text { O } & \text { D } & \text { C } & \text { M } & \text { O } & \text { D }\end{array}$
Leaves

$-\mathrm{C}_{2} \mathrm{H}_{4} \quad+\mathrm{C}_{2} \mathrm{H}_{4}$

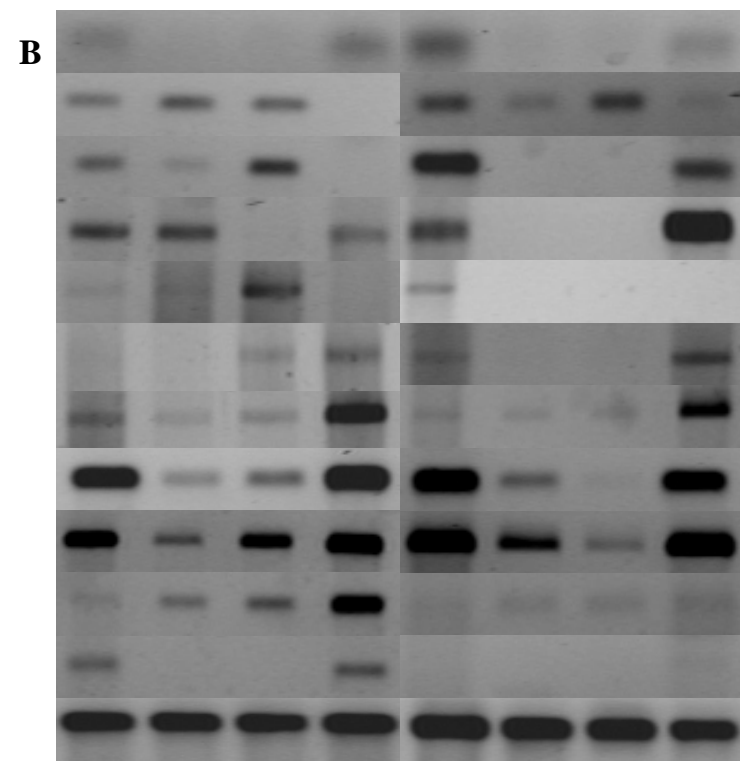

$\begin{array}{lllllllll}\mathrm{C} & \mathrm{M} & \mathrm{O} & \mathrm{D} & \mathrm{C} & \mathrm{M} & \mathrm{O} & \mathrm{D}\end{array}$

Fig. 16. Expression of genes for ethylene biosynthesis enzyme, ethylene perception and ethylene signal transduction in miniature potted rose cultivar 'Lavender' (A, B) in untreated (control) plant and pretreatment with 1-MCP, 1-OCP and 1-DCP after 9 days of continuous exposure of exogenous ethylene $\left(+\mathrm{C}_{2} \mathrm{H}_{4}\right)$ and without ethylene treatment $\left(-\mathrm{C}_{2} \mathrm{H}_{4}\right)$. Lane 1, control $(\mathrm{C})$; lane 2, 1-MCP (M); lane 3, 1-OCP (O) and lane 4, 1-DCP (D). PCR reaction contained $20 \mathrm{pg}^{-1} \mathrm{l}^{-1}$ of cDNA. $\beta$-Actin was used as an internal control to normalize the amount of cDNA loaded. 


\subsection{Discussion}

Differences in flower display quality are partly due to differences in endogenous ethylene production and/or sensitivity to exogenous ethylene (Müller et al., 1998, 2001). 'Vanilla' and 'Lavender' showed differences in ethylene sensitivity for their leaf abscission. After 9 days of continuous exposure to ethylene, 'Vanilla' control plants showed about $80 \%$ leaf drop, while display quality of 'Lavender' control plants was clearly reduced by $100 \%$ leaf drop (see chapter 2). In rose, 1-MCP protects against exogenous ethylene, increasing display life and reducing abscission of buds, flowers and leaves (Serek et al., 1994c). To investigate the role of ethylene response in miniature roses pretreated with ethylene action inhibitors, 1-MCP, 1-OCP and 1-DCP, the differential regulation of genes for ethylene biosynthesis enzyme, ethylene perception and signal transduction pathway in petals and leaves following ethylene treatment and ethylene freeair was assessed by reverse transcription-PCR (RT-PCR) analysis. Northern blot hybridization analysis was also used to compare the results from RT-PCR, but transcription signals of the ethylene receptor, RhETR2, on the gel made it difficult to distinguish the clear bands. It could be due to a cross hybridization between other members of the ethylene receptor family in miniature rose that are highly homologous. Nucleotide sequence for probe of RhETR2 is $77 \%$ identical to RhETR 4 and $63 \%$ identical to RhETRl, indicating that RhETR2 is the most homolog with RhETR4 and RhETR1. Northern blotting depends on minimal RNA degradation, efficient transfer out of the gel, and ability to reliably detect the sequence of interest (Sobel et al., 2002). This method, however, is time-consuming and requires a large quantity of RNA (Chelly and Kahn, 1994). Northern blot analysis is effective for quantifying gene expression, while RT-PCR converts RNA into first strand cDNA used as a template for PCR. Moreover, RT-PCR is more rapid and sensitive and can be more specific than northern blot analysis (Gause and Adamovicz, 1995). Gene-specific primer pairs were used since they are able to detect lower levels of gene expression. RT-PCR has a disadvantage in that, quantification is difficult because many sources of various exist, including template concentration and amplification efficiency. For RT-PCR to be accurate and quantitative, it must be analyzed in the linear range of amplification before reaction components become limiting, which occurs after 20 cycles. RT-PCR, however, with 35 cycles was shown to closely resemble northern blot analysis, indicating relatively low template amount or amplification efficiency (Dean et al., 2002). In this study, 40 cycles were used for RT-PCR analysis, which was considered to be effective in amplifying some genes, such as RhACSI and 
RhACS2. The number of cycles to reach saturation greatly depends on the amplification efficiency (Diaco, 1995). However, qualitative RT-PCR in this study was difficult to explain the variations in RNA levels. Marone et al. (2001) suggests that in most cases, a qualitative study is not sufficient to deliver a satisfactory answer for the detection of any variation in the expression levels under different experimental conditions. RT-PCR analysis showed that the expression of all genes investigated was undetectable in both 'Vanilla' and 'Lavender' petals in the absence of ethylene.

In carnation (Wang and Woodson, 1991; Woodson et al., 1992) and Orchid flowers (O'Neill et al., 1993), senescence is associated with increased ethylene production arising from concomitant increases in the activities of both ACC synthase and ACC oxidase enzymes. ACS gene is encoded by gene families, which are responsible for the differences in the regulation of expression among the different family members. Transcription of the ACS family members in Arabidopsis is differentially regulated during development, in different stimuli (Liang et al., 1992; Vahala et al., 1998). In this study, RhACSI was upregulated in 'Vanilla' control leaves by treatment of ethylene, while expression of both RhACS1 and RhACS2 were downregulated in 'Lavender' control leaves. The expression of RhACS1 and RhACS2 was also induced by ethylene treatment in 'Lavender' control petals (Fig. 16A), indicating that these genes were specifically expressed in different organs and cultivars of rose. Müller et al. (2000a) has shown that the ACC synthase transcript increases during flower senescence in 'Vanilla', with long-lasting flower longevity but remains constant at a low level in 'Bronze', a sensitive flower. However, RhACSI in rose leaves and buds is not detectable but is expressed in rose floral organs, such as ovary and sepals, and at very low level in anthers (Wang et al., 2004). Functionally, ACS genes can be classified in terms of their primary stimulus such as wounding, auxin or ripening that induces expression. The primary stimulus-induced expression of $A C S$ genes is further positively or negatively modulated by secondary stimuli (Imaseki, 1999). In tomato fruit, a massive ethylene production is responsible for increases in LE-ACS2 and LE-ACS4 transcripts (Van Der Streten et al., 1990; Olson et al., 1991; Rottmann et al., 1991; Yip et al., 1992; Lincoln et al., 1993; Barry et al., 1996). Expression of these genes in preclimacteric tomato fruit is rapidly induced and/or enhanced by ethylene (Maunder et al., 1987; Rottmann et al., 1991; Lincoln et al., 1993). Additionally, expression of ACC synthase gene is proposed to be the rate-limiting step that controls the burst of ethylene occurring during fruit ripening in Prunus mume (Mita et al., 1999). In carnation flower, 
expression of CARAS1 and CARACC3 transcripts in ovary is rapidly induced by ethylene (Have and Woltering, 1997). There might be several mechanisms that regulate the expression of ethylene biosynthesis genes during fruit ripening and flower senescence, and these mechanisms might depend, in turn, on plant species and tissue (Mita et al., 1999).

Ethylene perception requires specific receptors and a signal transduction pathway to coordinate downstream response (Müller et al., 2000a). Hua et al., (1998) showed in Arabidopsis leaves that the receptor genes are differentially regulated by ethylene. The different receptors have tissue- or stage-specific functions (Chang and Stewart, 1998). Exposure to ethylene may also increase tissue sensitivity of ethylene receptors, possibly providing a mechanism to react to low ethylene concentration (Müller et al., 2000a). The present results indicate that the putative ethylene receptor genes were upregulated in both 'Vanilla' and 'Lavender' petals in the absence of ethylene, while RhETR4 transcript was not detectable in 'Lavender' control petals (Fig. 15-16A). The expression pattern of the ethylene receptor in both cultivar petals was similar to that of leaves, in which RhETR1, RhETR2 and RhETR4 transcripts were upregulated by treatment of ethylene. However, RhETR 3 was constitutively expressed in 'Vanilla' control leaves as opposed to 'Lavender' control leaves, whereby RhETR 3 was downregulated by ethylene treatment (Fig. 15-16B). This was consistent with the findings of Müller et al. (2000a, b) with miniature rose cultivars 'Bronze' and 'Vanilla' in which, exposure to low ethylene concentrations results in upregulation of RhETR1 in 'Vanilla' flowers. RhETR2 was constitutively expressed during flower senescence, while the RhETR 3 transcript in 'Vanilla' flowers appeared to be constitutively expressed at a very low level. Tieman and Klee (1999) found that expression levels of LeETR4 and LeETR 5 transcripts in tomato are highly regulated among plant tissue with high levels of expression in productive tissues such as flower buds and mature flowers. Additionally, $\mathrm{Nr}$ gene expression can be induced by treatment with exogenous ethylene, or with treatments that induce in vivo ethylene production such as fruit ripening (Wilkinson et al., 1995; Payton et al., 1996), while other ETR homologues, LeETR1, LeETR2, LeETR4 and LeETR5, are constant throughout the ripening process (Lashbrook et al., 1998). In Arabidopsis leaves, transcript levels of ERS1, ETR2 and ERS2 genes are upregulated, while ETR1 and EIN4 are not affected by ethylene treatment (Hua et al., 1998). In mung bean seedlings, ethylene positively modulates the expression of its receptor genes (Kim et al., 1999). By contrast, exogenous ethylene does not induce PhETRI or PhETR2 mRNA accumulation in geranium, suggesting control of ethylene- 
induced petal abscission in geranium florets may lie in another member of the PhETR gene family or at a post-transcriptional point (Dervinis et al., 2000).

Regulation of ethylene response can possibly occur downstream of the ethylene receptor. RhCTR $1-2$ transcripts were upregulated after ethylene treatment in both 'Vanilla' and 'Lavender' control petals (Fig. 15A and 16A). This result was consistent with Müller et al. (2002). In 'Bronze' petals exogenous ethylene increases expression of RhCTRl and 2 and results in accelerated flower senescence (Müller et al. 2002). RhCTR1-2 were constitutively expressed in 'Vanilla' leaves after ethylene treatment and RhCTRI was also ethylene-independent expressed in 'Lavender' control leaves. These results were consistent with the Arabidopsis CTRl gene that was not ethylene inducible (Kieber et al., 1993; Guo et al., 2003). However, RhCTR2 was upregulated in ethylenetreated 'Lavender' leaves.

EIN3 and its homologues have been shown to act as a positive regulator of ethylene response (Chao et al., 1997). The present study showed that expression of RhEIN3 and RhEIL transcripts in petals and leaves of both cultivars were upregulated by treatment of ethylene (Fig. 15-16A, B). However, Müller et al. (2003) found that the RhEIN3 gene was constitutively and stably expressed in petals during flower development in cultivar 'Bronze' and 'Vanilla' and in response to ethylene and ABA. Additionally, ethylene does not affect the level of EIN3 and EIL1 genes in Arabidopsis (Chao et al., 1997; De Paepe et al., 2004) and in tobacco (Kosugi and Ohashi, 2000). In contrast to carnation flowers, the expression pattern of EIL1 (a homologue to AtEIN3) decreases during senescence, suggesting EIN3 and its homologue may possibly be involved in the regulation of ethylene sensitivity (Waki et al., 2001). However, EIN3/EIL transcription factors are not primarily regulated by ethylene at the transcriptional level (Chao et al., 1997; Tieman et al., 2001; Lee and Kim, 2003). Post-transcriptional regulation in ethylene signal transduction pathway is under regulation of a key transcription factor, EIN3. In the absence of ethylene, EIN3 is continuously degraded through the proteasome-mediated pathway, and prevents activation of its transcriptional targets. In the presence of ethylene, degradation of EIN3 is suppressed, and allows EIN3 protein levels to increase and thus promotes the ethylene response (Guo and Ecker, 2003; Potuschak et al., 2003). 
The primary ethylene response element, ERF1, is considered as an immediate target of EIN3 (Solano et al., 1998).

The protein of the newly-isolated gene $R h E R F 1$ contained a highly-conserved Ap2 DNA binding domain. This domain was the only part of the protein that exhibited significant sequence homology with ERF proteins from other species. The binding of some ERF proteins to the GCC box in the ethylene-responsive element suggests a role for proteins in the regulation of expression of the ethylene-responsive gene. As a transcription factor initiating the expression of related target genes, the ERF protein plays an important role in physiological plant processes (Qin et al., 2004).

Both 'Vanilla' and 'Lavender' miniature rose cultivars showed that RhERF1 was positively regulated when exposed to exogenous ethylene (Fig. 15-16A, B). In Arabidopsis, AtERF1, $A t E R F 2$ and AtERF5 are rapidly induced by ethylene, $12 \mathrm{~h}$ after treatment and their roles are to regulate the ethylene-inducible gene (Solano et al., 1998). The transcripts of $G b E R F$ accumulate rapidly to a high level of $G$. barbadense in the leaf, when treated with exogenous ethylene (Oin et al., 2004). This study indicated that all genes are specifically expressed in miniature roses and the levels of mRNAs are regulated in a tissue-specific manner (Shibiya et al., 2002).

Ethylene-receptor inhibitors such as 1-MCP and CPs long-chain, are thought to act by binding to a metal in the receptor (Sisler and Serek, 2003). 1-MCP suppresses the ethylene response pathway by permanently binding to a sufficient number of ethylene receptors that are bound to the copper cofactor of the ethylene receptor. Due most likely to steric hindrance, the binding is insufficient to convert the receptors to the inactive (off) state, which keeps CTR1 in its active (inhibiting) state (Binder and Bleecker, 2003). By analogy to 1-MCP, CPs long-chain binds to the receptor in the same way (Sisler et al., 2003). Lelievre et al. (1997) showed that treatment with 1-MCP results in reduced accumulation of ACC oxidase and ACC synthase transcripts, and ethylene production during chilling of pear fruits. In addition, 1-MCP antagonizes not only ethylene responses but also ethylene biosynthesis, by downregulating CsACSI and CsACO1 in citrus fruitlets (Katz et al., 2004). Moreover, 1-MCP results in the elimination of mRNA levels for receptor genes of pears during the cold treatment (El-Sharkawy et al., 2003). In miniature roses, pretreatment with 1-MCP obviously reduces the rise in autocatalytic ethylene production in 
flowers (Müller and Stummann, 2003). In the present study, pretreatment with 1-MCP and 1-OCP showed strong suppression of the expression of all genes investigated in both 'Vanilla' and 'Lavender' petals in the absence and presence of ethylene, while RhETR3, RhEIN3 and RhEIL were strongly expressed in 'Lavender' petals pretreated with 1-DCP in the presence of ethylene. 1-MCP, 1-OCP and 1-DCP eliminated the expression of all genes in 'Vanilla' leaves in the absence of ethylene, while RhEIN3 transcript was upregulated after pretreatments of 1-MCP and 1-OCP in the presence of ethylene. In contrast to 'Lavender' leaves, 1-MCP and 1-OCP pretreatments prevented the accumulation of RhEIN3 mRNA (Fig. 15-16B). The results provided evidence that at least some signal transduction genes may play an important role in ethylene perception and signal transduction pathway, and are involved in ethylene-induced flower senescence. RhEIN3 transcript is probably rate-limiting for ethylene perception and signal transduction pathway, which is regulated during flower senescence. The expression of RhEIN3 transcript in 'Vanilla' and 'Lavender' leaves pretreated with 1-MCP and 1-OCP may also be regulated at the transcriptional level. A physiological investigation can explain a large difference of display qualities in both miniature rose cultivars, when pretreated with 1-OCP and 1-MCP, caused the increased number of leaf drop in 'Vanilla' more than in 'Lavender' (Fig. 7A, B, C, D).

In accordance with 1-MCP, pretreatment of 1-OCP of 'Lavender' leaves reduced the expression of all genes investigated except for RhEIL, which was upregulated in the presence of ethylene, while 1-DCP treatment upregulated transcripts of RhETR1, RhCTR2 and RhEIN3. This may result in plants being more sensitive to ethylene. Additionally, the abundance of the individual transcripts varied with different tissues (Lashbrook et al., 1998; Tieman and Klee, 1999). 'Vanilla' was characterized by excellent longevity (Müller et al., 1998), while 'Lavender' exhibited short postharvest life. Therefore, exposure to ethylene may increase the sensitivity of tissues in 'Lavender' than that of 'Vanilla', thus resulting in reduction in postharvest longevity.

It seems possible that 'Vanilla' differs from other miniature rose flowers in its ethylene-binding site or signal transduction pathway (Müller et al., 1998). Even though 'Vanilla' seemed insensitive to ethylene, exogenous ethylene positively modulates the expression of ethylene receptor gene in flowers (Müller et al., 1998, 2000). 
Based on the genetic evidence, these results correlated with physiological investigation that 1-MCP is an ethylene-action inhibitor that binds to the receptor site competitively, thereby preventing tissue response to ethylene (Sisler and Serek, 1997). 1-MCP was more effective than any other long chain CPs in preventing flowers from exogenous ethylene. Differences between 1-MCP and CPs long chain may be due to different chemical groups attached to the cyclopropene molecule or to the side chain(s), and some of them may have interesting physiological properties (Sisler et al., 2003).

In conclusion, it is known that ethylene biosynthesis, ethylene perception and the signal transduction pathway contribute to the regulation of ethylene responses in plant tissues. These results indicated both positive and negative feedback regulation mechanism exists in miniature rose cultivars 'Vanilla' and Lavender' pretreated with ethylene receptor inhibitors, 1-MCP, 1OCP and 1-DCP, in the presence or absence of ethylene. The mechanisms that regulate the expression of genes for ethylene biosynthesis, ethylene perception and the signal transduction pathway during flower senescence might depend on plant species and tissues under investigation. 1-MCP, 1-OCP and 1-DCP treatments suppressed the expression of these genes. Therefore, an explanation of the role of the ethylene receptor inhibitors treatment in miniature roses is required to understand the mechanism of gene expression in the same response but under different conditions. 


\section{Summary}

Ethylene-mediated flower senescence, especially in ornamental crops, is a significant problem in the horticulture industry (Müller and Stummann, 2003). Exogenous ethylene reduces longevity of commercial miniature rose cultivars (Serek, 1993; Serek et al., 1994c), which showed great variation in their display life in an ethylene-free environment. Sensitivity to ethylene seems to be an important natural regulator of rose flower senescence and varies greatly among cultivars (Müller et al., 2000). Therefore, developmental regulation of ethylene response in flowers may occur at the level of hormone sensitivity (Tieman and Klee, 1999).

Ethylene action involves binding to a specific receptor (Schaller and Bleecker, 1995). In the present study, the potency of two structural analogues of 1-MCP, 1-OCP and 1-DCP, containing a side chain at 1-position, was assessed. These chemicals are new putative inhibitors of ethylene action. Their potency was evaluated by testing their ability to counteract ethylene-induced responses (display life, bud, flower and leaf drop). 1-OCP and 1-DCP protected plant tissue against the detrimental effect of ethylene for a longer time as compared to untreated (control) plant, suggesting these analogues were similar to 1-MCP (Sisler and Wood, 1988; Sisler and Serek, 1997). These two analogues exerted their effect by blocking the site of ethylene binding at the receptor. The best response with 1-OCP and 1-DCP was achieved at a concentration 5 times higher than that with 1-MCP. The results of parallel experiments with 1-MCP showed that the two analogues were less potent than 1-MCP. 1-MCP improved display life by delaying bud, flower and leaf abscission for an extended period at $200 \mathrm{nl} \mathrm{l}^{-1}$, whereas two analogues improved display life at $1000 \mathrm{nl} \mathrm{l}^{-1}$. However, no phytotoxicity was observed at higher concentrations of 1-OCP and 1-DCP. The time of exposure had an influence on the binding of two chemicals to the ethylene receptor, thus affecting the display life of the plants. 4-h exposure time to 1-OCP and 1-DCP treatments was sufficient to improve the display life for about 9 days. This was significantly different from untreated plants, which showed 80\% leaf drop after 6 days. Continuous exposure of two analogues for a longer period of time possibly resulted in saturation of the receptor and did not give any additional benefit. However, after 9 days of pretreatment with 1-OCP and 1-DCP, the tissue became sensitive to ethylene again, indicating that free binding sites on the ethylene receptor were present in the tissue at the point of recovery from the inhibition, or these binding sites were newly formed, or the sites became dissociated from the 
inhibitors (Feng et al., 2004). Miniature roses pretreated with 1-OCP and 1-DCP at the range of $5-10^{\circ} \mathrm{C}$ were not significantly different but were different from untreated (control) plants in improving display life. However, 1-MCP was more effective than 1-OCP and 1-DCP. Based on the concentrations required and the duration of protection, 'Lavender' flowers, which are sensitive to ethylene pretreated with 1-OCP, was more effective in protecting detrimental effects of ethylene than pretreated with 1-DCP. Conversely, 1-DCP pretreatment was more effective in 'Vanilla', with long-lasting flowers, than with a 1-OCP pretreatment. We also showed that 1-MCP analogues, with substitution at the 1-position and bearing eight and ten carbon side chains, are effective as blockers of the ethylene receptor.

The molecular study explained the expression of genes for ethylene biosynthesis, ethylene perception and signal transduction after pretreatment with 1-MCP, 1-OCP and 1-DCP, and afterwards continuous exposure to exogenous ethylene was performed in petals and leaves of both 'Vanilla' and 'Lavender'. It is widely recognized that ethylene biosynthesis, ethylene perception and the signal transduction pathway involve the regulation of ethylene response in plants (Wilkinson et al., 1995). To gain a better understanding of the ethylene response pathway, therefore, new partially-putative ethylene-responsive element-binding factors (ERF) were isolated from Rosa hybrida. RhERF1 showed a similar, highly-conserved DNA-binding domain consisting of 30 amino acids and shared homology with other reported ERF-domain containing proteins.

Northern blot hybridization analysis was used to compare the results of RT-PCR. However, it was difficult to distinguish transcriptional signals of ethylene receptor, RhETR2, which is a high homologue to other members of the ethylene receptor family in miniature roses, such as RhETRI and RhETR4. Thus RT-PCR was utilized to compare the expression level of genes investigated in miniature potted roses. RT-PCR analysis revealed that the expression of mRNAs for many ethylene-related genes in both rose cultivars was regulated in a tissue-specific manner. Also, differential cultivars suggest they have different roles in ethylene biosynthesis enzyme, ethylene perception and signal transduction pathway. In the petals of the two miniature rose cultivars in the absence of ethylene, no expression of mRNAs for any genes in any treatments was detectable. However, the accumulation of mRNA transcripts was upregulated by ethylene in control petals. In vegetative tissues like leaves, the level of mRNAs was detectable in both untreated cultivars in 
the absence and presence of ethylene indicating the ethylene signaling pathway contains both positive and negative regulator genes. This implied that some proteins serve to induce the ethylene response while others suppress it (Chen et al., 2005). In 'Vanilla' control leaves, RhACS1, RhACS2, RhETR1, RhETR2, RhETR4, RhEIN3, RhEIL and RhERF1 transcripts were upregulated by ethylene, while RhETR3 and RhCTRI-2 were constitutively expressed. In 'Lavender' untreated leaves, RhACS1, RhACS2 and RhETR3 transcripts were downregulated, while RhETR1, RhETR2, RhETR4, RhCTR1-2, RhEIN3, RhEIL and RhERF1 transcripts were upregulated by ethylene. Pretreatment with ethylene receptor inhibitors, 1-MCP, 1-OCP and 1-DCP, suppressed the expression of all genes investigated in 'Vanilla' petals, in the absence or presence of ethylene, while pretreatment with 1-DCP upregulated the expression of RhETR3, RhEIN3 and RhEIL transcripts in 'Lavender' petals in the presence of ethylene. In 'Vanilla' leaves, in the absence of ethylene, all chemicals suppressed the expression of all genes investigated, whereas the level of RhEIN3 mRNA was upregulated by pretreatment of ethylene receptor inhibitors in the presence of ethylene, while the accumulation of RhEIN3 mRNA was suppressed in 'Lavender' leaves. These results suggest that the expression of RhEIN3 transcript in 'Vanilla', which is insensitive to ethylene, and 'Lavender', with short-flower life, may be rate-limiting for ethylene perception and the signal transduction pathway that is involved in ethylene-induced flower senescence. With physiological investigation, this can explain a great difference of display quality between 'Vanilla' and 'Lavender' when pretreated with 1-OCP and 1-MCP. Pretreating 'Lavender' leaves with 1-MCP and 1-OCP in the presence of ethylene suppressed the expression of other genes but upregulated the accumulation of RhETR1, RhETR2 and RhEIL transcripts, respectively, while pretreatment of 'Lavender' leaves with 1-DCP upregulated RhETR1, RhETR4, RhCTR2, RhEIN3 and RHEIL transcripts.

The regulation of genes for the ethylene biosynthesis enzyme, ethylene perception and signal transduction pathway in miniature rose is partly due to the differences in sensitivity of cultivars and tissues to ethylene. Exposure to ethylene may increase the sensitivity of tissues in 'Lavender' than that of 'Vanilla', thus resulting in reduction in postharvest longevity. This might depend on plant species and tissue. However, 1-MCP was more potent in protecting plants against ethylene than 1-OCP and 1-DCP, probably by blocking the binding site of ethylene on the ethylene receptor in plant tissues, thus controlling ethylene responses (Sisler and Wood, 1988; Sisler and Serek, 1997). 1-MCP is a highly strained olefin, which binds in an apparently irreversible manner 
to the ethylene receptor. Also, it seems that 1-OCP and 1-DCP inhibited ethylene action in a similar mode to that suggested for 1-MCP. These results were consistent with physiological investigation except after a certain period, when the plant tissues resumed sensitivity to ethylene (Sisler and Serek, 1997). 


\section{References}

Abeles, A.B., Morgan, P.W. and Saltveit, Jr. M.E. (1992). Ethylene. In: Plant Biology. (2 ${ }^{\text {nd }}$ Ed.). Academic Press. San Diego. pp. 414. ISBN: 0-1214-1451-1.

Adam, D.O. and Yang, S.F. (1979). Ethylene biosynthetic identification of 1-aminocyclopropane1-carboxylic acid as intermediate in the conversion of methionine to ethylene. Proc. Natl. Acad. Sci. USA 76: 170-176.

Al Dulayymi, A.R., Al Dulayymi, J.R., Baird, M.S., Koza, G. (1997). Simple four and five carbon cyclopropane and cyclopropenes synthetic intermediates. Russ. J. Org. Chem. 33: 798-816. Al Dulayymi, J.R., Baird, M.S., Simpson, M.J., Nyman, S. (1996). Structure based interference with insect behaviour cyclopropenes analogs of pheromones containing z-Alkenes. Tetrahadron 52: 12509-12520.

Allen, M.D., Yamasaki, K., Ohme-Takagi, M., Tateno, M. and Suzuki, M. (1998). A novel mode of DNA recognition by a beta-sheet revealed by the solution structure of the GCC-box binding domain in complex with DNA. EMBO J. 17: 5458-5496.

Alonso, J.M., Hirayama, T., Roman, G., Nourizadeh, S and Ecker, J.R. (1999). EIN2, a bifunctional transducer of ethylene and stress responses in Arabidopsis. Science 284: 2148-2152.

Altschul, S.F., Madden, T.L., Schäffer, A.A., Zhang, J., Zhang, Z., Miller, W. and Lipman, D.J. (1997). Gapped BLAST and PSI-BLAST: A new generation of protein database search programs. Nucleic Acids Res. 25(17): 3389-3402.

Aravind, L. and Ponting, C.P. (1997). The GAF domain-an evolutionary link between diverse phototransducting proteins. Trends Biochem. Sci. 22: 458-459.

Barry, C.S., Blume, b., Bouzayen, M., Cooper, W., Hamilton, A.J. and Grierson, D. (1996). Differential expression of the 1-aminocyclopropane-1-carboxylate oxidase gene family of tomato. Plant J. 9: 525-535.

Bernard, P., Gabant, P., Bahassi, E.M. and Couturier, M. (1994). Positive selection vectors using the F Plasmid $c c d$ B killer gene. Gene 148: 71-74.

Beyer Jr., E.M. (1976). A potent inhibitor of ethylene action in plants. Plant Physiol. 58: 268-271. Beyer, Jr. E.M. and Sundin, O. (1978). ${ }^{14} \mathrm{C}_{2} \mathrm{H}_{4}$ Metabolism in morning glory flowers. Plant Physiol. 61: 896-899. Bieleski, R.D. and Reid, M.S. (1992). Physiological changes accompanying senescence in the ephemeral daylily flower. Plant Physiol. 98: 1042-1049. 
Binder, B.M. and Bleecker, A.B. (2003). A model for ethylene receptor function and 1-methylcyclopropene action. Acta Hortic. (In press).

Blankership, S.M. and Dole, J.M. (2003). 1-Methylcyclopropene: a review. Postharvest Biol. Tech. 28: 1-25.

Bleecker, A.B. (1999). Ethylene perception and signaling: an evolutionary perspective. Trends Plant Sci. 4: 269-274.

Bleecker, A.B., Estelle, M.A., Somerville, C. and Kende, H. (1988). Insensitivity to ethylene conferred by a dominant mutation in Arabidopsis thaliana. Science 241: 1086-1089.

Boller, T. (1991). Ethylene in pathogenesis and disease resistance. In: The plant hormone ethylene. Matoo, A.K. and Suttle, J.C. (Eds.). CRC press. Boca Raton. pp. 293-314. ISBN: 0-8493-4566-9.

Boller, T., Herner, R.C. and Kende, H. (1999). Assay for and enzymatic formation of an ethylene precursor, 1-aminocyclopropane-1-carboxylic acid. Planta 145: 293-303.

Borochov, A. and Woodson, W.R. (1989). Physiology and biochemistry of flower petal senescence. Hort Rev. 11: 15-43.

Botha, M-L., Whitehead, C.S. and Halevy, A.H. (1998). Effect of octanoic acid on the ethylenemediated flower induction in Dutch iris. Plant Growth Regul. 25: 47-51.

Bovy, A.G., Angenent, G.C., Dons, H.J.M. and Van Altvorst, A.C. (1999). Heterologous expression of the Arabidopsis etr1-1 allele inhibits the senescence of carnation flowers. Mol. Breed. 5: 301-308.

Brandt, A.S. and Woodson, W.R. (1992). Variation in flower senescence and ethylene biosynthesis among carnations. HortSci. 27(10): 1100-1102.

Brown, J.H., Legge, R.L., Sisler, E.C., Baker, J.E. and Thompson, J.E. (1986). Ethylene binding to senescing carnation petals. J. Exp. Bot. 37(177): 526-534.

Burg, S.P. and Burg, E.A. (1967). Molecular requirements for the biological activity of ethylene. Plant Physiol. 42: 144-152.

Büttner, M. and Singh, K.B. (1997). Arabidopsis thaliana ethylene responsive element binding protein $(A t E B P)$, an ethylene-inducible, GCC box DNA-binding protein interacts with an ocs element binding protein. Proc. Natl. Acad. Sci. USA 94: 5961-5966.

Cameron, A.C. and Reid, M.S. (2001). 1-MCP blocks ethylene-induced petal abscission of Pelargonium peltatum but the effect is transient. Postharvest Biol. Tech. 22: 169-177. 
Cancel, J.D., Larsen, P.B. (2002). Loss-of-function mutations in the ethylene receptor ETRI cause enhanced sensitivity and exaggerated response to ethylene in Arabidopsis. Plant Physiol. 129: $1557-1567$.

Chang, C. and Meyerowitz, E.M. (1995). The ethylene hormone response in Arabidopsis: a eukaryotic two-component signaling system. Proc. Natl. Acad. Sci. USA 92: 4129-4133.

Chang, C. and Shockey, J.A. (1999). The ethylene response pathway: signal perception to gene regulation. Curr. Opin. Plant Biol. 2: 352-358.

Chang, C. and Stewart, R.C. (1998). The two-component system. Plant Physiol. 117: 723-731.

Chang, C., Kwok, S.F., Bleecker, A.B. and Meyerowitz, E.M. (1993). Arabidopsis ethyleneresponse gene ETRI: similarity of product to two-component regulators. Science 262: 539-544.

Chao, Q., Rothenberg, M., Solano, R., Roman, G., Terzaghi, W. and Ecker, J.R. (1997). Activation of the ethylene gas response pathway in Arabidopsis by the nuclear protein ETHYLENE-INSENSITIVE3 and related proteins. Cell 89: 1133-1144.

Chen, Y-F., Rendlett, M.D., Findell, J.L. and Schaller, G.E. (2002). Localization of the ethylene receptor ETRI to the endoplasmic reticulum of Arabidopsis. J. Bio. Chem. 277(22): 19861-19866.

Ciardi, J.A. and Klee, H. (2001). Regulation of ethylene-mediated responses at the level of the receptor. Annals Bot. 88: 813-822.

Clark, K.L., Larsen, P.B., Wang, X. and Chang, C. (1998). Association of the Arabidopsis CTRI Raflike kinase with the ETRI and ERS ethylene receptors. Proc Natl. Acad. Sci. USA 95: 5401-5406.

Closs, G.L. (1996). Cyclopropenes. Adv. Alicyclic Chem. 1: 53-127.

De Paepe, A., Vuylsteke, M. Van Hummelen, P., Zabeau, M. and Van Der Straeten, D. (2004). Transcriptional profiling by cDNA-AFLP and microarray analysis reveals novel insights into the early response to ethylene in Arabidopsis. Plant J. 39: 537-559.

Dean, J.D., Goodwin, P.H. and Hsiang, T. (2002). Comparison of relative RT-PCR and northern blot analyses to measure expression of $\beta-1,3-$ Glucanase in Nicotiana benthamiana infected with Collectotrichum destructivum. Plant Mol. Biol. Rep. 20: 347-356.

Dervinis, C., Clark, D.G., Barrett, J.E. and Nell, T.A. (2000). Effect of pollination and exogenous ethylene on accumulation of ETR1 homologue transcripts during flower petal abscission in geranium (Pelargonium x hortorum L.H. Bailey). Plant Mol. Biol. 42: 847-856.

Diaco, R. (1995). Practical considerations for the design of quantitative PCR analysis. In: PCR Strategies. Innis, M.A., Gelfand, D.H. and Sninsky, J.J (Eds.). Academic Press. San diago. pp. 84-108. ISBN: 0-1237-2182-2. 
Dupille, E. and Sisler, E.C. (1995). Effects of an ethylene receptor antagonist on plant material. In: Postharvest physiology and technologies of horticultural commodities: Recent Advances. Aït-Oubahou, A. and Elotmani, M. (Eds.). Institute Agronomique et Veterinaire Hassan II. pp. 294-301. ISBN: 9-9819-8422-1.

Ecker, J. R. (1995). The ethylene signal transduction pathway in plants. Science 268: 667-675. El-sharkawy, I., Jones, B., Li, Z.G., Lelièvre, J.M., Pech, J.C. and Latchè, A. (2003). Isolation and characterization of four ethylene perception elements and their expression during ripening in pears (Pyrus communis L.) with/without cold requirement. J. Exp. Bot. 54(387): 1615-1625. Feng, X., Apelbaum, A., Sisler, E.C. and Goren, R. (2004). Control of ethylene activity in various plant systems by structural analogues of 1-methylcyclopropene. Plant Growth Regul. 42: 29-38.

Finkelstein, R.R., Wang, M.L., Lynch, T.C., Rao, S. and Goodman, H.M. (1998). The Arabidopsis abscissic acid response locus ABI4 encodes and APETALA2 domain protein. Plant Cell 10: 1043-1054.

Fluhr, R. and Mattoo, A.K. (1996). Ethylene-biosynthesis and perception. Crit. Rev. Plant Sci. 15: 479-523.

Fujimoto, S.Y., Ohta, M., Usui, A., Shinshi, H. and Ohme-takagi, M. (2000). Arabidopsis ethylene-responsive element binding factors act as transcriptional activators or repressors of GCC box mediated gene expression. Plant Cell 12: 393-404.

Gause, W.C. and Adamovicz, J. (1995). Use of PCR to quantitate relative differences in gene expression. In: PCR Primer: A laboratory manual. Dieffenbach, C.W. and Dveksler, G.S. (Eds.). Cold Spring Harbor Laboratory Press. Cold Spring harbor. pp. 293-311. ISBN: 0-8796-9653-2. Geo, Z., Chen, Y.F., Randlett, M.D. Zhao, X.C., Findell, J.L., Kieber, J.J. and Schaller, G.E. (2003). Localization of the Raf-like kinase CTR1 to the endoplasmic reticulum of Arabidopsis through participation in ethylene receptor signaling complexes. J. Biol. Chem. 278: 34725-34732. Goren, R., Mattoo, A.K. and Anderson, J.D. (1984). Ethylene binding during leaf development and senescence and its inhibition by silver nitrate. Plant Physiol. 177: 243-248.

Gu, Y. Q., Wildermuth, M. C., Chakravarthy, S., Loh, Y. T., Yang, C., He, X., Han, Y. and Martin, G. B. (2002). Tomato transcription factors Pti4, Pti5, and Pti6 activate defense responses when expressed in Arabidopsis. Plant Cell 14: 817-831.

Guo, H. Ecker, J.R. (2003). Plant response to ethylene gas are mediated by SCF(EBF1/EBF2)dependent proteolysis of EIN3 transcription factor. Cell 115: 667-677. 
Guzmán, P. and Ecker, J.R. (1990). Exploiting the triple response of Arabidopsis to identify ethylene-related mutants. Plant Cell 2: 513-523.

Halevy, A.H. and Mayak, S. (1979). Senescence and postharvest physiology of cut flower. Part 1. Hort. Rev. 1: 204-236.

Halevy, A.H. and Mayak, S. (1981). Senescence and postharvest physiology of cut flower. Part 2. Hort. Rev. 3: 59-143.

Halevy, A.H., Porat, R., Spiegelstein, H, Borochov, A, Botha, L. and Whitehead, C.S. (1996). Short-chain fatty acids in the regulation of pollination-induced ethylene sensitivity of Phalaenopsis flowers. Physiol. Plant 97: 469-474.

Halevy, A.H., Whitehead, C.S. and Kofranek, M. (1984). Does pollination induce corolla abscission of cyclamen flowers by pollination ethylene production? Plant Physiol. 75: 1090-1093. Hao, D., Ohme-Takagi, M. and Sarai, A. (1998). Unique mode of GCC box recognition by the DNA-binding domain of ethylene responsive element binding factor ( $E R F$ domain) in plant. J. Biol. Chem. 273: 26857-26861.

Higgens, D.G. (1994). CLUSTAL V: multiple alignments of DNA and protein sequences. Methods Mol. Biol. 25; 307-318.

Hiriyama, T., Kieber, J.J., Hirayama, N., Kogan, M, Guzman, P., Nourizadeh, S., Alonso, J.M., Dailey, W.P., Dancis, A. and Ecker, J.R. (1998). Responsivet-to-antagonist1, a Menkes/Wilson disease-related copper transporter, is required for ethylene signaling in Arabidopsis. Cell 97: 383-393.

Holden, M.J., Marty, J.A. and Singh-Cundy, A. (2003). Pollination-induced ethylene promotes the early phase of pollen tube growth in Petunia inflate. J. Plant Physiol. 160: 261-269.

Hongwei, G. and Ecker, J.R (2004). The ethylene signaling pathway: new insight. Plant Biol. 7: 40-49.

Hsieh, Y.C. and Sacalis, J. (1987). Levels of ACC in various floral portions during aging of cut carnations. J. Amer. Soc. Hort. Sci. 111: 942-944.

Hua, J. and Meyerowitz, E.M. (1998). Ethylene responses are negatively regulated by a receptor gene family in Arabidopsis thaliana. Cell 94: 261-271.

Hua, J., Chang, C., Sun, Q. and Meyerowitz, E.M. (1995). Ethylene insensitivity conferred by Arabidopsis ERS gene. Science 269: 1712-1714.

Hua, J., Sakai, H., Nourizadeh, S., Chen, Q.C., Bleecker, A.B., Ecker, J.R. and Meyerowitz, E.M. (1998). EIN4 and ERS2 are members of the putative ethylene receptor family in Arabidopsis. Plant Cell 10: 1321-1332. 
Imaseki, H. (1999). Control of ethylene synthesis and metabolism. In: Biochemistry and Molecular Biology of Plant Hormones. Hookaas, P.J.J., Hall, M.A. and Libbenga, K.R. (Eds.). Elsevier Science. Amsterdam, pp. 209-244. ISBN: 0-4448-9825-5.

Jofuku, K.D., den Boer, B.G.W., Van Montagu. M. and Okamuro, J.K. (1994). Control of Arabidopsis flower and seed development by the homeotic gene APETALA2. Plant Cell 6: 1211-1225. Jones, M.L. and Woodson, W.R. (1999). Interorgan signaling following pollination in carnations. J. Amer. Soc. Hort. 124(6): 598-604.

Katz, E., Martinez, P., Riov, J., Weiss, D. And Goldschmidt, E.E. (2004). Molecular and physiological evidence suggests the existence of a system II-like pathway of ethylene production in non-climacteric Citrus fruit. Planta 219: 243-252.

Kehoe, D.M. and Grossman, A.R. (1996). Similarity of a chromatic adaptation sensor to photochrome and ethylene receptors. Science 273: 1409-1412.

Kende, H and Hanson, A.D. (1976). Relationship between ethylene evolution and senescence in morning-glory flower tissue. Plant Physiol. 57: 523-527.

Kende, H. (1989). Enzymes of ethylene biosynthesis. Plant Physiol. 91: 1-4.

Kende, H. (1993). Ethylene biosynthesis. Annu. Rev. Plant Physiol. Plant Mol. Biol. 44: 283-307.

Kende, H. and Buamgartner, B. (1974). Regulation of aging in flowers of Ipomoea tricolor by ethylene. Planta 116: 279-289.

Kenebei, Z., Sisler, E.C. Winkelmann, T. and Serek, M. (2003a). Effect of 1-octylcyclopropene and 1-methylcyclopropene on vase life of sweet pea (Lathyrus odoratus L.) flowers. J. Hortic. Sci. Biotech. 78(4): 433-436.

Kenebei, Z., Sisler, E.C. Winkelmann, T. and Serek, M. (2003b). Efficacy of new inhibitors of ethylene perception in improvement of display life of kalanchoë (kalanchoë blossfeldiana Poelln.) flowers. Postharvest Biol. Tech. 30(2): 169-176.

Ketsa, S. (1989). Vase life characteristics of inflorescences of dendrobium 'Pompadour'. J. Hort. Sci. 64: 611-615.

Ketsa, S., and Rugkong, A. (2000). Ethylene production, senescence and ethylene sensitivity of Dendrobium 'Pompadour' flowers. J. Hortic. Sci. Biotech. 75: 149-153.

Kieber, J.J., Rothenberg, M., Roman, G., Feldmann, K.A. and Ecker, J.A. (1993). CTR1, a negative regulator of the ethylene response pathway in Arabidopsis, encodes a member of the Raf family of protein kinases. Cell 72: 427-441. 
Kim, J.H., Lee, J.H., Joo, S. and Kim, W.T. (1999). Ethylene regulation of an ERS1 homolog in mung bean seedlings. Physiol. Plant 106: 90-97.

Kim, W.T., Campbell, A., Moriguchi, T., Yi, C.H. and Yang, S.F. (1997). Auxin induces three genes encoding 1-aminocyclopropene-1-carbixylate synthase in mung bean hypocotyls. J. Plant Physiol. 150: 77-84.

Kosugi, S. and Ohasi, Y. (2000). Cloning and DNA-binding properties of a tobacco EthyleneInsensitive3 (EIN3) homolog. Nucleic Acids Res. 28: 960-967.

Kyriakis, J.M., App, H., Zhang, X.F., Banerjee, P., Brautigan, D.L., Rapp, U.R. and Avruch, J. (1992). Raf-1 activates MAP kinase-kinase. Nature 358: 417-421.

Larsen, P.B., Ashworth, E.N., Jones, M.L. and Woodson, W.R. (1995). Pollination-induced ethylene in carnation: role of pollen tube growth and sexual compatibility. Plant Physiol. 108: 1405-1412.

Lashbrook, C.C., Tieman, D.M. and Klee, H.J. (1998). Differential regulation of the tomato ETR gene family throughout plant development. Plant J. 15: 243-252.

Lay-Yee, M., Stead, A.D. and Reid, M.S. (1992). Flowers senescence in daylily (Hemerocallis). Physiol. Plant 86: 308-314.

Lee, J.H. and Kim, W.T. (2003). Molecular and biochemical characterization of proteins. Plant Physiol. 132: 1475-1488.

Lelièvre, J.M., Tichit, L., Dao, P., Fillion, L., Nam, Y.W., Pech, J.C. and Latchè, A. (1997). Effects of chilling on the expression of ethylene biosynthetic genes in Passe-Crassane pear (Pyrus communis L.) fruits. Plant Mol. Biol. 33: 847-855.

Liang, X., Abel, S., Keller, J.A., Shen, N.C. and Theologis, A. (1992). The 1-aminocyclopropane1-carboxylate synthase gene family of Arabidopsis thaliana. Proc. Natl. Acad. Sci. USA 89: 11046-11050.

Lincoln, J.E., Campbell, A.D., Oetiker, J., Rottmann, W.H., Oeller, P.W., Shen, N.F. and Theologis, A. (1993). Le-Acs4, a fruit ripening and wound-induced 1-aminocyclopropene-1carboxylate synthase gene of tomato (Lycopersicon esculentum): expression in Escherichia coli, structural characterization, expression characteristics, and phylogenetic analysis. J. Biol. Chem. 268: 19422-19430.

Lukaszewski, T.A. and Reid, M.S. (1989). Bulb-type flower senescence. Acta Hortic. 261: 59-62. Maeda, T., Wurgler-Murphy, S.M. and Saito, H. (1994). A two-component system that regulates an osmosensing MAP kinase cascade in yeast. Nature 369: 242-245. 
Marone, M., Mozzetti, S., De Ritis, D., Pierelli, L. and Scambia, G. (2001). Semiquantitative RT-PCR analysis to assess the expression levels of multiple transcripts from the same sample. Biol. Proced. Online. 3(1): 19-25.

Marousky, F.J. and Harbaugh, B.K. (1979). Ethylene-induced floret sleepiness in kalanchoe blossfeldiana Poelln. HortSci. 14(4): 505-507.

Mayak, S. and Kofranek, A. (1976). Altering the sensitivity of carnation flowers (Dianthus caryophyllus L.) to ethylene. J. Amer. Soc. Hortic. Sci. 101: 203-206.

Mayak, S. and Tirosh, T. (1993). Unusual ethylene-related behavior in senescing flowers of the carnation Sandrosa. Physiol. Plant 88: 420-426.

Menke, F.L., Champion, a., Kijne, J.W. and Memelink, J. (1999). A novel jasmonate- and elicitor-responsive element in the periwinkle secondary metabolite biosynthesis gene Str interacts with a jasmonate- and elicitor-inducible AP2-domain transcription factor, ORCA2. EMBO J. 16: 4455-4463.

Mibus, H. (2003). Physiologische und molekulargenetische Charakterisierung der Geschlechtsausprägung bei der Gurke (Cucumis sativus L.): unter besonderer Berücksichtigung der Ethylensynthese und der Ethylensignaltransduktion. Dissertation. Universität Hannover, 221 pp. Mibus, H. and M. Serek, 2004. Easy PCR Method to isolate unknown ACC synthase genes in ornamental plant species. Acta Hortic. 682: 307-311.

Mita, S., Kirita, C., Kato, M. And Hyodo, H. (1999). Expression of ACC synthase is enhanced earlier than that of ACC oxidase during fruit ripening of mume (Prunus mume). Physiol. Plant 39: 1209-1217.

Mor, Y. Halevy, A.H., Spiegelstein, H. And Mayak, S. (1985). The site of 1-aminocyclopropane1-carboxylic acid synthesis in senescing carnation petals. Physiol. Plant 65: 196-202.

Mor, Y., Reid, M.S. and Kofranek, A.M. (1984). Pulse treatment with silver thiosulfate and sucrose improve the vase life of sweet peas. J. Amer. Soc. Hort. Sci. 109(6): 866-868.

Müller, R. and Stummann, B.M. (2003). Postharvest physiology; ethylene. In: Encyclopedia of Rose Science. Roberts, A.V., Debener, T. and Gudin, S. (Eds.). Elsevier Ltd. Oxford. pp. 557-564. ISBN: 0-12-227620-5.

Müller, R., Anderson, A. and Serek, M. (1998). Differences in display life of miniature potted roses (Rosa hybrida L.). Sci. Hortic. 76: 59-71. 
Müller, R., Lind-Iversen, S., Stummann, B.M., and Serek, M. (2000a). Expression of genes for ethylene biosynthetic enzymes and an ethylene receptor in senescing flowers of miniature roses. J. Hortic. Sci. Biotech. 75: 12-18.

Müller, R., Owen, C.A., Xue, Z-T., Walender, M. and Stummann, B.M. (2002a). Characterization of two CTR-like protein kinases in Rosa hybrida and their expression during flower senescence and in response to ethylene. J. Exp. Bot. 53: 1223-1225.

Müller, R., Stummann, B.M., and Serek, M. (2000b). Characterization of an ethylene receptor family with differential expression in rose (Rosa hybrida L.) flowers. Plant Cell Rep. 19: 1232-1239.

Müller, R., Stummann, B.M., Sisler, E.C. and Serek, M. (2001). Cultivar differences in regulation of ethylene production in miniature rose flowers (Rosa hybrida). Gartenbuawissenschaft 66(1): 34-38.

Nichols, R. (1968). The response of Carnations (Dianthus caryiophyllus) to ethylene. J. Hort. Sci. 43: 355-339.

Nichols, R. (1977). Sites of ethylene production in the pollinated and unpollinated senescing carnation (Dianthus caryiophyllus) inflorescence. Planta 135: 155-159.

Nichols, R. Bufler, G., Mor, Y., Fujino, D.W. and Reid, M.S. (1983). Changes in ethylene production and 1-aminocyclopropane-1-carboxylic acid content of pollinated carnation flowers. Plant Growth Regul. 2: 1-8.

Noodén, L.D., Guiamét, J.J. and John, I. (1997). Senescence mechanisms. Physiol. Plant 101:746-753. O'Neill, S.D., Nadeau, J.A., Zhang, X.S., Bui, A.Q. and Halevy. A.H. (1993). Interorgan regulation of ethylene biosynthetic genes by pollination. Plant Cell 5: 419-432.

Ohme-Takagi, M. and Shinshi, H. (1995). Ethylene-inducible DNA binding proteins that interact with an ethylene-responsive element. Plant Cell 7: 173-182.

Ohta, M., Matsui, K., Hiratsu, K., Shinshi, H. and Ohme-Takagi, M. (2001). Repression domains of class II $E R F$ transcriptional repressors share an essential motif for active repression. Plant Cell 13: 1959-1968.

Olson, D.C., White, J.A., Edelman, L., Harkins, R.N. and Kende, H. (1991). Differential expression of two genes for 1-aminocyclopropene-1-carboxylate synthase in tomato fruits. Proc. Natl. Acad. Sci. USA 88: 5340-5344.

Overbeek, J.H.M. and Woltering, E.J. (1990). Synergistic effect of 1-aminocyclopropane-1-carboxylic acid and ethylene during senescence of isolated carnation petals. Physiol. Plant 79:368-376. 
Parkinson, J.S. (1993). Signal transduction schemes of bacteria. Cell 78: 857-871.

Payton, S., Fray, R.G., Brown, S. and Grierson, D. (1996). Ethylene receptor expression is regulated during fruit ripening, flower senescence and abscission. Plant Mol. Biol. 13: 639-651. Peiser, G. (1986). Level of 1-aminocyclopropane-1-caboxylic acid (ACC) synthase activity, ACC and ACC-conjugate in cut carnation flowers during senescence. Acta Hortic. 181: 99-104. Pelech, S.L. and Sanghera, J.S. (1992). Mitogen-activated protein kinases: Versatile transducers for cell signaling. Trends Biochem. Sci. 17: 264-273.

Pemberton, H.B., Kelly, J.W. and Ferare, J. (2003). Pot rose production, Introduction and world market. In: Encyclopedia of Rose Science. Roberts, A.V., Debener, T. and Gudin, S. (Eds.). Elsevier Ltd. Oxford. pp. 587-593. ISBN: 0-1222-7620-5.

Philosoph-Hadas, S., Meir, S. and Aharoni, N. (1985). Autoinhibition of ethylene production in tobacco leaf discs: enhancement of 1-aminocyclopropane-1-carboxylic acid conjugation. Physiol. Plant 63(4): 431-437.

Porat, R. Borochov, A. and Halevy, A.H. (1994). Pollination-induced changes in ethylene production and sensitivity to ethylene in cut dendrobium orchid flowers. Sci. Hortic. 58: 215-221. Porat, R. Halevy, A.H. Serek, M. and Borochov, A. (1995). An increase in ethylene sensitivity flowing pollination is the initial event triggering an increase in ethylene production and enhanced senescence of Phalaenopsis orchid flowers. Physiol. Plant 93: 778-784.

Porat, R., Reuveny, Y., Borochov, A. and Halevey, A.H. (1993). Petunia flower longevity: the role of sensitivity to ethylene. Physiol. Plant 89: 291-294.

Potuschak, T. Lechner, E., Parmentier, Y. Yanagisawa, S., Grava, S., Koncz, C. and Genschik, P. (2003). EIN3-dependent regulation of plant ethylene hormone by two Arabidopsis F box proteins: $E B F 1$ and $E B F 2$. Cell 115: 679-689.

Qin, J., Zhao, J., Zuo, K., Cao, Y., Ling, H., Sun, X. and Tang, K. (2004). Isolation and characterization of an ERF-like gene from Gossypium barbadense. Plant Sci.167: 1383-1389.

Raikhel, N.V. (1992). Nuclear targeting in plants. Plant Physiol. 100: 1627-1632.

Ramassamy, S., Olmos, E., Bouzayen, M., Pech, J.C. and Latché, A. (1998). 1-aminocyalopropane1-carboxylate oxidase of apple fruit is periplasmic. J. Exp. Bot. 49: 1909-1915.

Reichmann, J.L. and Meyerowitz, E.M. (1998). The AP2/EREBP family of plant transcription factors. Biol. Chem. 379: 633-646.

Reid, M.S. (1989). Role of ethylene in flower senescence. Acta Hortic. 261: 157-169. 
Reid, M.S. and Wu, M.J. (1991). Ethylene in flower development and senescence. In: The plant hormone ethylene. Mattoo A.K. and Suttle J.C. (Eds.). CRC Press. Boca Raton. pp. 215-234. ISBN: 0-8493-4566-9.

Reid, M.S. and Wu, M.J. (1992). Ethylene and flower senescence. Plant Growth Regul. 11: 37-43. Rodriguez, F.I., Esch, J.J., Hall, A.E., Binder, B.M. Schaller, G.E. and Bleecker, A.B. (1999). A copper cofactor for the ethylene receptor ETR1 from Arabidopsis. Science 283: 996-998.

Roman, G., Lubarsky, B., Kieber, J.J., Rothenberg, M. and Ecker, J.R. (1995). Genetic analysis of ethylene signal transduction in Arabidopsis thaliana: five novel mutant loci integrated into a stress response pathway. Genetics 139: 1393-1409.

Rombaldi, C., Lelièvre, J.M., Latché, A., Petiprez, M., Bouzayen, M. and Pech, J.C. (1994). Immunocytolocalization of 1-aminocyclopropane-1-carboxylic acid oxidase in tomato and apple fruit. Planta 192: 453-460.

Rottmann, W.H., Peter, G.F., Oeller, P.W., Keller, J.A., Shen, N.F., Nagy, B.P., Taylor, L.P., Campbell, A.D. and Theologis, A. (1991). 1-Aminocyclopropene-1-carboxylate synthase in tomato id encoded by a multigene family whose transcription is induced during fruit and floral senescence. J. Mol. Biol. 222: 937-961.

Rychlick, W., Spencer, W.J. and Voetberg, G.S. (1990). Optimization of the annealing temperature for DNA amplification in vitro. Nucleic Acids Res. 18(21); 6409-6412.

Sakai, H., Hua, J., Chen, Q.G., Chang, C., Medrano, L.J., Breecker, A.B. and Meyerowitz, E.M. (1998). ETR2 is an ETR1-like gene involved in ethylene signaling in Arabidopsis. Proc. Natl. Acad. Sci. USA 95: 5812-5817.

Saltveit, M.E., Jr., (1978). Simple apparatus for diluting and dispensing trace concentrations of ethylene in air. HortSci. 13(3): 249-251.

Sankat, C.K. and Mujaffar, S. (1994). Water balance in cut anthurium flowers in storage and its effect on quality. Acta Hortic. 368: 723-732.

SAS Institute. (2002). SAS/STAT User's guide for Personal Computers, version 8. SAS Institute, Cary, N.C., USA.

Sato-Nara, K., Yuhashi, K-I., Ezura, H. (1999). Ethylene receptors and genetic engineering of ethylene sensitivity in plants. Plant Biotech. 16(5): 321-334.

Schaller, G.E. and Bleecker, A.B. (1995). Ethylene-binding sites generated in yeast expressing the Arabidopsis ETR1 gene. Science 270: 1809-1811. 
Schaller, G.E., Ladd, A.N., Lanahan, M.B., Spanbauer, J.M. and Bleecker, A.B. (1995). The ethylene response mediator ETRI from Arabidopsis forms a disulfide-linked dimmer. J. Biol. Chem. 270(21): 12526-12530.

Serek, M. (1993). Ethephon and silver thiosulfate affect postharvest characteristics of Rosa hybrida 'Victory Parade'. HortSci. 28(3): 199-200.

Serek, M. and Andersen, S. (1993). AOA and BA influence on floral development and longevity of potted 'Victory Parade' miniature rose. HortSci. 28(10): 1039-1040.

Serek, M. and Reid, M.S. (1993). Anti-ethylene treatment for potted Christmas cactus Efficacy of inhibitors of ethylene action and biosynthesis. HortSci. 28(12): 1180-1181.

Serek, M. and Reid, M.S. (2000a). Role of growth regulators in the postharvest life of ornamentals. In: Plant Growth Regulators in agriculture and Horticulture, Their Role and Commercial Uses, Basra, A.S. (Ed.). Food product press. New York, pp. 147-174. ISBN: 1-5602-2896-2.

Serek, M. and Reid, M.S. (2000b). Ethylene and postharvest performance of potted kalanchoë. Postharvest Biol.Tech.18: 43-48.

Serek, M. and Sisler, E.C. (2001). Efficacy of inhibitor of ethylene binding in improvement of the postharvest characteristics of potted flowering plants. Postharvest Biol. Tech. 23: 161-166.

Serek, M., Jones, R.B. and Reid, M.S. (1994a). Role of ethylene in opening and senescence of Gladiolus sp. Flowers. J. Amer. Soc. Hort. Sci. 119(5): 1014-1019.

Serek, M., Reid, M.S. and Sisler, E.C. (1994c). A volatile ethylene inhibitor improves the postharvest life of potted roses. J. Amer. Soc. Hort. Sci. 119(3): 572-577.

Serek, M., Sisler, E.C. and Reid, M.S. (1994b). Novel gaseous ethylene binding inhibitor prevents ethylene effect in potted flowering plants. J. Amer. Soc. Hort. Sci. 119(6): 1230-1233.

Serek, M., Sisler, E.C. and Reid, M.S. (1995a). Effect of 1-MCP on the vase life and ethylene response of cut flowers. Plant Growth Regul. 16: 93-97.

Serek, M., Sisler, E.C. Tirosh, T. and Mayak, S. (1995b). 1-Methylcyclopropene prevents bud, flower, and leaf abscission of Geraldton waxflower. HortSci. 30(6): 1310.

Serrano, M., Romojaro, F., Casas, J.L. and Acosta, M. (1991). Ethylene and polyamine metabolism in climacteric and nonclimacteric carnation flowers. HortSci. 26(7): 894-896.

Shibuya, K., Nagata, M., Tanikawa, N., Yoshihito, T., Hashiba, T. and Satoh, S. (2002). Comparison of mRNA levels of three ethylene receptors in senescing flowers of carnation (Dianthus caryophyllus L.). J. Exp. Bot. 53(368): 399-406. 
Shumam, S. (1991). Recombination mediated by Vaccinia virus DNA Topoisomerase I in Escherichia coli is sequence specific. Proc. Natl. Acad. Sci. USA 88; 10104-10108.

Shuman, s. (1994). Novel approach to molecular cloning and polynucleotide synthesis using Vaccinia DNA Topoisomerase. J. Biol. Chem. 269; 32678-32684.

Singh, A., Evensen, K.B. and Kao, T-H. (1992). Ethylene synthesis and floral senescence following compatible and incompatible pollination in Petunia inflata. Plant Physiol. 99:38-45.

Singh, K. and Moore, K.G. (1994). Site of ethylene production in flowers of sweetpea (Lathyrus odoratus L.). Sci. Hortic. 58: 351-335.

Sisler, E.C. (1991). Ethylene binding components in plants. In: The plant hormone ethylene. Matoo, A.K. and Suttle, J.C. (Eds.). CRC Press. Boca Raton. pp. 81-99. ISBN: 0-8493-4566-9. Sisler, E.C. and Blankenship, S.M. (1993). Diazocyclopentadiene (DACP), a light sensitive reagent for the ethylene receptor in plants. Plant Growth Regul. 12: 125-132.

Sisler, E.C. and Serek, M. (1997). Inhibitor of ethylene responses in plants at the receptor level: recent developments. Physiol. Plant. 100: 577-582.

Sisler, E.C. and Serek, M. (1999). Compounds controlling the ethylene receptor. Bot. Bull. Acad. Sinica 40: 1-7.

Sisler, E.C. and Serek, M. (2001). New development in ethylene control - compounds interacting with the ethylene receptor. Acta Hortic. 543: 33-40.

Sisler, E.C. and Serek, M. (2003). Compounds interacting with the ethylene receptor in plants. Plant Biol. 5: 473-480.

Sisler, E.C. and Wood, C. (1988). Competition of unsaturated compounds with ethylene for binding and action in plants. Plant Growth Regul. 7: 181-191.

Sisler, E.C., Alwan, T., Goren, R., Serek, M. and Apelbaum, A. (2003). 1-substituted cyclopropenes: effective blocking agents for ethylene action in plants. Plant Growth Regul. 40: 223-228.

Sisler, E.C., Blankenship, S.M. and Guest, M. (1990). Competition of cyclooctenes and cyclooctadienes for ethylene binding and activity in plants. Plant Growth Regul. 9: 157-164.

Sisler, E.C., Blankenship, S.M. and Guest, M. (1990). Competition of cyclooctenes and cyclooctadienes for ethylene binding and activity in plants. Plant Growth Regul. 9: 157-164.

Sisler, E.C., Dupille, E. and Serek, M. (1996a). Effect of 1-methylcyclopropene and methylenecyclopropene on ethylene binding and ethylene action on cut carnation. Plant Growth Regul. 18: 79-86. 
Sisler, E.C., Reid, M.S. and Fujino, D.E. (1983). Investigation of the mode of action of ethylene in carnation senescence. Acta Hortic. 141: 229-234.

Sisler, E.C., Reid, M.S. and Yang, S.F. (1986). Effect of antagonists of ethylene action on binding of ethylene in cut carnations. Plant Growth Regul. 4: 213-218.

Sisler, E.C., Serek, M. and Dupille, E. (1996b). Comparison of cyclopropene, 1-methylcyclopropene, and 3,3-dimethylcyclopropene as ethylene antagonists in plants. Plant Growth Regul. 18: 169-174.

Sisler, E.C., Serek, M., Dupille, E. and Foren, R. (1999). Inhibition of ethylene responses by 1-methylcyclopropene and 3-methylcyclopropene. Plant Growth Regul. 27: 105-111.

Sisler, E.C., Serek, M., Roh, K. and Goren, R. (2001). The effect of chemical structure on the antagonism by cyclopropenes of ethylene responses in banana. Plant growth Regul. 33: 107-110.

Smith, J.J. and John, P. (1993a). Activation of 1-aminocyclopropane-1-carbxylate oxidase by bicarbonate/carbon dioxide. Phytochem. 32: 1381-1386.

Smith, J.J. and John, P. (1993b). Maximising the activity of the ethylene-forming enzyme. In: Cellular and molecular aspects of the plant hormone ethylene. Pech, J.C., Latché, A. and Balagué, C. (Eds.). Kluwer. Dordrecht. pp. 96-97. ISBN: 0-7923-2169-3.

Sobel, R., Dubitsky, A. and Brickman, Y. (2002). Northern hybridization analysis. Gen. Eng. News 23(2). Solano, R., stepanova, A., Chao, Q. and Ecker, J.R. (1998). Nuclear events in ethylene signaling: A transcriptional cascade mediated by ETHYLENE-INSENSITIVE3 and ETHYLENE-RESPONSE-FACTOR1. Genes Dev. 12: 3703-3714.

Stead, A.D. (1985). The relationship between pollination, ethylene production and flower senescence. In: Ethylene and Plant Development. Robert, J.A. and Tucker, G.A. (Eds.). Butterworths. London. pp. 71-81. ISBN: 0-4070-0920-5.

Steve, R. and Skaletsky, H. J. (2000). Primer3 on the WWW for general users and for biologist programmers. In: Bioinformatics Methods and Protocols: Methods in Molecular Biology. Krawetz, S., Misener, S. (Eds.). Humana Press. Totowa. pp 365-386. ISBN: 0-89603-732-0.

Stock, A.M., Robinson, V.L. and Goudreau, P.N. (2000). Two-component signal transduction. Annu. Rev. Biochem. 69: 183-215.

Taiz, L. and Zeiger, E. (2002). Ethylene: The gaseous hormone. In: Plant physiology. (3 ${ }^{\text {rd }}$ Ed.). Sinauer Associates, Inc., Publichers. Massachusette. pp. 519-538. ISBN: 0-87893-823-0.

Teiman. D.M. and Klee, H.J. (1999). Differential expression of two novel members of the tomato ethylene-receptor family. Plant Physiol. 120: 165-172. 
ten Have, A. and Woltering, E.J. (1997). Ethylene biosynthetic genes are differentially expressed during carnation (Dianthus caryophylus L.) flower senescence. Plant Mol. Biol. 34: 89-97. Terefe, D. (2005) Molecular genetic and physiological studies on the sex-determining $M / m$ and A/a genes in Cucumber (Cucumis sativus L.). Dissertation. Universität Hannover, 131 pp.

Tian, M.S., Bowen, J.H., Bauchot, A.D., Gong, Y.P. and Lallu, N. (1997). Recovery of ethylene biosynthesis in diazocyclopentadiene (DACP)-treated tomato fruit. Plant Growth Regul. 22:73-78. Tieman, D.M. and Klee, H.J. (1999). Differential expression of two novel members of the tomato ethylene-receptor family. Plant Physiol. 120: 167-172.

Tieman, D.M., Taylor, M.G., Ciardi, J.A. and Klee, H.J. (2000). The tomato ethylene receptors $N R$ and LeETR4 are negative regulators of ethylene response and exhibit functional compensation within a multigene family. Proc. Natl. Acad. Sci. USA 97, 5663-5668.

Tournier, B., Sanchez-Ballesta, M.T., Jones, B., Pesquet, E., Regad, F., Latché, A., Pech, J-C. and Bouzayen, M. (2003). New members of the tomato $E R F$ family show specific expression pattern and diverse DNA-binding capacity to the GCC box element. FEBS Letters 550: 149-154. Trewavas, A.J. (1983). Is plant development regulated by changes in the concentration of growth substances or by changes in the sensitivity to growth substances? Trends Biochem. Sci. 8: 354-357. USDA. (2003). Research project: Transformation for disease resistance in floral monocots. http://www. ars.usda.gov/research/projects/projects.htm?ACCN_NO=404941\&fy=2003. 01/17/06. Vahala, J., Schlagnhaufer, C.D., Pell, E.J. (1998). Induction of an ACC synthase cDNA by ozone in light-grown Arabidopsis thaliana leaves. Physiol. Plant. 103: 45-50.

Van Altvorst, A.C. and Bovy, A.G. (1995). The role in the senescence of carnation flowers, a review. Plant Growth Regul. 16: 43-53.

Van Altvorst, A.C., Bovy, A.G., Angenent, G.C. and Dons, J.J.M. (1997). Genetic modification of ethylene biosynthesis and ethylene sensitivity in carnation. In: Biology and Biotechnology of the plant hormone ethylene. Kanallis, A.K. and Chang, C. (Eds.). Kluwer Academic Publichers. Dordrecht. pp. 339-345. ISBN: 0-79234-587-8.

Van Altvorst, A.C., Riksen, T., Koehorst, H. and Dons, J.J.M. (1995). Transgenic carnation plants obtained by agrobacterium tumefaciens-mediated transformation of leaf explants. Transgenic Res. 4: 105-113.

Van Der Straeten, D., Van Wiemeersch, L., Goodman, H.M and Van Montagu, M. (1990). Cloning and sequence of two different cDNAs encoding 1-aminocyclopropene-1-carboxylate synthase in tomato. Proc. Natl. Acad. Sci. USA 87: 4859-4863. 
Veen, H. (1979). Effects of silver on ethylene synthesis and action in cut carnations. Planta 145: 467-470. Veen, H. (1986). A theoretical model for anti-ethylene effects of silver thiosulfate and 2,5norbornadiene. Acta Hortic. 181: 129-134.

Veen, H. and Kwakkenbos, A.A.M. (1982). The effect of silver thiosulfate pretreatment on 1-aminocyclopropane-1-cyboxylic acid content and action in cut carnations. Sci. Hortic. 18: 277-286. Waki, K., Shibuya, K., Yoshioka, T., Hashiba, T. and Satoh, S. (2001). Cloning of a cDNA encoding EIN3-like protein (DC-EILI) and decrease in its mRNA level during senescence in carnation flower tissues. J. Exp. Bot. 355: 377-379.

Wang, D., Fan, J. and Ranu, R.S. (2004). Cloning and expression of 1-aminocyclopropane-1carboxyylate synthase cDNA from rosa (Rosa x hybrida). Plant Cell Rep. 22: 422-429.

Wang, H. and Woodson, W.R. (1989). Reversible inhibition of ethylene action and interruption of petal senescence in carnation flowers by norbornadiene. Plant Physiol. 89: 434-438.

Wang, H. and Woodson, W.R. (1991). A flower senescence-related mRNA from carnation shares sequence similarity with fruit ripening-related mRNAs involved in ethylene biosynthesis. Plant Physiol. 96: 1000-1001.

Whitehead, C.S. and Halevy, A.H. (1989). Ethylene sensitivity: the role of short-chain saturated fatty acids in pollination-induced senescence of Petunia hybrida flowers. Plant Growth Regul. 8: 41-54.

Whitehead, C.S. and Vasiljevic, D. (1993). Role of short-chain saturated fatty acids in the control of ethylene sensitivity in senescing carnation flowers. Physiol. Plant 88: 243-250.

Wilkinson, J.Q., Lanahan, M.B., Clark, D.G., Bleecker, A.B., Chang, C., Meyerowith, E.M. and Klee, H.J. (1997). A dominant mutant receptor from Arabidopsis confers ethylene insensitivity in heterologous plants. Nature Biotech. 15: 444-447.

Wilkinson, J.Q., Lanahan, M.B.Yen, H-C., Giovannoni, J.J., and Klee, H.J. (1995). An ethyleneinducible component of signal transduction encoded by Never-ripe. Science 270: 1807-1809.

Williums, J.G.K., Kubelik, A.R., Livak, K.J., Raflaski, J.A.A. and Tingey, S.V. (1990). DNA polyphisims amplified by arbitrary are useful as genetic markers. Nucleic Acids Res. 18(22): 6531-6535.

Witte, Y.D. and Van Doorn, W.G. (1991). The mode of action of bacteria in the vascular occlusion of cut rose flowers. Acta Hortic. 298: 165-167.

Woeste, K.E. and Kieber, J.J. (2000). A strong loss-of-function mutation in RAN1 results in constitutive activation of the ethylene response pathway as well as rosette lethal phenotype. Plant Cell 12: 443-455. 
Woltering, E.J. and van Doorn, W.G. (1988). Role of ethylene in senescence of petalsmorphological and taxonomical relationships. J. Exp. Bot. 39(208): 1605-1616.

Woodson, W.R., Hanchey, S.H. and Chisholm, D.N. (1985). Role of ethylene in the senescence of isolated Hibiscus petals. Plant Physiol. 79: 679-683.

Woodson, W.R., Park, K.Y., Drory, A., Larsen, P.B. and Wang, H. (1992). Expression of ethylene biosynthetic pathway transcripts in senescing carnation flowers. Plant Physiol. 99: 526-532.

Wu, K., Tian, L., Hollingworth, J., Brown, D. C. W., and Miki, B. (2002). Functional analysis of tomato Pti4 in Arabidopsis. Plant Physiol. 128: 30-37.

Wu, M.J., Van Doorn, W., Mayak, S., Reid, M.S. (1989). Senescence of 'Sandra' carnation. Acta Hortic. 261: 221-225.

Wu, M.J., Van Doorn, W.G. and Reid, M.S. (1991a). Variation in the senescence of carnation (Dianthus caryophyllus L.) cultivars. I. Comparison of flower life, respiration and ethylene biosynthesis. Sci. Hortic. 48: 99-107.

Wu, M.J., Van Doorn, W.G. and Reid, M.S. (1991b). Variation in the senescence of carnation (Dianthus caryophyllus L.) cultivars. II. Comparison of sensitivity to exogenous ethylene and of ethylene binding. Sci. Hortic. 48: 109-116.

Yamagami, T., Tsuchisaka, A., Yamada, K., Haddon, W.F., Harden, L.A. and Theologis, A. (2003). Biochemical diversity among the 1-amino-cyclopropane-1-carboxylate synthase isozyme encoded by the Arabidopsis gene family. J. Biol. Chem. 278(49): 49102-49112.

Yang, S.F. (1985). Biosynthesis and action of ethylene. HortSci. 20(1): 41-45.

Yang, S.F. and Hoffman, N.E. (1984). Ethylene biosynthesis and its regulation in higher plants. Annu. Rev. Plant Physiol. 35: 155-158.

Yip, W.K., Moore, T. and Yang, S.F. (1992). Differential accumulation of transcripts for 4 tomato 1-aminocyclopropane-1-carboxylate synthase homologs under various conditions. Proc. Natl. Acad. Sci. USA 89: 2475-2479.

Zarembinski, T.I. and Theologis, A. (1994). Ethylene biosynthesis and action: a case of conservation. Plant Mol. Biol. 26: 1579-1597.

Zhou, J., Tang, X. and Martin, G.B. (1997). The Pto kinase conferring resistance to tomato bacterial speck disease interacts with proteins that bind a cis-element of pathogenesis-related genes. EMBO J. 16: 3207-3218. 


\section{Appendices}

Appendix 1. gene-specific primer pairs for RhERF1 using partial DNA fragment of Arabidopsis thaliana

TACAGAGGCGTTAGGAAGCGTCCTTGGGGCCGTTATGCCGCCGAGATCCGAGATCCGGGCAAGAAAACCCGCGTCTGG CTTGGCACTTTCG

Appendix 2. Sequence analysis of Rosa hybrida 92 bp partial DNA fragment. (a) nucleotide sequence, (b) mRNA sequence, (c) deduced amino acid sequence (d) homology comparison with LeERF1 (GeneBank Accession No. AY192367), LeERF2 (GeneBank Accession No. AY192368), AtERF1 (GeneBank Accession No. AAL25588), AtERF2 (GeneBank Accession No. NM_124093) and AtERF5 (GeneBank Accession No. NM_124094) using CLUSTAL W program. ${ }^{*}=$ identical amino acid, $:=$ two nucleotides out of the triplicate amino acid code are identified,.$=$ one nucleotide out of the triplicate amino acid code are identified.

(a)

CGAAAGTGCCAAGCCAGACTCTCGTCTTCTTCCACGGGTCTCTGATCTCGGCGGCGTAGCGACCCCACGGCCGCTTCC TAACGCCTCTGTAA

(b)

CGAAAGTGCCAAGCCAGACTCTCGTCTTCTTCCACGGGTCTCTGATCTCGGCGGCGTAGCGACCCCACGGCCGCTTCC TAACGCCTCTGTAA

(c)

YRGVRKRPWGRYAAEIRDPWKKTRVWLGTF

(d) YRGIRQRPWGKWAAEIRD-PRKGVRVWLGTFNTAEEAARAYDREARKIRGKKAKVNFPNE 119 YRGVRKRPWGKYAAEIRDSARHGARVWLGTFNTAEDAARAYDRAAFGMRGQRAILNFPHE 62 YRGVRQRPWGKFAAEIRDPAKNGARVWLGTFETAEDAALAYDIAAFRMRGSRALLNFPLR 176 YRGVRQRPWGKFAAEIRDPNKRGSRVWLGTFDTAIEAARAYDEAAFRLRGSKAILNFPLE 215 YRGVRKRPWGRYAAEIRDPWKK-TRVWLGTF-- - - - - - - - - - - - - - - 30

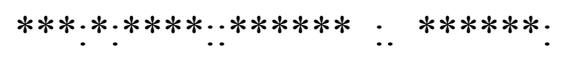


Appendix 3. Sequence analysis for specific primers of Rosa hybrida (a) nucleotide sequence, (b) mRNA sequence. Border between intron and exon sequence was detected with splicing specific sequence $\mathrm{GT}$ and $\mathrm{AG}$, respectively.

$\beta$-Actin: X55751 373 bp mRNA

(b)

$\beta$-Actin_s CCATGTTCCCTGGTATTGCT

$\beta$-Actin_as TAGATGTGGATTGCAAAGGC

mRNA size 150 bp

ACAACTCTATCATGAAATGTGATGTGGATATTAGAAAAGATCTTTATGGAAACATTGTGCTCAGTGGTGGTACTACCA TGTTCCCTGGTATTGCTGATAGAATGAGCAAAGAAATTACTGCATTGGCTCCTAGCAGCATGAAGATTAAGGTGGTCG CTCCACCAGAGAGGAAATACAGTGTCTGGATTGGAGGCTCTATCTTGGCTTCCCTCAGCACCTTCCAGCAGGTCTCGT CGCCCCTTCCCCTTCCCCCTCCCTCCTAATAATTATAAGTTTGCTTTTTTTTCGGTGTCTATTGTACTTCGAAGCTTGA CAGTTACTGACGGTCTTTTCTGCTTCTCTTATTTTCTGTAGATGTGGATTGCAAAGGCAGA

RhACS1: AY061946 1089 bp mRNA

(b)

RhACSIS GCCACTGGAGCTAACGAGAC

RhACSIas TGTTTCGGGCCTTTTCATAG

mRNA size: 205 bp

ATGGGTCTGGCGGAAAATCAGCTTTCTTTCGACGTGATTGAAGAGTGGATTAAGAAAAATCCCAAGGCCTCCATTTGC ACTCCTGAAGGAGTTGCGGAGTTCAAAAATGTAGCCAACTTTCAAGACTATCATGGCTTTCCAGACTTCAGAAAGGCT ATTGCTAACTTCATGTCAAAGGCGAGAGGAGGCAGAGTCAAATTTGATCCTGATCGCGTAGTCATGGCCGGCGGAGCC ACTGGAGCTAACGAGACGGTCATGTTTTGCTTGGCTGACCCCGGAGATGCTTTCCTAGTTCCCTCTCCTTACTATCCA GCGTTCTACCGAGACTTGGGGTGGCGAACGGGAGTGAAAATTGTTCCAGTCGATTGTGATAGCTCAAACAATTTCCAA GTGACCAGAGCAGCACTTGAAGCAGCCTATGAAAAGGCCCGAAACAACAACATCAACATAAAGGGCTTGATCATAACA AACCCTTCAAACCCATTGGGGACAACCGTAGACAGAGACACACTCACTAGCTTGGTCAAATTCATCAATGACAAGAAC ATCCACTTGGTCTGCGACGAAATATACGCAGGCACAGTGTTCAGCTGCCCAAAATTCACTTGCGTTACAGAGGTCCTA CAAGACGTGAAGAATTGCAACCGCGATTTGATTCACATTGTCTATAGCTTGTCCAAGGACATGGGTGTCCCCGGTTTA AGGATCGGGATCGTTTACTCCTACAACGACGCCGTCGTGAACTGCGCTCGCAAGATGTCAAGTTTCGGCTTGGTCTCC TCCCAAACTCAACACATGCTCTCCGCCATGCTTCTGGACGACGAATTTGTCTCCAACTTCCTTGAGACCAGCTCTAAG AGGCTGGCGAGGAGGCACCGGTTTTTCACCACGGGGCTCGAGGAGGTAGGCATCAACTGCTTGAAAGGCAATGCCGGG CTCTATTGCTGGATGGACTTGAGGAAGCTGCTCAAAGACCAAACTTTCGAGGCGGAAATGGTGCTGTGGCGTATGATT ATCAACGAAGTGAAGCTCAACGTTTCGCCGGGGTCTTCCTTCCGTTGCGTGGAGCCAGGCTGGTTCCGGGTTTGT 
RhACS2: AY525066 1346 bp DNA

(a)

RhACS2S AAAACCCAGAAGCCTCCATT

RhACS2as ATTTCTGGTTCCCGTTCCTT

Genomic size 369 bp

ATGGGGCTGGCGGAAAATCAAGTAAGAGATTCAAAGACAGAAACCTTGTTTTACAAGCATAATTTCATCTCTTGGCTA TTTACTAATTGGTTTCTTCTGTATGCAGCTTTCTTTTGGTTTGATTCAAGAATGGGTTCTGAAAAACCCAGAAGCCTC CATTTGCACTGCACAAGGAGCAAAAGCATTCAAGGACATAGCCATCTTTCAAGACTATCATGGCCTGCCAGAGTTCAG AAATGTATGTATTGATCAACATCTACAAGATTTTCTTAGCATCACTAATTAACTCATTACACAATCTTACCAAGTTTG TTGTTCAAATATTAACAAAGTTAATTATTGTTGTGAAACTCCACAGGCTGTTGCAAATTTCATGGGAAAAGTGAGAGG AAATCGAGTCACATTCGACCCTGACCGCATTGTTATGAGCGGCGGAGCAACCGGAGCTCACGAGATGATTGCCTTTTG CTTGGCTGATCCCGGAGAGGCATTTCTGGTTCCCGTTCCTTATTATCCTGGGTAAGCTTAATTTTATATATCTTTCTA AGATTGACTATGATCCAACTAAGACGGGAAAAATTAGCTAATTAATTTAGGCGAGTTGCCTAATATTTTATGAGAAAT TAGCAATGAAAGAGACTGGTGTTGACCCTTATGTGGTCTTGGACCATCTTGAATTATTGAGGGGGGAATCAAAACGAT CTTTGTACAAATTGTCTTGGCTAGACACCATTCAATCTATACCTCACTTTGATAAACATGAAAGATGCCTTGGGAAAA TAAGGACCATCCTTCCTTTTAAAAGGACAAGTAAAACTGTACAATTGGACACTTGTAAACTTCTTATGGTAGCTAGGC GCACTGATCACGTCATTAAAATATATTCTTTATGGAGATCTGACAAGTAGATTATCTACTTTGATACTTATTTATTGT TATGCGAAATTTAGAATTCTCGACGTAGAATTCCATATTTATTCATAACGTACGGTTAAAATATTCTCCATGCATGAG TTGCTTATAAGTAGATTATCTACTCTGATACTTATTTATTGCTATGCGAAATTTAGAATTCTCGACGTAGAATTTCAT ATTTGTTTACAACGTACGGTTAAAATATTCTCCATGCATGAGTTGCTTGCGAAATAACTTTTTTACATCATTGCAGAT TCGATAGAGATTTGAGATGGCGAACAGGGGTACAACTTCTTCCAGTTGCTTGTGAAAGCTCCAACAATCTCAAGATCA CCAGAGCAGCCTTGGAAGATGCCTATGAGAAAGCCCAAAAGGCCAACATCAGAGTTAAAGGCTTACTCATTACCAACC CCTCCAACCCCTTCGGCACA

(b)

mRNA size 249 bp

ATGGGGCTGGCGGAAAATCAAGTAAGTTTTGGTTTGATTCAAGAATGGGTTCTGAAAAACCCAGAAGCCTCCATTTGC ACTGCACAAGGAGCAAAAGCATTCAAGGACATAGCCATCTTTCAAGACTATCATGGCCTGCCAGAGTTCAGAAATGCT GTTGCAAATTTCATGGGAAAAGTGAGAGGAAATCGAGTCACATTCGACCCTGACCGCATTGTTATGAGCGGCGGAGCA ACCGGAGCTCACGAGATGATTGCCTTTTGCTTGGCTGATCCCGGAGAGGCATTTCTGGTTCCCGTTCCTTATTATCCT GGGTTCGATAGAGATTTGAGATGGCGAACAGGGGTACAACTTCTTCCAGTTGCTTGTGAAAGCTCCAACAATCTCAAG ATCACCAGAGCAGCCTTGGAAGATGCCTATGAGAAAGCCCAAAAGGCCAACATCAGAGTTAAAGGCTTACTCATTACC AACCCCTCCAACCCCTTCGGCACA

RhETR1: AF394914 1479 bp mRNA

(b)

RhETRIS TGGTATGAACCTTCAACTTTCTCA

RhETRIas CGCATAGACTCTTCAAGAATAGCA

mRNA size: 393 bp

GAAACCACTCTTGTTGAGCTGGGAAGGACTTTAGGCCTTGAGGAATGCGCTTTGTGGATGCCGTGCAGGAGTGGTATG AACCTTCAACTTTCTCATACTCTCAACTATGAAGCACAAATTGGGTCTACTGTGCCATTTAGCCTTCCTGTAGTTAGT GAAGTTTTCAAGAGCTCTCAAGCAATGCGTATACCATATACCTGCCCCTTGGCCCGGGTCAGACCACTTGTGGGAAGA TATGTGCAACCTGAGGTTGTTGCTTTGCGTGTACCGCTGTTGAATCTTTCAAATTTCCAAATCAACGACTGGCCTGAT GTCTCTGCGAAAAGCTATGCCATCATGGTTCTGATTCTACCAACAAATAGCACTAGAAAGTGGCGAGACCATGAACTT GAACTGGTTGATGTTGTTGCCGATCAGGTCGCTGTTGCTCTTTCACACGCTGCTATTCTTGAAGAGTCTATGCGAGCC AGTGATCAGCTCGTAGAGCAGAATGGTGCTTTAGATTTGGCCCGGAGAGAGGCAGAGCTGGCAATCCATGCTCGCAAC 
GACTTCCTTGCTGTCCTGAACCATGAAATGAGGACACCAATGCATGCAATTATTGCATTGTCTTCACTTCTTTTAGAA ACGGACCTTGAAGATGGCAGTCTAGACTTGGACATTGGAAAGTTTAACCTCCATGGAGTTTTCAGAGAGGCAATCAAT TTAATAAAGCCTATTGCAACTGTGAAGAAGTTATCTATGACTTTAATTCTGGCCCCAGATGTGCCTGTGTGTGCTGTT GGAGATGAGAACCGGCTTATGCAAACTATTTTAAATGTTGCTGGTAATGCTGTCAAGTTTACAAAGGAGGGTTATATT TCAGTTATAGCATCTGTTGCAAAACCAGATTCTTCAAGAGATTGGCGACCGCCTGAATTTTATCCAGCGTCAAGTGAC GGCCATTTTTACCTACGAGTTCAGGTTAAAGATTCTGGCAGTGGTATTCTTCCACAAGATATTCCTCATATTTTCACC AAATTTGCTGAGCCCAGAAATGGATCCAATCGAGTAAAAGATGGTGCAGGACTTGGACTTGCCATTTGCAAACGGTTT GTGAATACCATGGGAGGTCATATTTGGATCGAGAGTGAGGGCATTGACAAGGGGACCCTTGTTGTATTCATCGTCAAA CTCGGGATATGCGACAATTGCGGTAATACAACAATAGCACATCAAAAAGTACCCAAAGGGGAGGCAAATCATGGAAGT GCAGATCTCATTGGATACAAACCAGCATTTAGAGATGGTTACGGTTTAGCTTCAACAAATCCGCGTTATCAAAGAAGT CTTTGACTGCAAAAGTCTTTGGCTGCAATAACCGTAAATGCTGTGCTAAAAAAGAGAGATTTCCTGGAGTATGGAATG TAGATTTTAGTAGAAGAAATTTGCGGTTTATATGATTTTATCATTTGCCTGAGTTCAAAAAAAAAAAAAAAAAAA

RhETR2: AF127220 534 bp DNA

RhETR2S CTCAAACTTCCAAATCAATGACTG

RhETR2as ATATTCTGCTCCATTAGCAGATCC

(a)

Genomic size: 978 bp

GAGTGCGCATTGTGGATGCCCACGCGTACTGCGTTAGAGCAGCAACTGTCGTACACACTCCATCAGCAGAATCCGGTG GGACATACCGTACCCATTCATCTTCCTGTGATCAATCAAGTGTTTAGCAGCAACCATGCCGTGAAGATATCGCCGAAT TCCCCAGTGGCAAGACTGAGGCCACGTGCGGGAAACCATATGCCTGGAGAGGTTGTTGCTGTTCGTGTCCCTCTCCTG CATCTCTCAAACTTCCAAATCAATGACTGGCCTGAGCTCTCAACAAAACGCTATGCTTTGATGGTGTTGATGCTCCCT TCCGATAGTGCAAGGCAATGGCATATGCATGAGTTAGAGCTGGTTGAGGTAGTTGCTGACCAGGTATGGAACCACAAT GTTGATCATTTTCTTTTTGACATCATTAGTTATCACCCAATGCCTAAATTGCAAAAAAGAAAAAAGAAAAAAAACAAT TTTTTTTATACAACTCTCCTTTATGTTATTGTTTGTCTCTTTCTTAAGATGGTTACTTTATGTATTCATAATAATAAA TTTTTTTATTGTTTATGACATTCTTCATTCCTTTGGCAGTCACTTGCAATAGGAATTCTCAGGATATCCCAGCGTCTA GGTTGTCTTATTATGAAAATGAAAAGTGTGTGAATCATAAGTAATTGTCGATCTGCAAAATGGTGGATCTATGCTCTG TCATTTTATTTTATATTCACAAGTCTGCAAGTAGACATAAATAGTAATCCTCACTAACTAGTATTTACTGGTCAAATG TCCAGATACTTTTAGAGGAGGGCTGGGACCCTAAAACCTTCTGAGTAGGCTGCAACTTTTCCTTTTTTTCTGATTCTTA TACAACAGCCCTTGGATTAGGATGAAGTTACGTTGGCTCTTAGGAAACTATCATATAATGTAGCTTGATTGTCGCAAG CATGAACCTTTATAGATGCCTTGCTTATAATAAAAGAAAACAAAAATGTCTTGCAGTACTTAGTGGATCTAATGAGAA CAAAACATACATAATCATCTTATAATAACTGAACACATATACTATCTGTTTATTGCTTGCTTCATTAGTAATGGTTGC TTATAATAAGAAGCATCAATTTATTTAATCTTATGAATTATGATACAGGTAGCAGTTGCTCTATCACACGCTGCTATC TTAGAAGAGTCAAGGAGAGCGAGGGATCTGCTAATGGAGCAGAATATTGCACTTGATCTGGCTAGGAGGGAAGCAGAA ACGGCAATTTGTGCTCGCAATGATTTCTTGGCCGTGATGAACCACGAGAT

(b)

mRNA size: $213 \mathrm{bp}$

GAGTGCGCATTGTGGATGCCCACGCGTACTGCGTTAGAGCAGCAACTGTCGTACACACTCCATCAGCAGAATCCGGTG GGACATACCGTACCCATTCATCTTCCTGTGATCAATCAAGTGTTTAGCAGCAACCATGCCGTGAAGATATCGCCGAAT TCCCCAGTGGCAAGACTGAGGCCACGTGCGGGAAACCATATGCCTGGAGAGGTTGTTGCTGTTCGTGTCCCTCTCCTG CATCTCTCAAACTTCCAAATCAATGACTGGCCTGAGCTCTCAACAAAACGCTATGCTTTGATGGTGTTGATGCTCCCT TCCGATAGTGCAAGGCAATGGCATATGCATGAGTTAGAGCTGGTTGAGGTAGTTGCTGACCAGGTAGCAGTTGCTCTA TCACACGCTGCTATCTTAGAAGAGTCAAGGAGAGCGAGGGATCTGCTAATGGAGCAGAATATTGCACTTGATCTGGCT AGGAGGGAAGCAGAAACGGCAATTTGTGCTCGCAATGATTTCTTGGCCGTGATGAACCACGAGAT 
RhETR3: AF154119 798 bp mRNA

(b)

RhETR3S CACTGCTATAACGCTCATCACTCT

RhETR3as CATTAGTTGGGACTCTTCAAGGAT

mRNA size: $661 \mathrm{bp}$

TTTATCGCGTTTATCGTGCAATGTGGAATGACACATTTGCTGAATGGCTGGACTTATGGTCCTCACCCTTTTCAGCTA ATGCTTGCTCTCACAGTTTTCAAAATTCTCACTGCTCTGGTATCATGTGCCACTGCTATAACGCTCATCACTCTCATT CCTTTGCTTCTCAAGGTCAAAGTGAGAGAATTTATGTTGAAGAAGAAGACTTGGGACCTTGGAAGAGAGGTTGGGATT ATAATGAGACAGAAAGAAGCTGGAATGCATGTTCGAATGCTTACCCAAGAGATTCGCAAGTCTCTTGATAGACATACA ATATTGTCCACAACCCTCTTTGAGCTATCTGAGACATTGGGTTTGCAGTACTGTGCAGTTTGGATGCCTAATGAAATT AAAACGGAGATGATCCTGACCCATGAGTTGAAAGGGAGGAATTATTCTAATATGTACAACTTTTCTATACCAATAGGT GATCCAGATGTTGCACTTATCAAAGGGAGTGATGGGGTCAACATCCTTGGGCCAGATTCAATACTCGTGTCCGGAAGC AGTGGTGATTTTGGTGAGCCGGGACCAGTAGCTGCAATACGGATGCCAATGCTTCGGGTTTCCAATTTCAAAGGGGGG ACCCCTGAGTTCATCCAGACTTGTTATGCGATTTTGGTTCTGGTTCTCGCTGGTGGACAGCCTAGATCTTGGAGCAGC CAGGAACTTGAGATAATTAAGGTGGTTGCCGATCAGGTGGCTGTGGCTTTATCCCATGCTGCAATCCTTGAAGAGTCC CAACTAATGCGCGAGAAA

RhETR4: AF159172 534 bp mRNA

(b)

RhETR4S TTTGAATCTGCAACTTTCTCACAC

RhETR4as GCATTTCGTGGTTCATGACAG

mRNA size: 500 bp

GAATGTGCTTTTTGGATGCCATCGCGAACGGGTTTGAATCTGCAACTTTCTCACACCCTAACCCAGGTATCGTCGGGA GCTAATGTGTCAATAAACCTCCCAATAGTCACTGAGGTTTTCAACAGTGCCCGAGCATTGCGTATACCATATACATGC CCGTTGGCTAGGTTTAGACCTCTTGTTGGGCGGTATATGTCACCGGAGGTTGTTGCTGTGCGAGTACCGCTTTTAAAT CTCTCGAACTTCCAAATTAATGATTGGCCTGAACTCTCTGCGAAAAGCTATGCTATAATGGTTCTGATTCTTCCTACG GATAGTGCAAGGCAATGGCGGGAACATGAGTTGGAACTTGTTGAAGTCGTTGCAGACCAGGTCGCTGTTGCTCTTTCA CATGCCGCTATTCTGGAGGAGTCCATGCGTGCCCGTGATCAGCTCATGGAGCAGAACGTTGCTCTAGATTTAGCTCGA AGAGAAGCTGAGATGGCAATCCATGCTCGCAACGACTTCCTTGCTGTCATGAACCACGAAATGCGA

RhCTR1: AY032953 3121 bp mRNA

(b)

RhCTRIS GGCTCTGATGTTGCTGTGAA

RhCTRIas TCAATGGCCTCAAAGATTCC

mRNA size:706 bp

ATGGAAATGCCCGGTAGGAGATCGAACTACACGCTTCTCAGCCAAGTCCCCGACGATCACTTCGCTGCGGCGACGGCG ACGTCGTTTTACGAGTCGGAGGGGAAGAACAACAATAATAAGGCGAAGGGGGATAGCAGAGGGTTTGATTGGGAAACG GGAGGCGGCGAGTACCGGGCGGCGCCGGCGAATCGGATCGGAAACGTGTACTCGTCGGTCGGATTGCAGCGGCAGTCG AGCGGGAGCAGCTTCGGAGAGAGCTCGCTGTCCGGCGAGTACTACGCGCCGACTCTGTCGACCACGGCGGCGAATGAG ATTGACGGATTCGGGTACGTCAACGACGACGGGTTTAAAACCGGCGGAGGAGGCGGTGAGTTCAGAGGGAAAGGAGGA GGGATGGATGGGGGTGTGGGCCCCCCCGGAGGTTCGTCGTCGGGGAAGAGCTGGGCGCAGCAGACTGAGGAGAGTTAT CAGCTGCAGTTGGCTTTGGCGCTTCGGCTCTCGTCGGAAGCCACTTGCGCCGATGATCCTAATTTCTTGGATCCAGTG CCGGATGAATCTTCGTCGAGGTTGTCCAGCTCTGCCGATGCAGTTTCGCATCGATTTTGGGTGAATGGCTGTCTGTCA 
TACTTTGACAAAGTGCCTGATGGGTTTTACCTTATTCATGGGATAGATTCGTATGTATGGTCTATGTGCACTGATGTG CAAGAGAGTGGTCGTATACCATCAATTGAATCACTAAAATCTGTTGATCCTGGTACTGGATCTTCCATAGAAGTGGTC TTAATCGATCGACGTAGTGATCCCAGCTTAAAGGAGCTTCAAAATAGGGTCCTCAGCATTTCTTATGCTTGCATAACC ACGACAGAGATTGTTGATCAGCTGGCAAAGCTTGTATGCAGCCGTATGGGGGGTTCAGCATCTGTAGGAGAGGCTGAA TTTTTCTCCATATGGAGGGAGAGCAGTGATGATCTAAAAGATTGCTTAGGATCTGTAGTTGTTCCAATCGGCAGCCTT TCTATTGGCCTCTGTAGACATCGTGCTTTATTATTCAAGGTTCTAGCTGACACAATTGACCTACCGTGCCGAATTGCC AAAGGCTGTAAATATTGTACAAGAGATGATGCTTCCTCTTGTCTTGTTCGTTTTGGTATTGACAGGGAATTGTTAGTT GATTTGATTGGGAATCCAGGTTGCTTATGTGAGCCTGATTCCTTGCTCAATGGTCCATCATCCATCTCAATTTCTTCA CCGCTGCGATTTCCAAGACTCAGAACAGTTGAACCTACCATTGATTTCAGGTCACTGGCCAAACAGTACTTCTCGGAC TGTCAGTTGCTTAATCTTGTATTCGATGAAGCTCCGGCAGGAAGTGCTGGTGATGAGGACAATAAAGGATTCTCTATG TATCCTAAGCAGAAGTTTACAGATGGAAACAACCTCTTTCTGGTTTCAGGTCTTGGTGATGACACTTCTATGCATGTT GACGATCGGAATCCCCAGTTCCTTAAATCATTTAATCCTTCTCAGAACATTGTACACCAACAAACAGTATTAAAAGAT CAAATCCCCCTAAAGCGTATACCACCTATAGGACATAGAGATATTTCAAGGTTGGATACAAGTAAGGACTCGAGGTTT GGTGAGGGACTTCAAGTGGTTCCTAGTAAACCAAATAAAGAGCTGACTCTCGATGTGGATGATTTGGACATTCCATGG AGTGACCTTGTACTGAAGGAGAGAATCGGTGCAGGTTCTTTTGGAACTGTTCATCGTGCTGATTGGCATGGCTCTGAT GTTGCTGTGAAGATTCTTATGGAGCAAGAATTTCATGCTGAACGCTTTAATGAGTTCTTGAGGGAGGTTGCAATTATG AAACGCCTGCGGCATCCAAATATTGTGCTGTTTATGGGTGCAGTTACAAAGCCCCCAAACTTGTCCATAGTCACAGAA TATCTATCAAGAGGGAGCTTGTATAGGCTGTTGCATAAACCTGGCCCAATACTGGATGAGAGGCGCCGGTTGTATATG GCTCATGATGTGGCAAAGGGGATGAATTATCTTCATAGGCGGAATCCTCCCATTGTTCATCGAGATTTAAAATCACCA AACCTTTTGGTTGACAAAAAGTATACTGTGAAGGTTTGTGATTTTGGTCTTTCCCGATTAAAGGCCAACACCTTTCTT TCATCAAAATCAGCTGCAGGGACTCCTGAATGGATGGCACCAGAAGTCCTGCGTGATGAACCATCAAATGAGAAGTCA GATGTTTACAGTTTTGGTGTAATATTGTGGGAACTTGCAACATTGCAACAGCCCTGGGGTAATTTGAATCCAGCGCAG GTTGTGGCAGCTGTTGGTTTTAAGAACAAAAGGCTTGAGATTCCACGTGATTTGAATCCTCAAGTGGCTTCTATAATT GAGGCTTGCTGGGCCAATGAGCCCTGGAAACGACCTTCATTTGCTAGTATCATGGAATCTTTGAGGCCATTGATTAAA GCTCCCACACCTCAACCTAGTCATGCAGACCGGAGTGGATGGCGCCAGAAGTCCTGCGTGATGAACCATCAAATGAGA AGTCAGATGTTTACAGTTTTGGTGTAATATTGTGGGAACTTGCAACATTGCAACAGCCCTGGGGTAATTTGAATCCAG CGCAGGTTTGTCTTTTAAGCAATATGATGAATGTTAACACCCATACATACAACATTCAGTGATGTTGCTCTTATAGAT TAGAAAGAATATCTACAAGAGCTGATGGCTATAATAACGCTTCCAAATAATTTTTTACAGTTCTTCATTTGAGAATAT TACAGAATGGTGTTTCTCGTATTACCCTTGCTTGAACTCTTATACCCTGATGATATTCAGTTTTTCTATACAACGTTG TAGGTTGTGGCAGCTGTTGGTTTTAAGAACAAAAGGCTTGAGATTCCACGTGATTTGAATCCTCAAGTGGCTTCTATA ATTGAGGCTTGCTGGGCCAAGTGAGTTTTAGATTCTAATTTGTATATTAAACTACACTCCTCAAATAACTACTTTTTC ATTAACAACAAAGATCATGCTGCAGTGAGCCCTGGAAACGCCCA

RhCTR2: AY029067 681 bp mRNA

(b)

RhCTR2S TTCCTTCCAAGGGGAAGTCT

RhCTR2as CCCACTCCAAGCCAATTTTA

mRNA size: 375 bp

GAAGTGTATCATGCGGACTGGAATGGCACGGAAGTTGCTGTGAAGAAGTTCCTAGACCAGGATTTCTCGGGTGCTGCT TTGGCTGAGTTCAAAAGAGAAGTACGGATAATGCGTAGGCTGCGCCATCCAAATGTTGTGCTTTTTATGGGTGCTATT ACGCGTCCTCCTAACCTCTCTATCATTACAGAGTTCCTTCCAAGGGGAAGTCTATATCGGATTATCCATCGTCCTCAT TGTCAAATTGAAGAGAGACGAAGATTAAAGATGGCTCTTGATGTGGCAAGGGGTATGAATTGCTTGCATTCGAGCAAC CCCACTATTGTTCACCGGGATTTGAAATCTCCAAATCTATTGGTTGATAAGAACTGGAATGTGAAGGTAGGTGATTTT GGACTGTCGCGCTTGAAACATAACACTTTCTTGTCCTCCAAATCAACTGCTGGAACGCCTGAGTGGATGGCACCAGAA GTTTTGCGCAACGAAAACTCAAATGAAAAGTGTGATGTATATAGCTTTGGAGTAATTTTGTGGGAACTTGCTACTCTA AAATTGGCTTGGAGTGGGATGAACCCGATGCAAGTTGTGGGTGCGGTGGGTTTCCAGAATCGCCGCCTTGACATCCCT AAAGAAGTTGATCCCCCTGTTGCAAGGATAATTTGGCAATGCTGGCAAAACGACCCC 
RhEIN3: AF443783 553 bp mRNA

(b)

RhEIN3S CCCTGCAGCCATAGACAAGT

RhEIN3as ACCCTGATTTCATCCACCAA

mRNA size: $236 \mathrm{bp}$

ATGCTGAAGATGATGGAGGTGTGTCAAGCTCGTGGATTTGTGTATGGTATCATTCCTGAGAAGGGCAAGCCAGTAAGC GGTGCTTCTGATAACATCAGAGCATGGTGGAAAGAAAAAGTGAAGTTTGATAAGAATGGCCCTGCAGCCATAGACAAG TATGAAGCAGAGATTCTTGCCATGACTGATGCAGACAATAACCGAAATGGTAATTCTCATACCATCCTCCAAGATCTA CAAGATGCAACTCTTGGTTCTCTACTATCTGCATTGATGCAACATTGCGACCCCCCTCAAAGGAAGTATCCATTAGAA AAGGCAGTTCCGCCTCCTTGGTGGCCGACAGGAAATGAAGATTGGTGGATGAAATCAGGGTTACCCTGTGGTCAGAGT CCTCCTTATAAGAAGCCACATGACTTAAAGAAGATGTGGAAAGTTGGGGTGTTAACAGCTGTGATAAAGCACATGTCC CCTGATATTGCAAAGATAAGGCGGCATGTCCGTCAGTCAAAATGCTTACAGGATAAGATGACTGCCAAAATCACTAGT GAATTCT

RhEIN3-like: AY052825 407 bp mRNA

(b)

RhEILS TCCCTGGTTTGATGGAAGAC

RhEIlas GAGGCCACCATTCCTCATTA

ATGATGGAAGTGTGTCGAGCTCAGGGTTTTGTTTATGGGATTATACCTGAAAAAGGAAAACCAGTGAGTGGTGCCTCT GACAATCTTCGAGAATGGTGGAAGGACAAAGTAAGATTTGATCGTAATGGCCCAGCTGCCATTTCCAAATATCAGGCA GATAATTCAATCCCTGGTTTGATGGAAGACTGCATTTCAGTGGCATCCACTCCACACACCCTGCAGGAGCTCCAGGAC ACCACTCTTGGTTCACTTTTGTCAGCCCTGATGCAGCACTGTGACCCACCCCAAAGGCGTTTCCCATTGGAGAAGGGT GTTTCCCCACCATGGTGGCCAACTGGTAATGAGGAATGGTGGCCTCAATTGAACTTGGCCAATCAGGGACCTCCCCCC TACAAAAAGCCCCACGG

RhERF: 92 bp DNA

$(a, b)$

RhERFS CTTCCACGGGTCTCTGATCT

RhERFAS GCTTCCTAACGCCTCTGTAA

CGAAAGTGCCAAGCCAGACTCTCGTCTTCTTCCACGGGTCTCTGATCTCGGCGGCGTAGCGACCCCACGGCCGCTTCC TAACGCCTCTGTAA 
Appendix 4. Computer programs used for analysing gene sequences (a) NCBI Blast program, (b) ClustalW program, (c) Chromas and construction of primers (d) Primer 3 Input program.

(a). NCBI Blast program

(http://www.ncbi.nlm.nih.gov/blast/Blast.cgi?CMD=Web\&LAYOUT=TwoWindows\&AUTO_F ORMAT=Semiauto\&ALIGNMENTS=50\&ALIGNMENT VIEW=Pairwise \&CLIENT=web\&D $\underline{\text { ATABASE }=\text { nr\&DESCRIPTIONS }=100 \& E N T R E Z \text { QUERY }=\% 28 \text { none } \% 29 \& E X P E C T=10 \& F I L}$ $\underline{T E R=L \& F O R M A T}$ OBJECT=Alignment\&FORMAT TYPE=HTML\&NCBI_G).

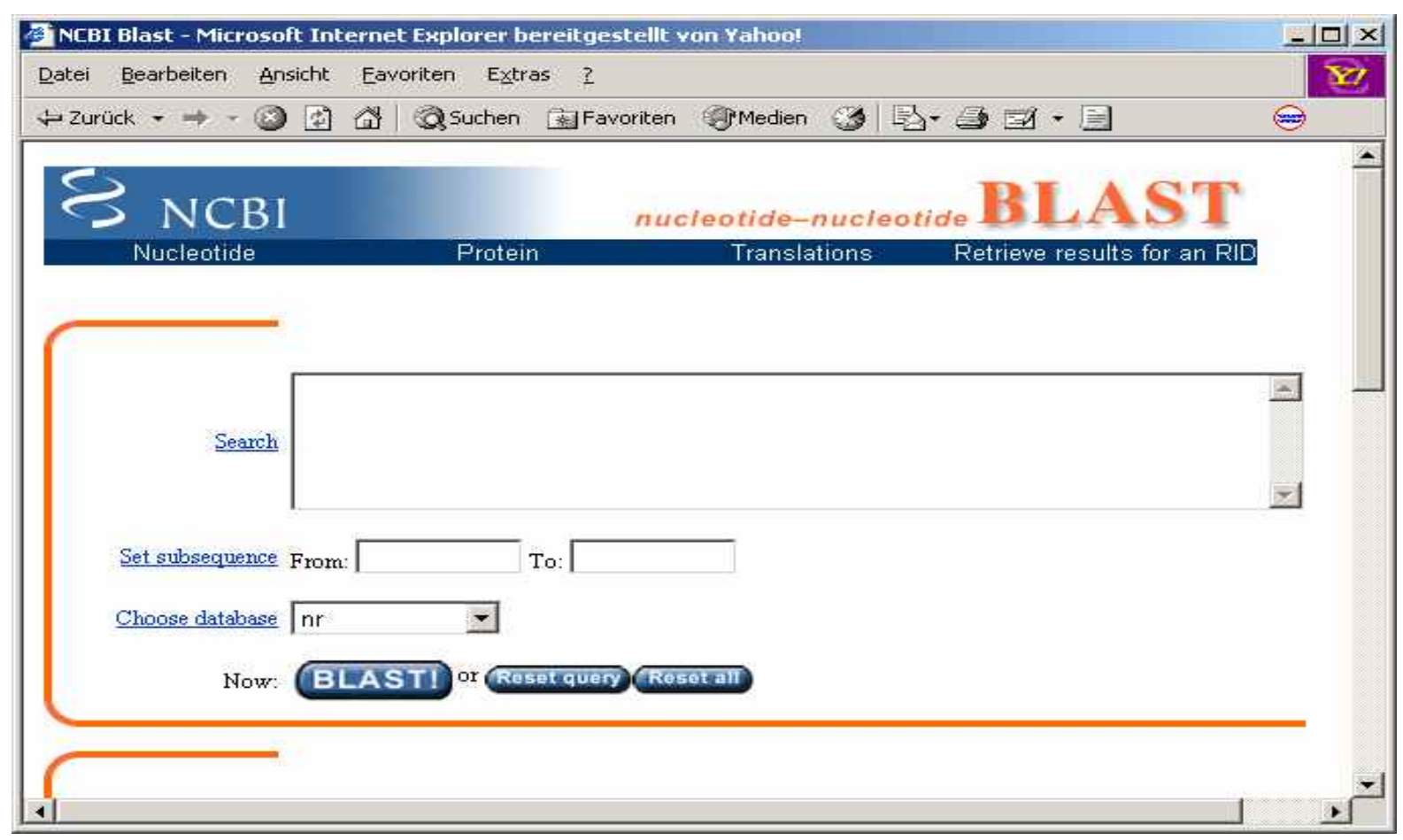


(b). ClustalW program (http://www.ebi.ac.uk/clustalw/).

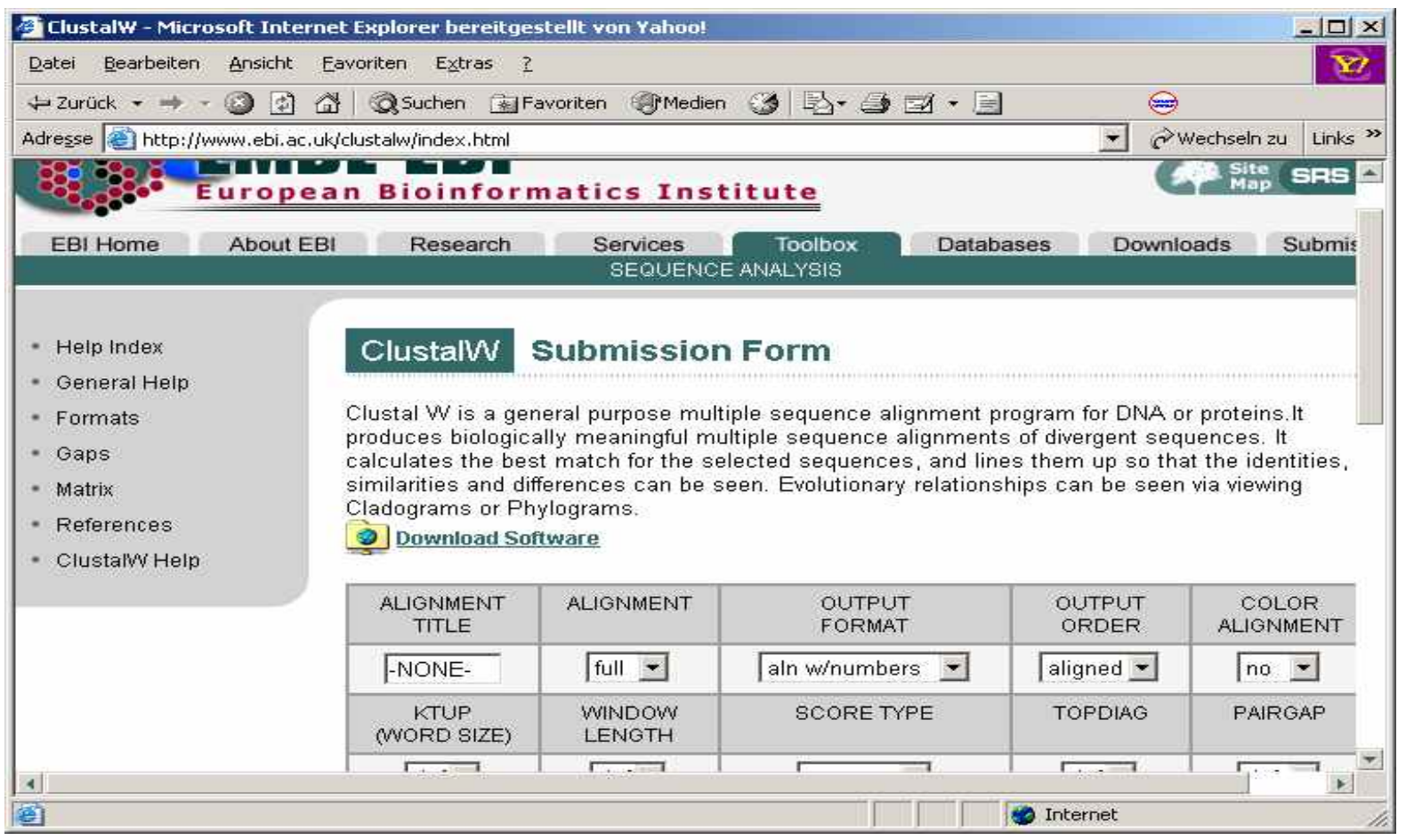

(c). Chromas (http://www.technelysium.com.au/chromas.html).

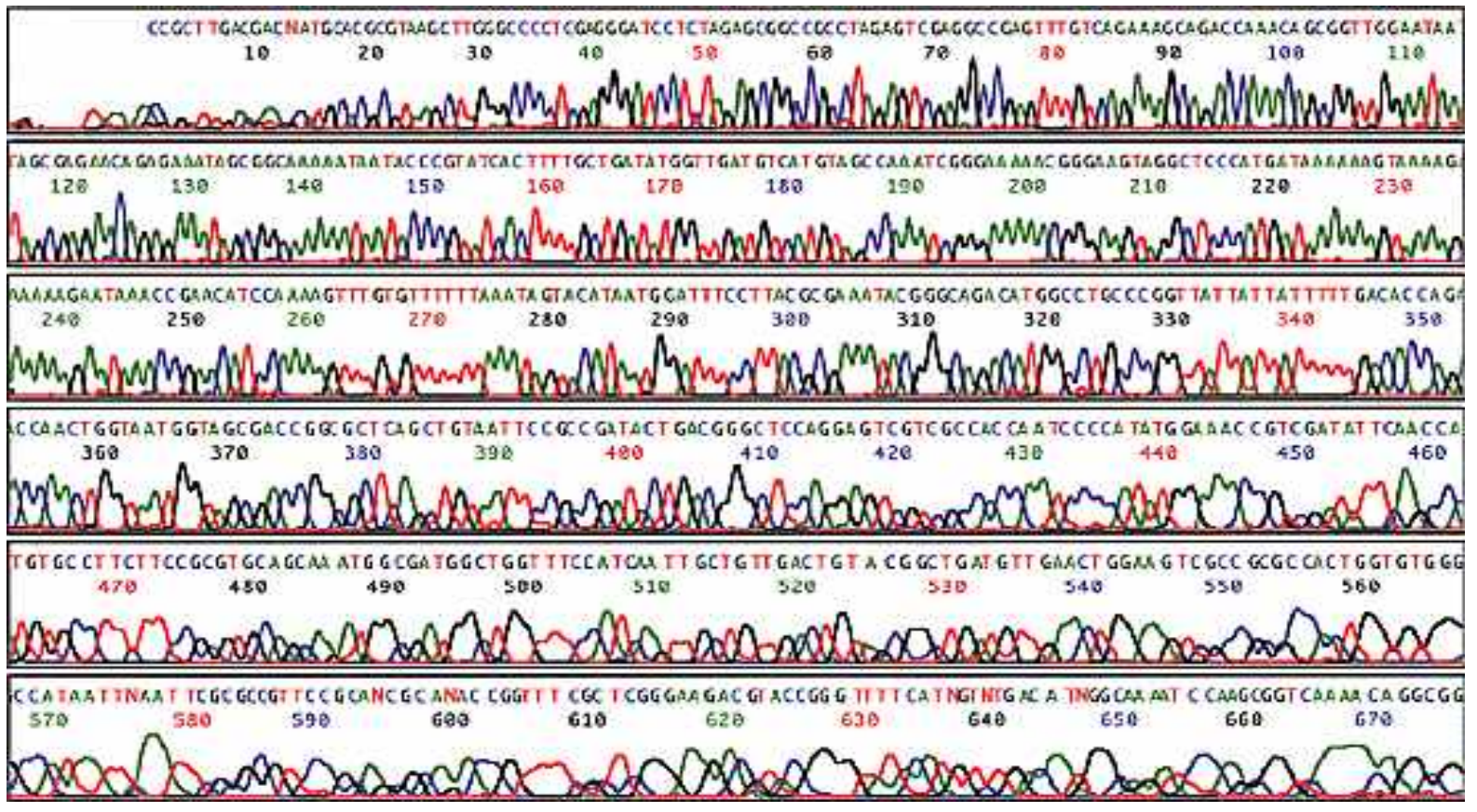


(d). Primer 3 Input program (http://frodo.wi.mit.edu/cgi-bin/primer3/primer3_www.cgi).

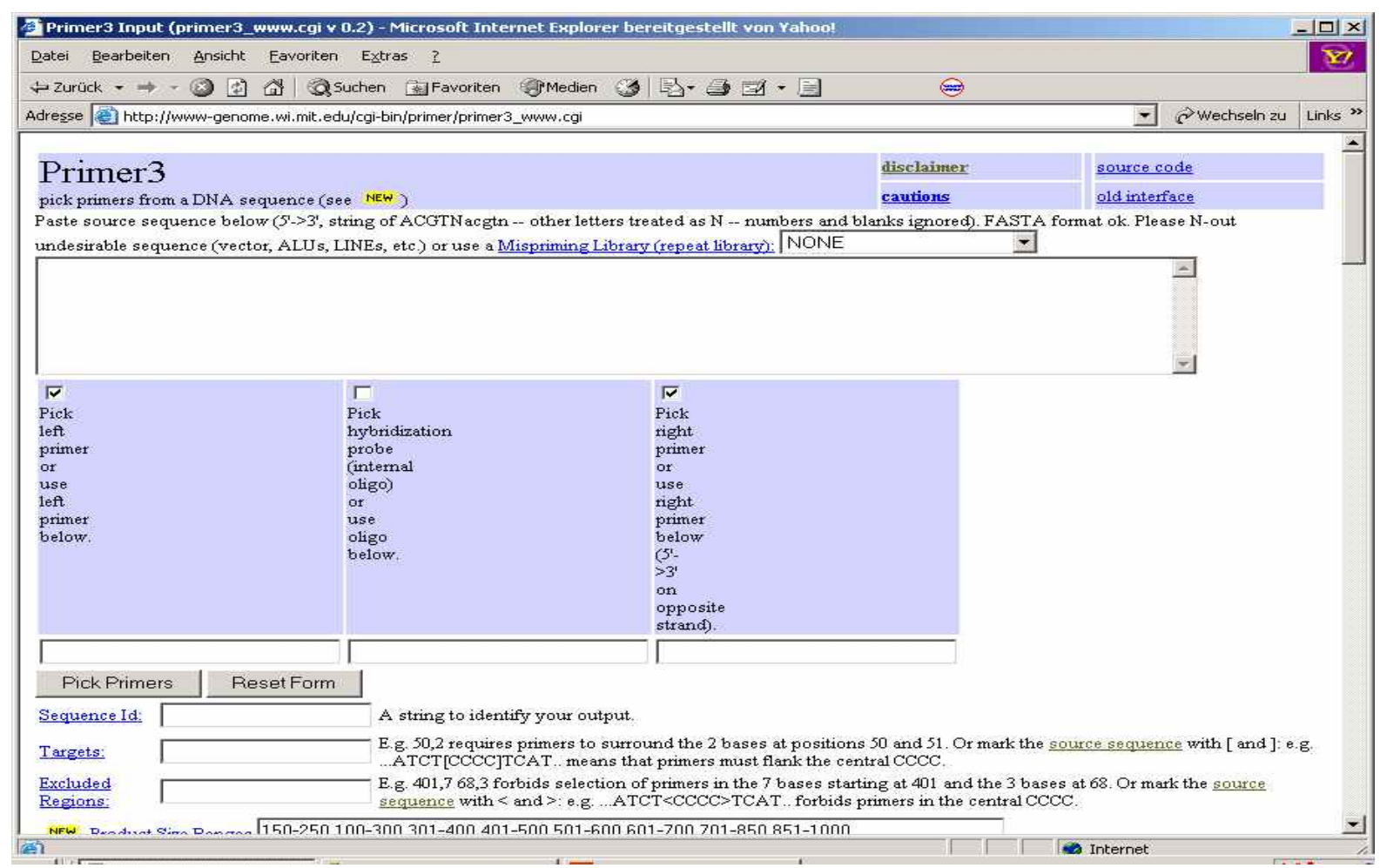


Appendix 5. The principle of ligation into a Topo TA Cloning Kit (Invitrogen, Carlsbad, CA, http://www.invitrogen.com/content/sfs/vectors/pcr4topo_map.pdf).

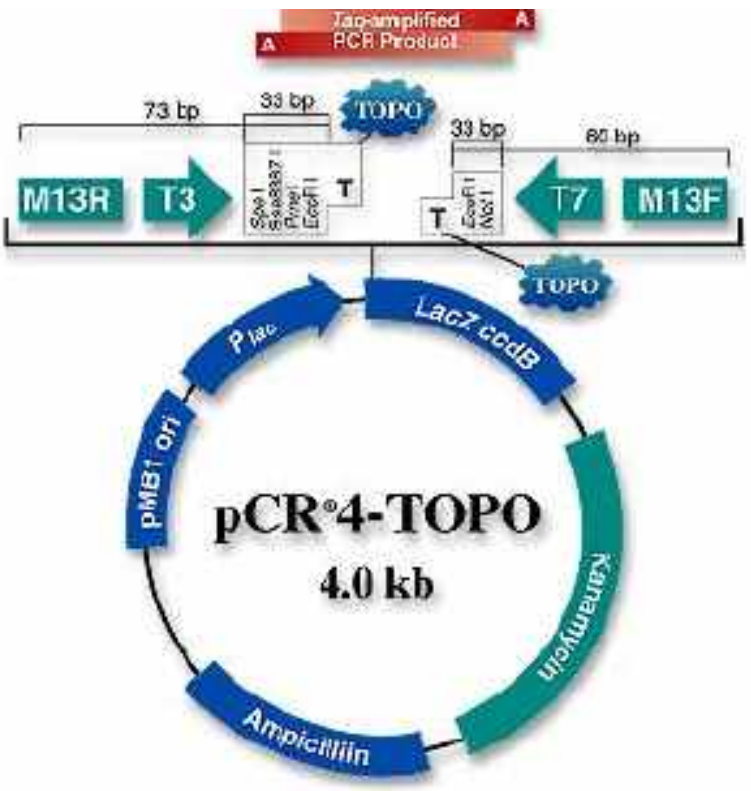

파일 Represents covalently-bound topoisomerase I

Appendix 15. The principle of ligation into a Topo TA Cloning Kit (Invitrogen, Carlsbad, CA, http://www.invitrogen.com/content/sfs/vectors/pcr4topo_map.pdf). 


\section{Eidesstattliche Erklärung}

Hiermit erkläre ich an Eides Statt, das ich die vorliegende Arbeit selbständig angefertigt habe und keine anderen als die angegebenen Quellen und Hilfsmittel benutzt habe sowie dass diese Arbeit noch nicht als Dissertation oder andere Prüfungsarbeit vorgelegt worden ist.

Hannover, den 18.10.2005

Mantana BUANONG 


\section{Publication}

Buanong, M., Mibus, H., Sisler, E.C. and Serek, M. (2005). Efficacy of new inhibitors of ethylene perception in improvement of display quality of miniature potted roses (Rosa hybrida L.). Plant Growth Regul. 47:29-38. 


\section{Curriculum Vitae}

\section{Personal data}

Name:

Address:

Date and Place of Birth:

Nationality:

School and Higher Education

1992-1996

1997-2000

Since 09/2002

\section{Work Experience}

2001-2002

Research Interests

\section{Honours and Awards}

Since 09/2002:

2000

1998
Mantana BUANONG

Zim. 491, Dorotheen Str. 5A, 30419, Hannover

08.11.1973, Khonkaen-Thailand

Thai
Horticulture at King Mongkut's Institute of Technology

Ladkrabang, Bangkok, Thailand.

Bachelor Degree of Science (Agriculture).

Postharvest Technology at King Mongkut's University of

Technology Thonburi, Bangkok, Thailand.

Master Degree of Science (Postharvest Technology).

Ph.D. Student at University of Hannover, Faculty of Natural

Science, Department of Horticulture.

Researcher at Division of Postharvest Technology, School of Bioresources and Technology, King Mongkut's University of Technology Thonburi, Bangkok, Thailand.

Physiology and Molecular effects after pretreatment of inhibitors

of ethylene receptor in improving postharvest quality of ornamental plants.

Scholarship by the Asian Development Bank (ADB) for Doctoral studies at University of Hannover.

Scholarship by University Mobility in Asia and the Pacific (UMAP), as an exchange student at Faculty of Science and Technology, University of Western Sydney, Hawkesbury, New South Wales, Australia.

Scholarship by King Mongkut's University of Technology

Thonburi, as assistant researcher. 